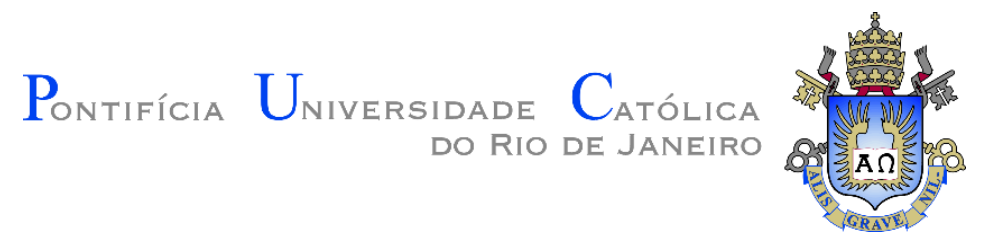

Cristiano Saad Travassos do Carmo

Structural engineering and architecture collaboration in the conceptual design through structural optimization within the BIM methodology

Dissertação de Mestrado

Dissertation presented to the Programa de Pósgraduação em Engenharia Civil of PUC-Rio in partial fulfillment of the requirements for the degree of Mestre em Engenharia Civil.

Advisor: Prof. Elisa Dominguez Sotelino 

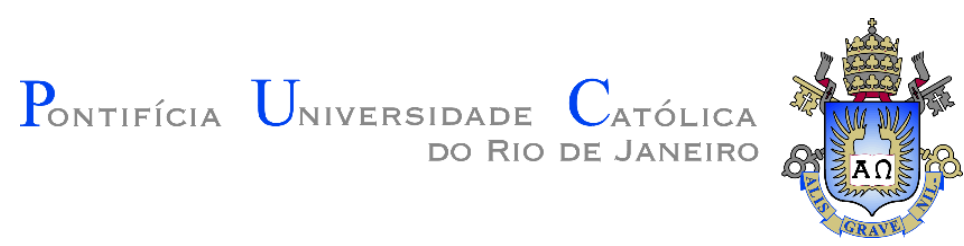

Cristiano Saad Travassos do Carmo

\title{
Structural engineering and architecture collaboration in the conceptual design through structural optimization within the BIM methodology
}

\begin{abstract}
Dissertation presented to the Programa de Pós-graduação em Engenharia Civil of PUC-Rio in partial fulfillment of the requirements for the degree of Mestre em Engenharia Civil. Approved by the undersigned Examination Committee.
\end{abstract}

Prof. Elisa Dominguez Sotelino

Advisor

Departamento de Engenharia Civil e Ambiental - PUC-Rio

Prof. Luiz Fernando Campos Ramos Martha

Departamento de Engenharia Civil e Ambiental - PUC-Rio

Prof. Sergio Scheer

UFPR

Prof. Izabella Pessoa de Castro

UFF

Prof. Márcio da Silveira Carvalho

Vice Dean of Graduate Studies

Centro Técnico Científico - PUC-Rio

Rio de Janeiro, December $4^{\text {th }}, 2018$ 
All rights reserved.

\section{Cristiano Saad Travassos do Carmo}

The author graduated in Civil Engineering from Fluminense Federal University (UFF) in 2016. He entered the masters program in Pontifical Catholic University of Rio de Janeiro in August 2016 and worked on research related to Structural Optimization applied to Building Information Modeling.

Bibliographic data

Carmo, Cristiano Saad Travassos do

Structural engineering and architecture collaboration in the conceptual design through structural optimization within the BIM methodology / Cristiano Saad Travassos do Carmo; advisor: Elisa Dominguez Sotelino. - Rio de Janeiro: PUC-Rio, Civil Engineering Department, 2018.

95 f.: il. Color.; $29,7 \mathrm{~cm}$

Dissertação (mestrado) - Pontifícia Universidade Católica do Rio de Janeiro, Departamento de Engenharia Civil e Ambiental, 2018.

Inclui bibliografia

1. Engenharia Civil e Ambiental - Teses. 2. BIM. 3. Otimização estrutural. 4. IDM. 5. Engenharia estrutural. 6. Arquitetura. I. Sotelino, Elisa Dominguez. II Pontifícia Universidade Católica do Rio de Janeiro. Departamento de Engenharia Civil e Ambiental. III. Structural engineering and architecture collaboration in the conceptual design through structural optimization within the BIM methodology.

CDD: 624 
I dedicate this to my family, for their support and encouragement; amare et sapere vix deo

conceditur. 


\section{Acknowledgements}

A very special gratitude goes out to CNPQ and PUC-Rio for the financial support in my master studies.

I would like to thank my thesis advisor Prof. Elisa Sotelino of the Civil Engineering Department at PUC-Rio. The door to Prof. Sotelino office was always open whenever I ran into a trouble spot or had a question about my research or writing. She consistently allowed this paper to be my own work, but steered me in the right the direction whenever he thought I needed it. More than only technical supervision, Sotelino helped me with social and life concerns, acting almost as my "psychologisteacher".

I would also like to thank Prof. Luiz Fernando Martha (PUC-Rio), Prof. Sergio Scheer (UFPR) and Prof. Izabella Castro (UFF) for participating of the Examination Committee. I am gratefully indebted to them for their very valuable comments on this thesis.

I would also like to thank the RioBIM research group and all experts who were involved, specially Guilherme Santos and Matheus Peres. Without their passionate participation, this work could not have been successfully conducted.

I would also like to thank God: I am nothing without you, I need you every single day and I will always stay at your side.

To my late grandmother and grandfather, Eleonora and Noé, for their emotional support and protection in all my life.

To my life-coach, my grandfather Michel: because I owe it all to you. Many Thanks!

To my party girl, my grandmother Marly: thank you for teaching me about be happy!

To my bosses, my mother Maria Auxiliadora and my father José Roberto: who have provided me through moral and emotional support in my life.

To my mothers of creation, Alice and Aparecida, without you and your care, I would be nothing.

To my best friend, my brother Gabriel: we are only two people but one big family.

To my love foundation, my girlfriend Isabella: thank you for your enormous patient with me in these almost 6 years together. Every smile, hug and kiss worked as fuel to continue my studies.

I am also grateful to my other family members and friends who have supported me along the way.

And finally, last but by no means least, also to everyone in the impact hub... it was great sharing laboratory with all of you during last two years.

Thanks for all your encouragement! 


\section{Abstract}

Do Carmo, Cristiano Saad Travassos; Sotelino, Elisa Dominguez (Advisor). Structural engineering and architecture collaboration in the conceptual design through structural optimization within the BIM methodology. Rio de Janeiro, 2018. 95p. Dissertação de Mestrado. Departamento de Engenharia Civil e Ambiental, Pontifícia Universidade Católica do Rio de Janeiro.

There has been an increasing global tendency in the adoption of Building Information Modeling (BIM) paradigm for the implementation of Architectural, Engineering, and Construction (AEC) projects. In Brazil, a governmental nominated commission is studying how to disseminate BIM as applied to governmental projects. At the same time, Structural Optimization (SO) has received a lot of attention in civil engineering applications to reduce material and enhance structural performance. The purpose of this work, thus, is to understand how SO can be inserted in a BIM project, specifically analyzing the interface between architects and structural engineers. The investigation included a Systematic Literature Review (SLR) to comprehend the current scientific scenario in these areas. It was observed that there is a scientific gap in works that connect SO and BIM. To help fill this gap, an Information Delivery Manual (IDM) structure was developed which maps the information flow to connect architects and engineers through SO in a BIM environment. The proposed methodology was applied to three experiments of increasing complexity. It was verified that $\mathrm{SO}$ can be inserted in a BIM project once interoperability and collaboration issues are improved. To validate the structural solutions based on the SO results, detailed analysis using Finite Element Models (FEM) were developed and analyzed. It was found that the solutions were structurally acceptable according to current design codes. However, they may require advanced construction techniques to be economically feasible. It is worth pointing out that this study was limited to usual building projects in the early stages of the design.

\section{Keywords}

BIM; Structural Optimization; IDM; structural engineering; architecture. 


\section{Resumo}

Do Carmo, Cristiano Saad Travassos; Sotelino, Elisa Dominguez. Colaboração entre engenharia estrutural e arquitetura no projeto conceitual por meio da otimização estrutural com a metodologia BIM. Rio de Janeiro, 2018. 95p. Dissertação de Mestrado. Departamento de Engenharia Civil e Ambiental, Pontifícia Universidade Católica do Rio de Janeiro.

Há uma tendência global crescente na adoção do paradigma Building Information Modeling (BIM) para a implementação em projetos de arquitetura, engenharia e construção (AEC). No Brasil, uma comissão nomeada pelo governo estuda como disseminar o BIM aplicado a projetos governamentais. Ao mesmo tempo, a Otimização Estrutural (OE) vêm recebendo atenção em projetos de engenharia civil para reduzir o material e melhorar o desempenho estrutural. $\mathrm{O}$ objetivo deste trabalho, portanto, é entender como a OE pode ser inserido em um projeto BIM, analisando especificamente a interface entre arquitetos e engenheiros estruturais. A investigação incluiu uma Revisão Sistemática da Literatura (SLR) para compreender o cenário científico atual nessas áreas. Foi observado que existe uma lacuna científica em trabalhos que conectam a $\mathrm{OE}$ dentro do BIM. Para ajudar a preencher essa lacuna, foi desenvolvida uma estrutura de Manual de Entrega de Informações (MEI) que mapeia o fluxo de informações para conectar arquitetos e engenheiros por meio da OE em um ambiente BIM. A metodologia proposta foi aplicada a três estudos de caso de complexidade crescente. Verificou-se que a OE pode ser inserido em um projeto BIM quando os problemas de interoperabilidade e colaboração forem aprimorados. Para validar as soluções estruturais com base nos resultados da OE, foi desenvolvida e analisada a análise detalhada usando Modelos de Elementos Finitos (MEF). Verificou-se que as soluções eram estruturalmente aceitáveis de acordo com os códigos de projeto atuais. No entanto, podem ser necessárias técnicas avançadas de construção para serem economicamente viáveis. Vale ressaltar que este estudo se limitou a projetos de construção habituais nos estágios iniciais de desenvolvimento do projeto.

\section{Palavras-chave}

BIM; Otimização Estrutural; IDM; engenharia estrutural; arquitetura. 


\section{Table of contents}

1 Introduction 16

1.1. Motivation 16

$\begin{array}{ll}\text { 1.2. Objective } & 16\end{array}$

$\begin{array}{ll}\text { 1.3. Methodology } & 17\end{array}$

$\begin{array}{lr}\text { 1.4. Research structure } & 17\end{array}$

2 Background Concepts 18

2.1. Building Information Modeling, Model, Management (BIM $\left.{ }^{3}\right) \quad 18$

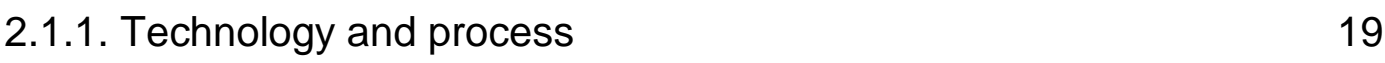

2.1.2. Policies 20

2.2. Structural Optimization (SO) 21

2.2.1. Topology Optimization (TO) 22

2.2.2. Shape and Sizing Optimization (ShO and $\mathrm{SiO})$

2.2.3. Optimization solvers 23

$\begin{array}{ll}\text { 2.3. Synergy } & 24\end{array}$

3 Literature Review 26

3.1. Research methodology 26

3.1.1. Question formulation 27

3.1.2. Locating studies $\quad 27$

3.1.3. Selection and quantitative evaluation 29

3.1.4. Qualitative analysis 30

3.2. Results from SLR 31

3.3. Bibliometric analysis 36

3.4. Selected articles review 38

3.4.1. BIM-related articles 38

3.4.2. SO related articles $\quad 41$

3.4.3. BIM and SO related articles 45

4 Methodology $\quad 48$

4.1. Information Delivery Manual (IDM) 48 
4.2. Proposed IDM 49

4.2.1. Process map 49

4.2.2. Tools 51

4.2.3. Interoperability 52

4.2.4. Exchange requirements $\quad 53$

5 Analysis $\quad 57$

5.1. Description $\quad 57$

5.2. Task evolution 58

5.2.1. Architectural preliminary study 58

5.2.2. Structural optimization 60

5.2.3. Technical and economic viability study 61

5.2.4. Architectural conceptual design 61

5.2.5. Conceptual structural project 63

5.2.6. Other tasks 64

5.3. Structural engineering processes 66

5.3.1. Structural optimization 66

5.3.2. Structural analysis 74

6 Results and Discussion 81

6.1. From structural analysis $\quad 81$

6.2. From BIM implementation 82

7 Conclusion $\quad 84$

8 Bibliography $\quad 87$

Appendix A - SLR initial quantitative and qualitative analysis, before the full reading 


\section{List of figures}

Figure 1 - IFC historic evolution 20

Figure 2 - TO, ShO, and SiO differences, adapted from Gebisa (2017) 23

Figure 3 - Practical examples of the connection between SO and AEC industry 25

Figure 4 - Systematic Literature Review (SLR) Methodology 27

Figure 5 - Word tree adopted 28

Figure 6 - Number of articles by search terms 32

Figure 7 - World occurrence map in SO related papers 35

Figure 8 - World occurrence map in BIM related papers 35

Figure 9 - Number of publications per year in each scientific area $\quad 36$

Figure 10 - Co-occurrence terms map from all articles 37

Figure 11 - Example of one word ("conceptual design") that connect BIM and SO worlds

Figure 12 - Difference of scope between IFC and IDM according to buildingSMART (2017)

Figure 13 - Structural Optimization process inserted in the BIM methodology in the early stages for building projects

Figure 14 - BIM and SO tools interoperability between architect and structural engineer in early stages

Figure 15 - Preliminary architectural model A 59

Figure 16 - Preliminary architectural model B 59

Figure 17 - Preliminary architectural model C. 59

Figure 18 - Preliminary architectural model C 60

Figure 19 - Design alternatives based on structural optimized model A 73

Figure 20 - Design alternatives based on structural optimized model B 73

Figure 21 - Design alternatives based on structural optimized model C 74

Figure 22 - Architectural conceptual model A 62

Figure 23 - Architectural conceptual model B 62

Figure 24 - Architectural conceptual model C 63

Figure 25 - Structural conceptual model A 63

Figure 26 - Structural conceptual model B 64 
Figure 27 - Structural conceptual model C

Figure 28 - Conceptual SO process in case A using Fusion360 68

Figure 29 - Conceptual SO process in case B using Fusion360 68

Figure 30 - Conceptual SO process in case B using Fusion360 69

Figure 31 - SO process in case A using ANSYS $\quad 70$

Figure 32 - Parallel conceptual SO process in case B, using ANSYS 71

Figure 33 - Parallel conceptual SO process in case C, using ANSYS 71

Figure 34 - SO process in case A using Abaqus/TOSCA 72

Figure 35 - SO process in case B using Abaqus/TOSCA 72

Figure 36 - SO process in case $C$ using Abaqus/TOSCA (half building) 73

Figure 37 - FE model for case A $\quad 75$

Figure 38 - FE model for case B $\quad 75$

Figure 39 - FE model for case C $\quad 75$

Figure 40 - Water tank loads $(\mathrm{kN})$ applied to the structural grip support 78 Figure 41 - Structural model for buckling analysis in case B, column T3 79 Figure 42 - First (critical), second and third buckling modes for the more solicited column T3 in the first floor of Tree Building 


\section{List of tables}

Table 1 - Strings used in search engines 29

Table 2 - Inclusion/Exclusion Criteria $\quad 29$

Table 3 - Evolution in number of articles using inclusion/exclusion criteria

Table 4 - Evolution in number of articles using qualitative analysis 31

Table 5 - Group division for BIM and ARCHITECTURE results 31

Table 6-Chosen articles: Part A 33

Table 7 - Chosen articles: Part B 34

Table 8 - VOS viewer configuration to term search 36

Table 9 - List of software used 52

Table 10 - Proposed Exchange Requirement for the architectural preliminary model $\quad 54$

Table 11 - Proposed Exchange Requirement for the structural optimized model 55

Table 12 - Cases studies initial description with owner requirements $\quad 57$

Table 13 - Optimization parameters in F360 67

Table 14 - Optimization parameters in ANSYS $\quad 70$

Table 15 - Optimization parameters in Abaqus/TOSCA 72

Table 16 - FEA configuration for case A, B, and C 76

Table 17 - Convergence test for mesh refinement in model A 77 


\section{List of abbreviations}

\begin{tabular}{ll} 
AEC & Architecture, Engineering, and Construction \\
BbCN & BIM based Construction Network \\
BESO & Bidirectional Evolutionary Structural Optimization \\
BIM & Building Information Modeling \\
BIM & Building Information Modeling, Model, and Management \\
BPMN & Business Process Modeling Notation \\
EA & Evolutionary Algorithm \\
ER & Exchange Requirements \\
ESO & Evolutionary Structural Optimization \\
FA & Firefly Algorithms \\
FE & Finite Element \\
FEA & Finite Element Analysis \\
GA & Genetic Algorithm \\
GS & Ground Structure \\
HA & Heuristic Algorithms \\
HVAC & Heating, Ventilation, and Air Conditioning \\
IAI & International Alliance for Interoperability \\
IDM & Information Delivery Manual \\
IFC & Industry Foundation Classes \\
IFD & International Framework for Dictionaries \\
IPD & Integrated Project Delivery \\
ISO & International Organization for Standardization \\
MDO & Multidisciplinary Design Optimization \\
MEP & Mechanical, Electrical, and Plumbing \\
MH & Man Hour \\
MMA & Method of Moving Asymptotes \\
MMFD & Modified Method of Feasible Directions \\
MVD & Model View Definition \\
PIDO & Process Integration and Design Optimization \\
ShO & Shape Optimization \\
SIMP & Solid Isotropic Microstructure with Penalization \\
SiO & Sizing Optimization \\
\hline
\end{tabular}


SLR Systematic Literature Review

SO Structural Optimization

SQP Sequential Quadratic Programming

TO Topology Optimization

USC Universal Scissor Component

XML Extensible Markup Language 
The biggest thing about BIM is that it is moving us back to interdisciplinary work.

Kathleen Liston 


\section{1 \\ INTRODUCTION}

\section{1. \\ Motivation}

The current economic scenario in Brazil demands that the Architecture, Engineering, and Construction (AEC) industry provide better projects, that use less material, produce less waste, and have better performance. At the same time, the Building Information Modeling (BIM) paradigm, which is the most prominent methodology for improving design and construction, is growing worldwide. This is also the tendency in Brazil after the government officialized its strategic plan to disseminate the adoption of BIM through the Decree number 9377, in 2018.

To be effectively implemented, however, two inherent principles have to support a BIM project: interdisciplinarity and collaboration. These terms refer to many disciplines, such as architecture, structural engineering, and construction, working together in synchrony with the same objective: the best project. However, in most traditional projects, each discipline works separately without any collaboration and communication occurring between them (EASTMAN et al., 2011). For this reason, more studies trying to connect disciplines are necessary to implement the BIM paradigm in a project.

Therefore, this study is oriented to analyze the integration and collaboration between structural engineering and architecture through structural optimization processes in a BIM project. By doing so, it is expected a better project environment to work within the BIM methodology. At the same time, using optimization techniques, beyond the BIM methodology, better projects are expected with material consumption reduction and higher structural performance.

\section{2.}

\section{Objective}

The main objective of this work is to understand if structural optimization can be inserted into a project within the BIM framework, and if so, how can it be inserted, and what impacts it can provide. Specifically, it seeks to shed some light on how it can impact the collaboration between architects and structural engineers 
in the early stages of design of a building project. Thus, the specific objective of this work is to develop the initial steps towards the integration between structural engineers and architects using structural optimization processes in a BIM environment.

\section{3.}

\section{Methodology}

To support the objective, a Systematic Literature Review (SLR) is conducted in order to understand the current stage of development in this scientific area. Using this impartial and complete methodology, scientific gaps are found and, thus, orient the study to fill them. After that, a framework of information flow to insert structural optimization processes in a BIM project is created, using Information Delivery Manual (IDM) and Industry Foundation Classes (IFC) concepts. This structured process map helps to understand which players interaction produce information losses and orient the elaboration of exchanges information requirements to improve workflow and collaboration. To test the applicability of the proposed framework and the potential impacts that it might have, three experiments were developed and analyzed.

\section{4 . Research structure}

This work is structured as follows. Chapter 2 presents brief concepts about BIM and structural optimization that is basic knowledge to support the understanding of the next chapters. Chapter 3 presents the Systematic Literature Review (SLR) framework used in this work and the results on current studies in this scientific field. Chapter 4 presents an IDM structure, composed of a process map and exchange requirements, which are necessary to initiate the standardization IFC. Chapter 5 apply the IDM to three experiments and Chapter 6 presents the results and impacts in a BIM project, related to structural feasibility, collaboration improvements and software interoperability. Finally, Chapter 7 presents conclusions and recommendations for future research. 


\section{2 \\ BACKGROUND CONCEPTS}

This chapter explains the fundamental concepts involved in this study. They are addressed briefly, but sufficiently in-depth as to not require additional reading. They are organized under two main topics: Building Information Modeling (BIM) and Structural Optimization (SO).

\section{1. \\ Building Information Modeling, Model, Management (BIM³)}

There are numerous definitions for the acronym BIM, one of the most popular among these is as follows:

a BUSINESS PROCESS for generating and leveraging building data to design, construct and operate the building during its lifecycle. BIM allows all stakeholders to have access to the same information at the same time through interoperability between technology platforms. (NBIMS, 2015, p.3)

It is important to not confuse the three BIMs: BIModeling, BIModel and BIManagement $\left(\mathrm{BIM}^{3}\right)$. The definition above is related to the first one: BIModeling. The second term (BIModel) refers to a physical digital model with information regarding the enterprise's entire lifecycle, whereas the third (BIManagement) is related to organizational issues regarding information flow throughout the building life. Lastly, it is worth pointing out that all three BIMs are necessary for complete BIM implementation (NBIMS, 2015).

As defined by Succar et al. (2012), BIM ${ }^{3}$ also can be described by three keywords: technology, process, and policies. Technology involves all informatics support to create a BIModel; process refers to the method of creating this "object" and, thus, it is an activity (BIModeling), and policies is defined by how contracts are organized and controlled, as well as other administrative attributes and information management (BIManagement).

As reported by many authors (AZHAR et al., 2012; ROGERS et al., 2015; OLAWUMI et al., 2018) and verified in this study, there is a significant barrier on BIM dissemination related to two types of communication: digital (between 
software) and human (between players). BIM implementation will only be complete when these issues are addressed.

\subsection{1.}

\section{Technology and process}

The technology and process pillars, that support BIM methodology, contain two fundamental definitions for this study: parametrization and interoperability. In the parametrization stage, the enterprise involves object creation, through 3D representation and rules. 3D models first appeared in the 1960s and later (1982), at the movies, on the Walt Disney Productions film TRON, while the concept of parametrization is more recent dating of the 1990s (EASTMAN et. al, 2011).

According to Díaz et al. (2017), the parametrization provides to an object intelligent information, which is either geometrical or non-geometrical (e.g., cost, fire-resistance), which enables automatic updates in the model during modification. In addition, these object rules bring coherence and non-redundancy to the project (EASTMAN et. al, 2011).

There are numerous types of BIM software that allow parametrization. Abanda et al. (2015) list almost all of the existing types with their features. However, a key issue is how they communicate with each other, i.e., how they "interoperate". This is known as interoperability and it means "the ability of diverse systems and organizations to work together" (VENUGOPAL et al., 2012, p.412).

Unfortunately, each software vendor has its own extension, which complicates BIM implementation since often there is a lack of interoperability. However, aiming to solve this problem of digital communication, big companies worked together to create the common language known as Industry Foundation Classes (IFC) in 1994 (LAAKSO; KIVINIEMI, 2012). Figure 1 shows the IFC evolution history according to buildingSMART (2017).

The main idea of IFC standardization refers to open interoperability (or openBIM), which positively impacts BIM by facilitating information flow throughout a building lifecycle, avoiding redundancy and increasing the productivity coupled with efficiency (LAAKSO; KIVINIEMI, 2012). Beyond these abstract gains, a better interoperability also implies financial savings, as indicated by Gallaher et al. (2004) and Jones et al. (2008). 


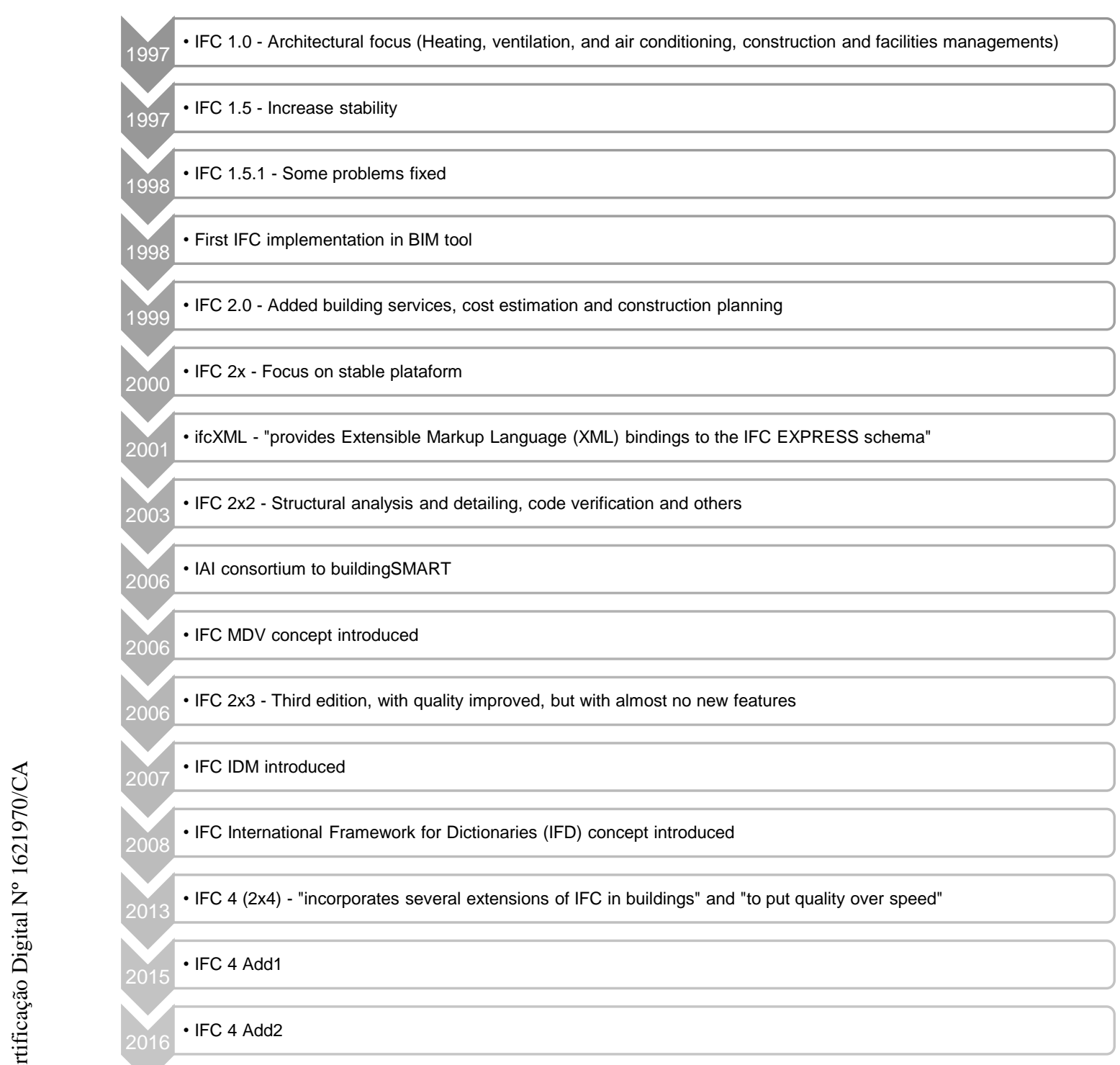

Figure 1 - IFC historic evolution

\subsection{2.}

\section{Policies}

Another fundamental pillar in the BIM paradigm is called by policies or people according to Abanda et al. (2015). It involves nontechnical issues: collaboration and interdisciplinarity, i.e., teams working and thinking together. Sometimes, these topics require cognitive studies rather than technical (SUWAL; SINGH, 2018), which is beyond the scope of the present work.

First, the multi-disciplinary nature of construction demands collaboration. However, in fact, there is a classical barrier, and a source of conflict that occurs between designers and constructor and, thus, from conception to construction (ABRISHAMI et al., 2015). This situation is incompatible with the BIM environment, 
according to Azhar et al. (2012), who state that: "the foundations of BIM are laid on two pillars, communication and collaboration".

Therefore, a better collaboration is indispensable for the success of BIM implementation. This is well defined by Ashcraft (2008), who says that BIM without collaboration is like scratching the surface. However, this is not unidirectional, BIM implementation also promotes a better environment for communication and collaboration (LU et al., 2014). In fact, in accordance with Ghaffarianhoseini et al., (2017), when this occurs in the early stages, it can reduce requests for information and rework, which directly impacts cost and time.

In terms of interdisciplinarity, traditionally "architects are taught entirely separately from engineers, and both are again separated from constructors" (GHAFFARIANHOSEINI et al., 2017, p.1050). This education problem prejudices the BIM environment, since projects follow only individual thoughts and cultures, hindering communication. According to the same author, it is necessary to reformulate teaching in the $\mathrm{AEC}$ industry, to achieve interdisciplinarity and collaboration to generate good results and improve the BIM experience.

The present work focuses on technical issues that affect the people BIM pillar, especially those related to process mapping and information flow. However, it should be noted that the technical processes proposed in this study will only be successful if there exists integration, collaboration, and interdisciplinary between architects and structural engineers.

\section{2.}

\section{Structural Optimization (SO)}

Structural optimization is often concerned with reducing weight and improving structural performance. These objectives generally imply in lower project cost and higher durability. Michell (1904), an Australian inventor, was one of the first researchers to apply structural optimization, specifically topology optimization, in the layout of trusses, in an attempt to determine the structure with lowest possible weight. More recently, Prager and Rozvany (1977) and Rozvany (1972a,1972b) extended Michell's theory for analytical optimal solutions of gridtypes structures (XIA et al., 2016).

Numerous techniques and approaches exist and, thus, it is important to distinguish the different types of SO, e.g.: Topology Optimization (TO), Shape Optimization (ShO), and Sizing Optimization (SiO) (PAPALAMBROS; WILDE, 2000). In short Topology Optimization is better adopted in early stages of the 
design, when there are few shape restrictions, and ShO and SiO can be adopted in more advanced stages of the design, i.e. in pre-detailed and detailed design, respectively. In the following subsections these concepts are described in more detail.

\subsection{1.}

\section{Topology Optimization (TO)}

Compared to other types of Structural Optimization, TO provides the most freedom of design; in other words, it can produce unexpected structures, with atypical shapes and curves, from a basic conceptual volume (DEATON; GRANDHI, 2014). According to these authors, at the beginning of the 21st century, TO has been the most studied area in Structural Multi-Objective Optimization.

From a technical perspective, Sigmund and Maute (2013) divide Topology Optimization into different approaches: based on density element variation (Solid Isotropic Microstructure with Penalization - SIMP, Random Amplified Microsatellite Polymorphism - RAMP, Level set, Phase field, etc.), discrete-based on element elimination (Evolutionary Structural Optimization - ESO, Bidirectional Evolutionary Structural Optimization - BESO, etc.), and Lagrangian approaches. There is a vast number of methods; however, almost all of them are derived from one another. An example of this is BESO modified with penalization schema, which is a fusion between the discrete (evolutionary) and density (SIMP) approaches.

According to Deaton and Grandhi (2014), almost all commercial tools are based on density approaches, or variations of this. Examples of such tools are: GENESIS, ANSYS, and TOSCA (Abaqus). However, they are more focused on mechanical engineering problems applied to the industrial sector (SIGMUND; MAUTE, 2013).

From a project perspective, according to Yi and Sui (2015), there are two TO methods: one focused on structural performance (displacements, stress, etc.) with economic limitations, and the another focused on minimizing structural economic indexes (volume, weight, cost, etc.) assuming that structural performance is satisfied.

In this work, the focus is in the early stages of the design, where there are few restrictions and only building mass is defined. For this reason, TO can be more useful than other types of $\mathrm{SO}$, since in the conceptual design there is more freedom to create. 


\subsection{2.}

\section{Shape and Sizing Optimization (ShO and SiO)}

It is easy to confuse ShO with TO because they are very similar concepts. However, it is worth pointing out that ShO is more specific than TO. For example, it would be used after the building envelope is defined using TO. As verified by Mattheck (1990), shape optimization sometimes returns natural shapes (e.g., plums and cherries). The reason being that natural shapes have a uniform surface stress.

According to (BENDSØE, 1989), shape optimization initiates with a structure layout or topology and assembly boundary variations to it. Thus, it can be seen that ShO has more restrictions in design than TO and can be used as a second optimization, after TO.

In the Sizing Optimization ( $\mathrm{SiO}$ ), the boundary and shape of the structure are defined, and the objective is to reduce the sections. Compared to TO and ShO, SiO allows less freedom in the design, because the majority of parameters are defined and restricted. For this reason, SiO often occurs during the detailed design, whereas ShO and TO offer a good opportunity to improve and facilitate the conceptual design. (DEATON; GRANDHI, 2014).

Figure 2 illustrates the difference between all SO processes, in terms of initial layout and freedom to design.

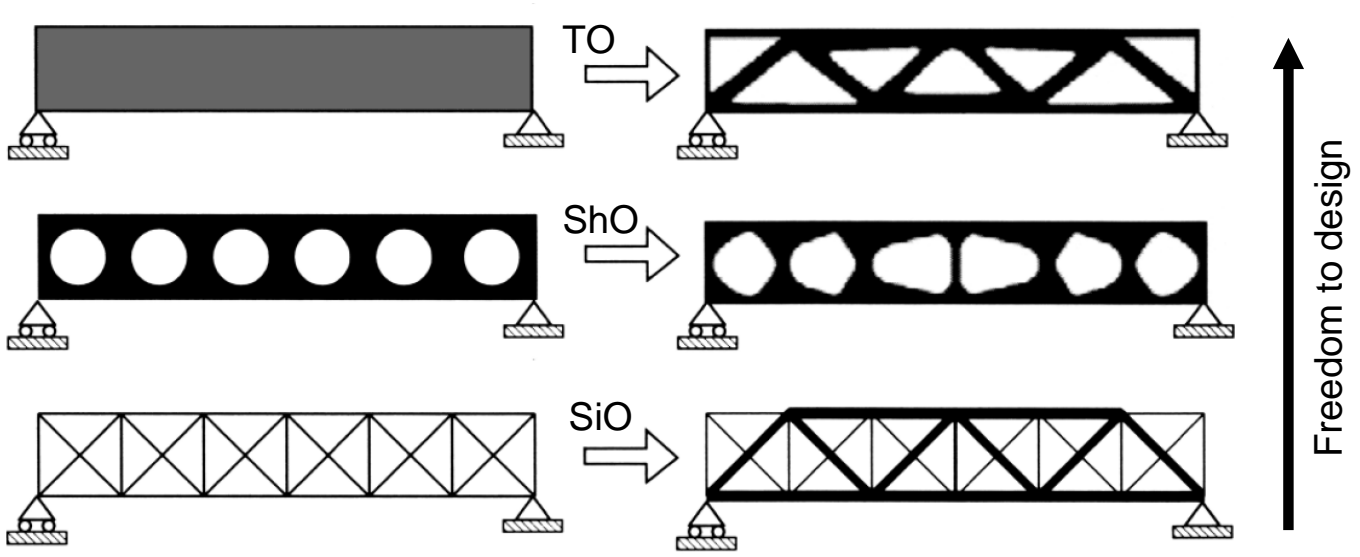

Figure 2 - TO, ShO, and SiO differences, adapted from Gebisa and Lemu (2017)

\subsection{3.}

\section{Optimization solvers}

Optimization solvers are algorithms that allow all approaches described previously increase the speed of the process. There are numerous solvers: Method 
of Moving Asymptotes (MMA), Sequential Quadratic Programming (SQP), Heuristic Algorithms (HA), Genetic Algorithms (GA), Firefly Algorithms (FA), Modified Method of Feasible Directions (MMFD), among others.

However, two of them are highlighted as density optimization methods: Optimality Criteria (OC) method and Method of Moving Asymptotes (MMA). The former is used in MATLAB codes and the latter in ANSYS, a commercial optimization tool (SIGMUND; MAUTE, 2013).

The difference between OC and other methods (e.g. SQP) is the way the iteration is performed: OC method can solve a lot of variables with fewer computational cost compared to other methods. However, the OC approach does not have the advantage of generality, this optimization solver was first developed for specific problems in engineering, such as trusses, topology, and shells (BELEGUNDU, 2015). Meanwhile, MMA solver, created and improved by Svanberg (1987) and Zillober (1993), is indicated for nonlinear optimization and Level Set density-based TO problems.

It is worth pointing out that there is no best solver, in each situation an algorithm is more recommended than another. For example, following RojasLabanda and Stolpe (2015), for TO, Globally Convergent MMA requires fewer iterations and reaches better solutions than MMA.

In this work, two optimization algorithms solvers that are used: the Optimally Criteria and the Moving Asymptotes methods, which are implemented in a commercial optimization software.

\section{3. \\ Synergy}

Conceptually, BIM and Structural Optimization areas have the same goal, which is to achieve better projects. Therefore, intrinsically, there is a connection between them, but in the scientific literature this is not well established, since there are very few articles and works published according to the structured literature review performed in this research.

However, there is a slight connection between Structural Optimization and AEC industry, carried out by larger architectural and engineering offices or renowned architectural offices in wealthy countries. Examples of that are the following projects: White Magnolia Plaza by Skidmore Owings \& Merrill office (Figure 3a); Qatar National Convention Center by Arata Isozaki (Figure 3d); the 
Bionic Tower project by LAVA architects (Figure 3b); and the first 3D printed steel bridge by MX3D company (Figure 3c).
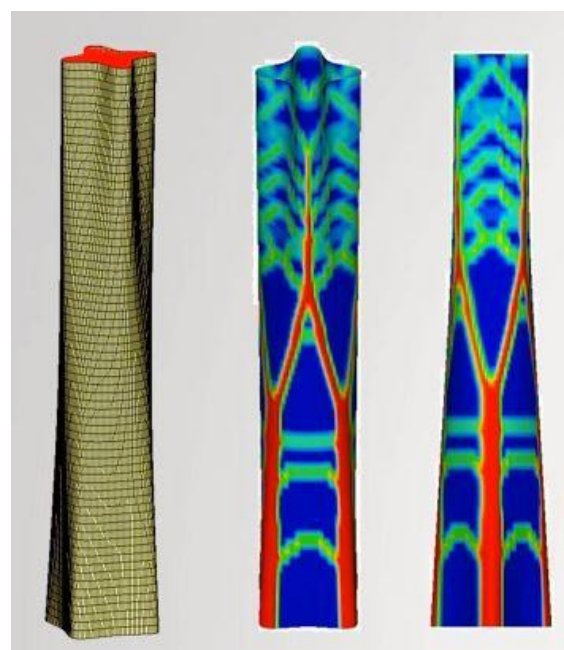

(a)
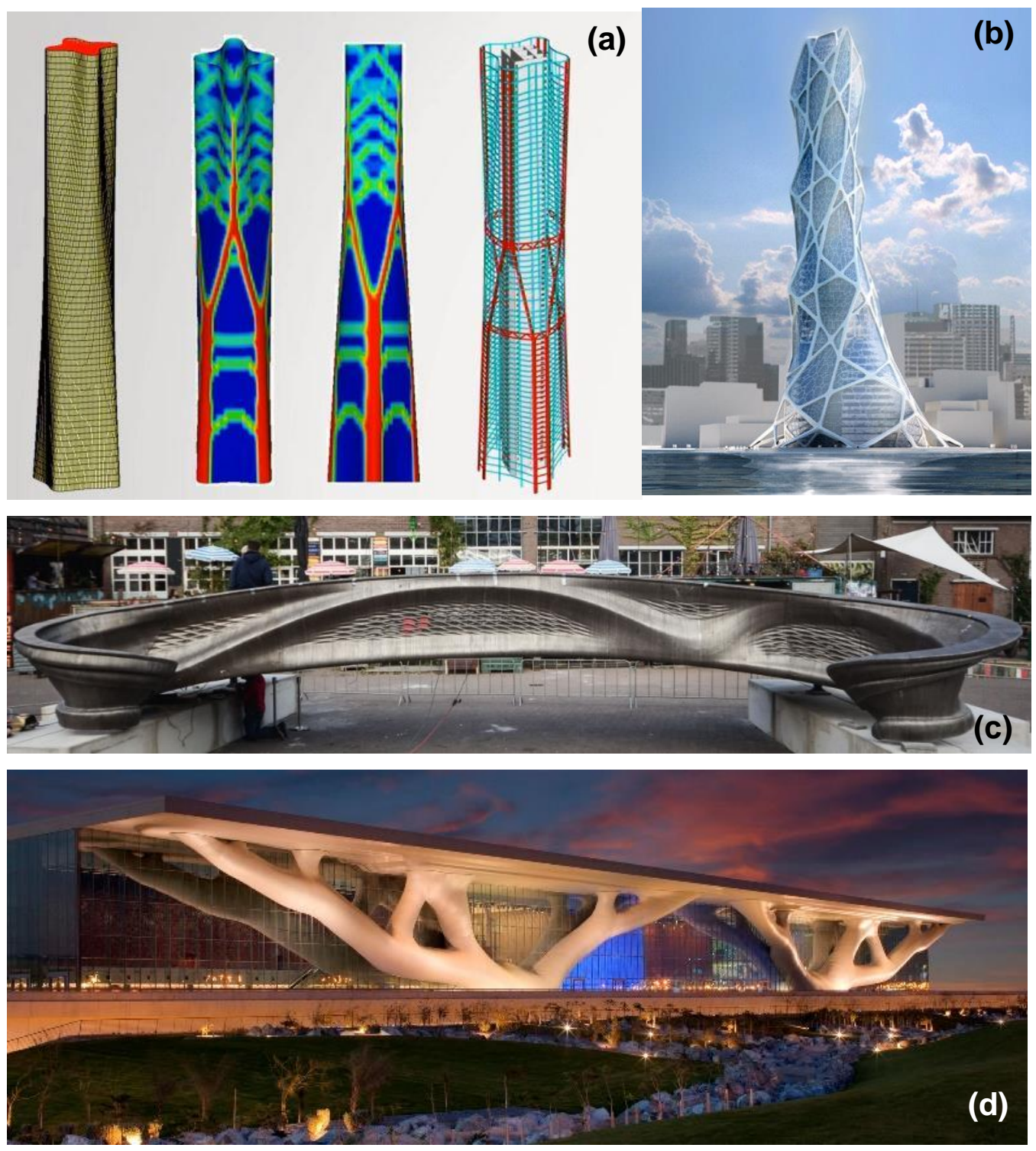

Figure 3 - Practical examples of the connection between SO and AEC industry ${ }^{1}$

1 a) Autodesk University AU Las Vegas 2016 - Presentation: Generative Design with Autodesk Nastran Topology Optimization by David Weinberg. Accessed on October 2018.

b) https://archello.com/project/bionic-tower. Accessed on October 2018.

c) https://www.dezeen.com/2018/10/22/worlds-first-3d-printed-steel-bridge-completedmx3d-technology/. Accessed on October 2018.

d) http://www.visitqatar.qa/businessevents/planning-an-event/venues/qatar-nationalconvention-centre. Accessed on October 2018. 


\section{3 \\ LITERATURE REVIEW}

This chapter describes the methodology adopted to identify scientific publications that involve BIM and SO and that will guide the research. Through a structured literature review it was possible to find the existing gaps in academic studies and, thus, direct the research to cover this void. Besides that, qualitative and quantitative analyses were done to measure how evolved is this area that connects BIM and SO.

\section{1. Research methodology}

The process adopted in this literature review is the Systematic Literature Review (SLR), whose main principles are reliability and impartiality (DENYER; TRANFIELD, 2009). According to Kitchenham and Charters (2007), SLR is important to understand current studies, identify gaps (areas not explored yet), and create the necessary background for the development of new research.

Figure 4 describes the five steps that structure the entire SLR process, following Khan et al. (2003); Denyer and Tranfield (2009). The first line refers to stages, the middle to activities, and the last to tools. It is worth pointing out that this process is cyclical, and it may be necessary to repeat some steps. 


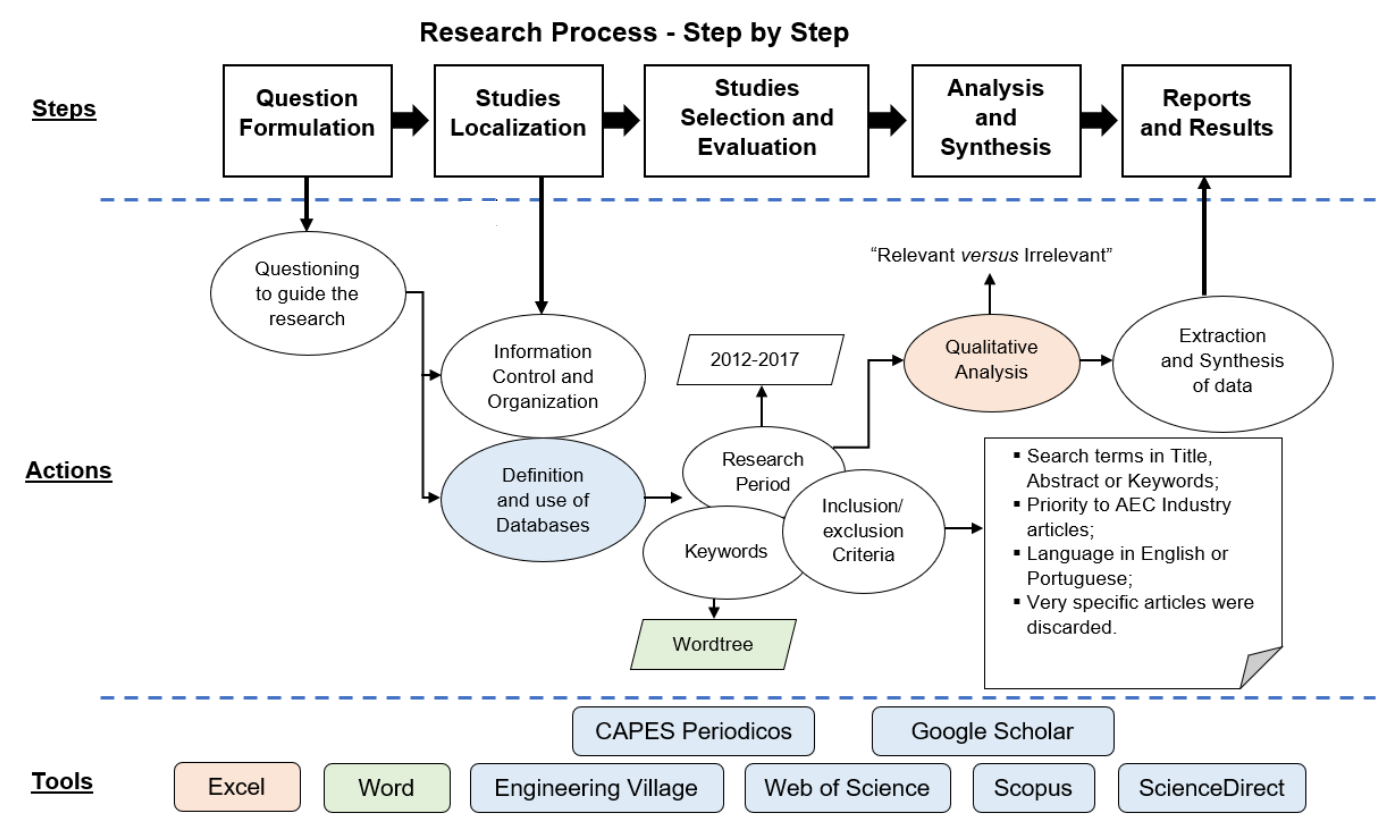

Figure 4 - Systematic Literature Review (SLR) Methodology

\subsection{1.}

\section{Question formulation}

To guide the scientific research, the following three questions were formulated following the SLR methodology proposed by KHAN et al. (2003):

1. Can the structural optimization process be inserted in the BIM methodology?

2. How can the structural optimization process be inserted in the BIM methodology?

3. What impact does the structural optimization process generate in the BIM process?

\subsection{2.}

\section{Locating studies}

After the question formulation, the next step, according to Figure 4, is to locate the studies. This phase refers to the identification of the databases and the creation of the word tree. Reliable databases should be correctly selected to validate the results and the word tree is responsible to guide the search engine.

This study aims cover a comprehensive set of academic databases. Specifically, six databases were used: Scopus, Engineering Village, Web of Science, Science Direct, Google Scholar, and CAPES Periódicos. The two last 
sources were used only as validation tools because their filters were not found to be satisfactory.

The word tree was developed based on the work of Hart (1998). Figure 5 illustrates the relevant terms used in the search engines, where level 1 (BIM, Structural Optimization, Topology Optimization, and Architecture) denotes macro terms and level 2 represents specific terms derived from them. It is worth to pointing out that this word tree was modified several times to reach these final terms, with the aim of not overlooking important studies.

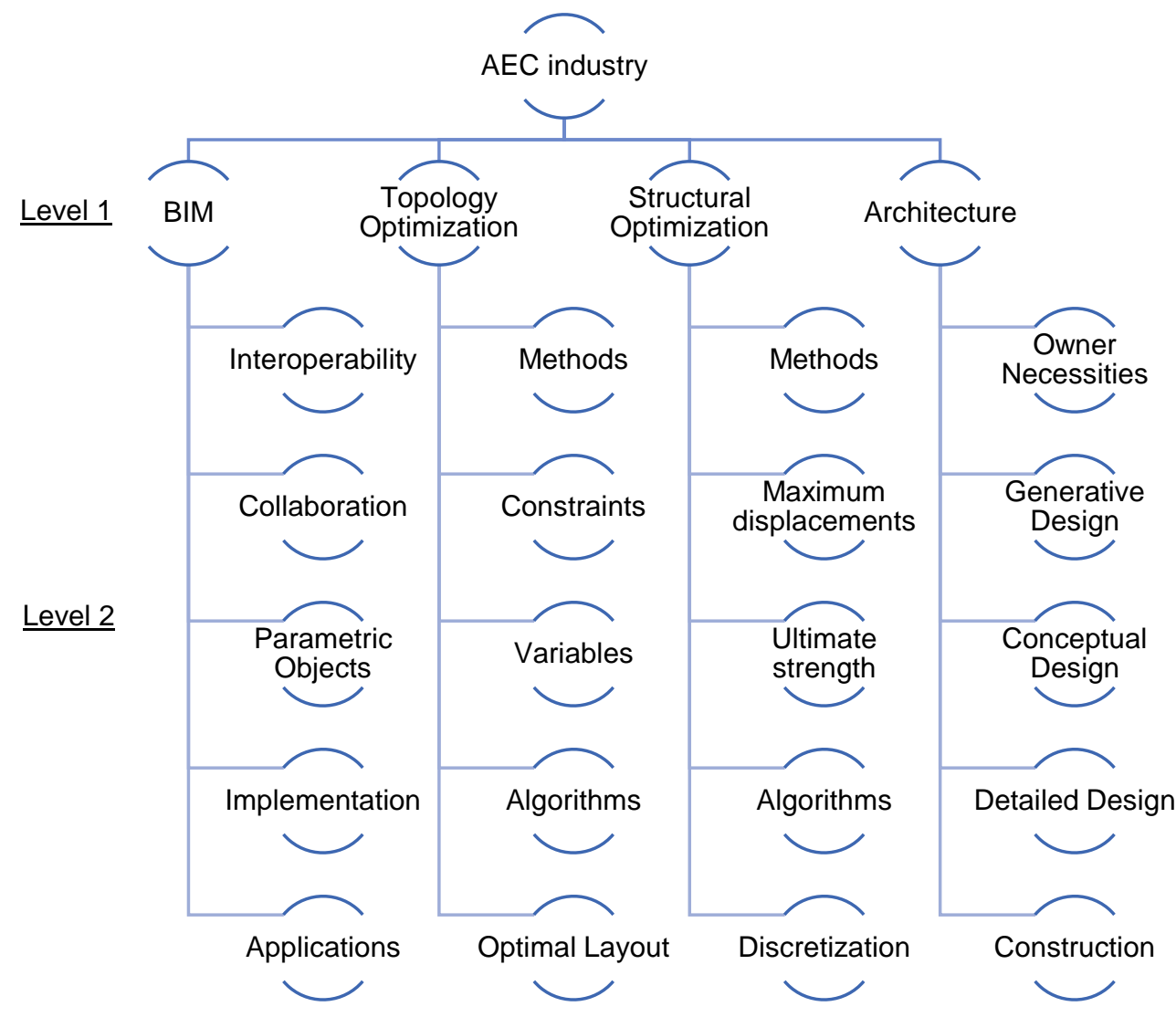

Figure 5 - Word tree adopted

In addition to the word tree, strings were created and associated using Boolean operators "AND" and "OR" (see Table 1) in the selected databases. They are combined pairwise, totalizing six combinations. Strings are important for the organization and support of the search with the aim of obtaining relevant results (SIDDAWAY, 2014). 
Table 1 - Strings used in search engines

\begin{tabular}{|c|c|c|c|}
\hline \multirow{5}{*}{ "BIM" } & \multirow{5}{*}{ and } & "INTEROPERABILITY" & or \\
\hline & & "COLLABORATION" & or \\
\hline & & "PARAMETRIC OBJECTS" & or \\
\hline & & "IMPLEMENTATION" & \\
\hline & & "APPLICATIONS" & \\
\hline \multirow{5}{*}{ "ARCHITECTURE" } & \multirow{5}{*}{ and } & "OWNER NECESSITIES" & or \\
\hline & & "CONCEPTUAL DESIGN" & or \\
\hline & & "GENERATIVE DESIGN" & or \\
\hline & & "DETAILED DESIGN" & or \\
\hline & & "CONSTRUCTION" & \\
\hline \multirow{5}{*}{$\begin{array}{c}\text { "STRUCTURAL } \\
\text { OPTIMIZATION" (“SO") }\end{array}$} & \multirow{5}{*}{ and } & "METHODS" & or \\
\hline & & "MAXIMUM DISPLACEMENTS" & or \\
\hline & & "ULTIMATE STRENGTH" & or \\
\hline & & "ALGORITHMS" & or \\
\hline & & "DISCRETIZATION" & \\
\hline \multirow{5}{*}{$\begin{array}{c}\text { "TOPOLOGY } \\
\text { OPTIMIZATION" (“TO”) }\end{array}$} & \multirow{5}{*}{ and } & "METHODS" & or \\
\hline & & "CONSTRAINTS" & or \\
\hline & & "VARIABLES" & or \\
\hline & & "ALGORITHMS" & or \\
\hline & & "OPTIMAL LAYOUT" & \\
\hline
\end{tabular}

For example, the following combination was used in the databases: "BIM" and ("INTEROPERABILITY or "COLLABORATION" or...) and "ARCHITECTURE" and ("OWNER NECESSITIES" or "CONCEPTUAL DESIGN" or...).

\subsection{3.}

\section{Selection and quantitative evaluation}

This step focuses on the application of appropriated filters to restrict the first sample resulting by the word tree, time period, subject area, and other inclusion/exclusion conditions. In so doing, the sample becomes more coherent, from which, conclusions can be drawn and gaps can be identified in the literature.

Only journal papers in English or Portuguese published from 2012 to 2018 were considered. Moreover, it is important to define the search terms that appear in the title, abstract, or keywords. Table 2 lists all the filters applied to the search engine.

Table 2 - Inclusion/Exclusion Criteria

\begin{tabular}{ll}
\hline \multicolumn{1}{c}{ Inclusion } & \multicolumn{1}{c}{ Exclusion } \\
\hline Journal Articles & Not Journal Papers (Conference paper, \\
& e.g.) \\
\hline From 2012 to 2018 & Out of the inclusion period \\
\hline Language in English or Portuguese & Other languages \\
\hline AEC area & non-AEC areas \\
\hline
\end{tabular}


Table 3 illustrates an example to better understand the evolution between the first sample and the more refined one (with filters applied). In this representation, of a single search (BIM + ARCHITECTURE), each line represents a database and the number of articles found is described in each column, following an evolution of addiction restrictions. The subtopics column refers to the inclusion of micro terms (Level 2) from the word tree. The column "Title Analysis" refers to the reading of all titles to discard irrelevant studies to this work and, thus, represent the beginning of the next step: qualitative analysis.

Table 3 - Evolution in number of articles using inclusion/exclusion criteria

\begin{tabular}{lcccc}
\hline TERMS: & \multicolumn{4}{c}{ BIM \& ARCHITECTURE } \\
\hline \multicolumn{1}{c}{ DATABASE } & $\begin{array}{c}\text { Without } \\
\text { Exc/Inc } \\
\text { Criteria }\end{array}$ & $\begin{array}{c}\text { Within Exc/lnc } \\
\text { Criteria }\end{array}$ & $\begin{array}{c}\text { Subtopics } \\
\text { included }\end{array}$ & Title Analysis \\
\hline SCOPUS & 1169 & 275 & 148 & 76 \\
\hline ENG. VILLAGE & 848 & 193 & 98 & 95 \\
\hline SCIENCE DIRECT & 190 & 165 & 31 & 17 \\
\hline WEB OF SCIENCE & 639 & 191 & 78 & 60 \\
\hline
\end{tabular}

It is worth pointing out that many of the articles found using the search engine were common to all databases. This "duplicated" papers were eliminated in the next SLR step and the result of this subtraction is presented in the column "Mixed Data" in Table 4. Altogether 138 papers, in the example search (BIM + ARCHITECTURE), were selected to carry out the qualitative analysis.

\subsection{4. \\ Qualitative analysis}

Following this methodology, it is necessary to conduct a qualitative evaluation of these samples. For this, all titles and abstracts from the second sample were read and analyzed. In this manner, studies that did not fit in this study, but for some reason fit in the quantitative filters, were discarded. Table 4 shows the evolution of the number of articles selected after this qualitative analysis in one of the six word pairs created using the word tree. 
Table 4 - Evolution in number of articles using qualitative analysis

\begin{tabular}{lccc}
\hline TERMS: & \multicolumn{3}{c}{ BIM \& ARCHITECTURE } \\
\hline \multicolumn{1}{c}{ DATABASE } & Title Analysis & Mixed Data & $\begin{array}{c}\text { Abstract } \\
\text { Analysis \& } \\
\text { Chosen Articles }\end{array}$ \\
\cline { 1 - 2 } SCOPUS & 76 & \multirow{2}{*}{138} & \\
\cline { 1 - 2 } ENGIN. VILLAGE & 95 & & 28 \\
\cline { 1 - 2 } SCIENCE DIRECT & 17 & & \\
\cline { 1 - 2 } WEB OF SCIENCE & 60 & &
\end{tabular}

To better understand how these 138 papers are divided, Table 5 shows how the papers were chosen. In this table, the articles are organized by subject area and the chosen papers are defined using the criteria described in the last column.

Table 5 - Group division for BIM and ARCHITECTURE results

\begin{tabular}{|c|c|c|c|c|}
\hline GROUP & AREA & $\begin{array}{c}\text { № } \\
\text { ARTICLES }\end{array}$ & CHOSEN & CRITERIA \\
\hline 1 & GENERIC & 43 & 10 & \multirow{5}{*}{$\begin{array}{l}\text { Fit in the scope of this } \\
\text { study, involving terms that } \\
\text { can be related to SO. }\end{array}$} \\
\hline 2 & INTEROPERABILITY & 22 & 5 & \\
\hline 3 & COLLABORATION & 17 & 3 & \\
\hline 4 & BIM 4D & 7 & 2 & \\
\hline 5 & IMPLEMENTATION & 19 & 3 & \\
\hline 6 & OPTIMIZATION & 1 & 1 & \multirow{4}{*}{$\begin{array}{l}\text { Can be inserted in the } \\
\text { scope of this study, related } \\
\text { to the interface between } \\
\text { architects and engineers. }\end{array}$} \\
\hline 7 & SURVEY & 5 & 1 & \\
\hline 8 & CUSTOMIZATION & 1 & 1 & \\
\hline 9 & CASE STUDY & 4 & 2 & \\
\hline 10 & CLOUD & 8 & 0 & \multirow{6}{*}{$\begin{array}{c}\text { Not in the scope of this } \\
\text { study. }\end{array}$} \\
\hline 11 & BIM 5D & 3 & 0 & \\
\hline 12 & LASER SCANNING & 2 & 0 & \\
\hline 13 & SMS or RISK ANALYSIS & 3 & 0 & \\
\hline 14 & AUGMENTED REALITY & 1 & 0 & \\
\hline \multirow[t]{2}{*}{15} & MODEL CHECKING & 2 & 0 & \\
\hline & TOTAL & 138 & 28 & \\
\hline
\end{tabular}

Tables 3 and 4 were generated also for other word combinations. For more details, see Appendix A.

\section{2.}

\section{Results from SLR}

The final step of the adopted SLR methodology is a final qualitative analysis consisting of the complete reading of all chosen articles. This makes it possible to analyze if the paper is relevant to the study. In this SLR step, the initial sample from all searches was 76 papers and after the full reading this number reduced to 43.

Finally, the mixed data from all databases and searches are listed in tables 6 and 7 . The second column refers to the title and the third column to the authors. From this list, an initial conclusion can be made: the universes of BIM and structural 
optimization appear to be not well connected, since these terms are not discussed together in almost no papers.

Figure 6 displays the number of articles found in each search. Initially, it can be concluded that there are few studies connecting BIM and structural optimization. As an observation, papers that were found in citations in other papers, but not found in the SLR methodology, were incorporated in the sample when relevant to the study.

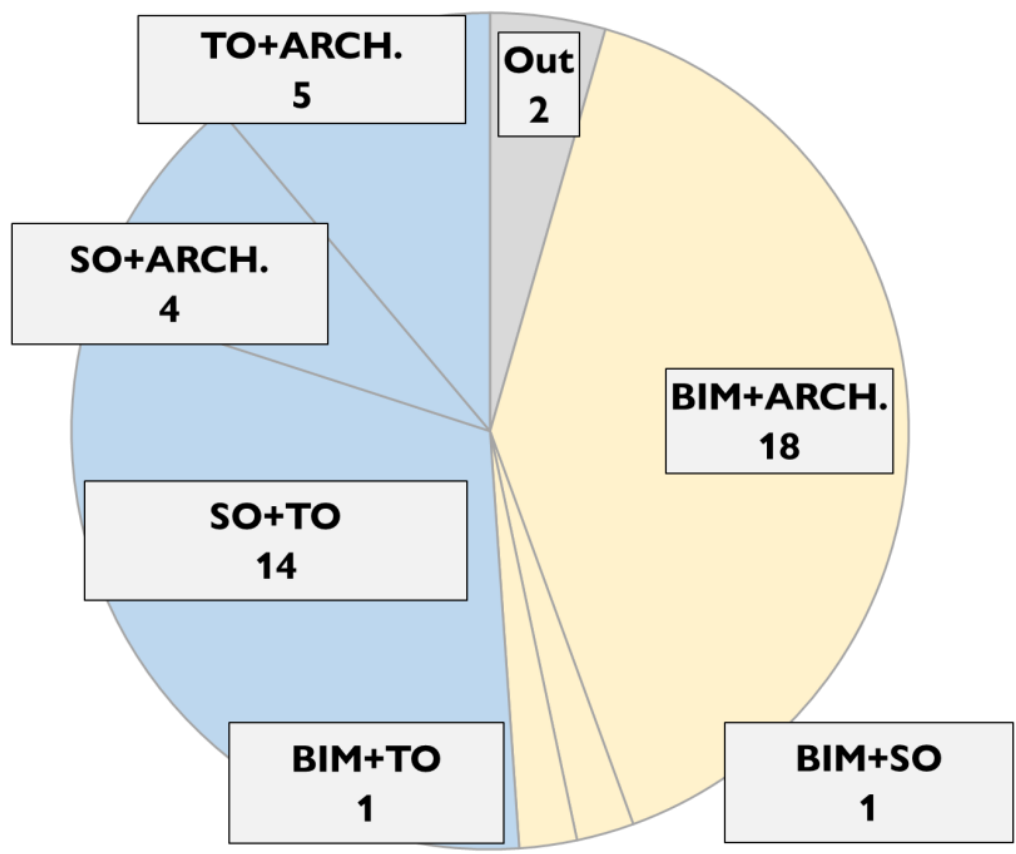

Figure 6 - Number of articles by search terms

With the aim of confirming this scientific gap, conference papers were searched using the keywords SO and BIM. However, no satisfactory results connecting these universes were returned. 
Table 6 - Chosen articles: Part A

\begin{tabular}{|c|c|c|}
\hline № & TITLE & AUTHORS \\
\hline 1 & $\begin{array}{l}\text { A critical analysis of Building Information Modeling systems used in } \\
\text { construction projects }\end{array}$ & (ABANDA et al., 2015) \\
\hline 2 & $\begin{array}{l}\text { BIM as a generic configurator for facilitation of customisation in the } \\
\text { AEC industry }\end{array}$ & (FARR et al., 2014) \\
\hline 3 & $\begin{array}{l}\text { Building Information Modeling (BIM) Collaboration from the Structural } \\
\text { Engineering Perspective }\end{array}$ & (SHIN, 2017) \\
\hline 4 & $\begin{array}{l}\text { Building Information Modeling (BIM) uptake: Clear benefits, } \\
\text { understanding its implementation, risks and challenges }\end{array}$ & $\begin{array}{l}\text { (GHAFFARIANHOSEINI et } \\
\text { al., 2017) }\end{array}$ \\
\hline 5 & Building information modeling: The tide is turning & (GILKINSON et al., 2015) \\
\hline 6 & $\begin{array}{l}\text { Collaboration in BIM-based construction networks: A bibliometric- } \\
\text { qualitative literature review }\end{array}$ & (ORAEE et al., 2017) \\
\hline 7 & $\begin{array}{l}\text { Cost-benefit analysis of Building Information Modeling implementation } \\
\text { in building projects through demystification of time-effort distribution } \\
\text { curves }\end{array}$ & (LU et al., 2014) \\
\hline 8 & $\begin{array}{l}\text { Data interoperability assessment though IFC for BIM in structural } \\
\text { design-a five-year gap analysis }\end{array}$ & (MULLER et al., 2017) \\
\hline 9 & $\begin{array}{l}\text { Demystifying construction project time-effort distribution curves: BIM } \\
\text { and Non-BIM comparison }\end{array}$ & (LU et al., 2015) \\
\hline 10 & Key factors for the BIM adoption by architects: A China study & (DING et al., 2015) \\
\hline 11 & Making friends with Frankenstein: Hybrid practice in BIM & (DAVIES et al., 2017) \\
\hline 12 & Measuring BIM performance: Five metrics & (SUCCAR et al., 2012) \\
\hline 13 & $\begin{array}{l}\text { Multidisciplinary Design Optimization through process integration in } \\
\text { the AEC industry: Strategies and challenges }\end{array}$ & (DÍAZ et al., 2017) \\
\hline 14 & $\begin{array}{l}\text { Product-Oriented Information Delivery Framework for Multistory } \\
\text { Modular Building Projects }\end{array}$ & (RAMAJl et al., 2017) \\
\hline 15 & $\begin{array}{l}\text { The building information modeling and its use for data transformation } \\
\text { in the structural design stage }\end{array}$ & (LIU et al., 2016) \\
\hline 16 & $\begin{array}{l}\text { The IFC standard - A review of history, development, and } \\
\text { standardization }\end{array}$ & (LAAKSO; KIVINIEMI, 2012) \\
\hline 17 & $\begin{array}{l}\text { Understanding the impact of BIM on collaboration: a Canadian case } \\
\text { study }\end{array}$ & (POIRIER et al., 2017) \\
\hline 18 & $\begin{array}{l}\text { Virtual generative BIM workspace for maximising AEC conceptual } \\
\text { design innovation: A paradigm of future opportunities }\end{array}$ & (ABRISHAMI et al., 2015) \\
\hline 19 & $\begin{array}{l}\text { BIM-Enabled Structural Design: Impacts and Future Developments in } \\
\text { Structural Modeling, Analysis and Optimisation Processes }\end{array}$ & (CHI et al., 2015) \\
\hline 20 & $\begin{array}{l}\text { Potential Use of Structural Layout Optimization at the Conceptual } \\
\text { Design Stage }\end{array}$ & (PARK et al., 2012) \\
\hline 21 & $\begin{array}{l}\text { An integrated framework for multi-criteria optimization of thin concrete } \\
\text { shells at early design stages }\end{array}$ & (GOMES et al., 2018) \\
\hline
\end{tabular}


Table 7 - Chosen articles: Part B

\begin{tabular}{|c|c|c|}
\hline № & TITLE & AUTHOR \\
\hline 22 & $\begin{array}{l}\text { Bi-directional Evolutionary Structural Optimization on Advanced } \\
\text { Structures and Materials: A Comprehensive Review }\end{array}$ & (XIA et al., 2016) \\
\hline 23 & $\begin{array}{l}\text { Comparative analysis of strut-and-tie models using Smooth } \\
\text { Evolutionary Structural Optimization }\end{array}$ & (ALMEIDA et al., 2013) \\
\hline 24 & $\begin{array}{l}\text { Evolutionary topology optimization of continuum structures with a } \\
\text { global displacement control }\end{array}$ & (ZUO; XIE, 2014) \\
\hline 25 & The ESO method revisited & (GHABRAIE, 2015) \\
\hline 26 & Topology optimization approaches: A comparative review & (SIGMUND; MAUTE, 2013) \\
\hline 27 & $\begin{array}{l}\text { A constraint and algorithm for stress-based evolutionary } \\
\text { structural optimization of the tie-beam problem }\end{array}$ & (ZHANG et al., 2015) \\
\hline 28 & $\begin{array}{l}\text { Topology and shape optimization methods using evolutionary } \\
\text { algorithms: a review }\end{array}$ & (MUNK et al., 2015) \\
\hline 29 & $\begin{array}{l}\text { A computational and experimental study for the optimum } \\
\text { reinforcement layout design of an } \mathrm{RC} \text { frame }\end{array}$ & (ÖZKAL; UYSAL, 2016) \\
\hline 30 & $\begin{array}{l}\text { A survey of structural and multidisciplinary continuum topology } \\
\text { optimization: Post } 2000\end{array}$ & (DEATON; GRANDHI, 2014) \\
\hline 31 & $\begin{array}{l}\text { Comparison study of some commercial structural optimization } \\
\text { software systems }\end{array}$ & (CHOl et al., 2016) \\
\hline 32 & $\begin{array}{l}\text { Automated design studies: Topology versus One-Step } \\
\text { Evolutionary Structural Optimisation }\end{array}$ & $\begin{array}{l}\text { (HOFMEYER; DAVILA } \\
\text { DELGADO, 2013) }\end{array}$ \\
\hline 33 & Computer program for directed structure topology optimization & (WANG et al., 2015) \\
\hline 34 & $\begin{array}{l}\text { Different effects of economic and structural performance indexes } \\
\text { on model construction of structural topology optimization }\end{array}$ & (YI; SUI, 2015) \\
\hline 35 & $\begin{array}{l}\text { Shear wall layout optimization for conceptual design of tall } \\
\text { buildings }\end{array}$ & (ZHANG; MUELLER, 2017) \\
\hline 36 & $\begin{array}{l}\text { The universal scissor component: Optimization of a } \\
\text { reconfigurable component for deployable scissor structures }\end{array}$ & (ALEGRIA MIRA et al., 2016) \\
\hline 37 & $\begin{array}{l}\text { Adaptive behavior of structural systems in unpredictable } \\
\text { changing environments by using self-learning algorithms: A case } \\
\text { study }\end{array}$ & (SHER et al., 2014) \\
\hline 38 & $\begin{array}{l}\text { Data-driven approximation algorithms for rapid performance } \\
\text { evaluation and optimization of civil structures }\end{array}$ & (TSERANIDIS et al., 2016) \\
\hline 39 & $\begin{array}{l}\text { Modular Truss-Z system for self-supporting skeletal free-form } \\
\text { pedestrian networks }\end{array}$ & (ZAWIDZKI; NISHINARI, 2012) \\
\hline 40 & Structural Optimization of 3D Masonry Buildings & (WHITING et al., 2012) \\
\hline 41 & $\begin{array}{l}\text { Applications of topology optimization in structural engineering: } \\
\text { High-rise buildings and steel components }\end{array}$ & (KINGMAN et al., 2014) \\
\hline 42 & $\begin{array}{l}\text { Connecting architecture and engineering through structural } \\
\text { topology optimization }\end{array}$ & (BEGHINI et al., 2014) \\
\hline 43 & $\begin{array}{l}\text { Flexible optimum design of a bracing system for façade design } \\
\text { using multiobjective Genetic Algorithms }\end{array}$ & (RICHARDSON et al., 2013) \\
\hline 44 & $\begin{array}{l}\text { Topology Optimization and Advanced Manufacturing as a Means } \\
\text { for the Design of Sustainable Building }\end{array}$ & (DONOFRIO, 2016) \\
\hline 45 & $\begin{array}{l}\text { Two-phase genetic algorithm for topology optimization of free- } \\
\text { form steel space-frame roof structures with complex curvatures }\end{array}$ & (KOCIECKI; ADELI, 2013) \\
\hline
\end{tabular}


Figures 7 and 8 show the location where the studies were conducted. The country associated with the article is that of the research funding sponsors. For better understanding, the studies were divided into BIM and SO articles, listed on tables 6 and 7 respectively. As shown, developed countries generate more publications, which occurs because these topics are related to new technologies that are more easily implemented in wealthy areas.

\section{World occurence per continent - SO related papers}

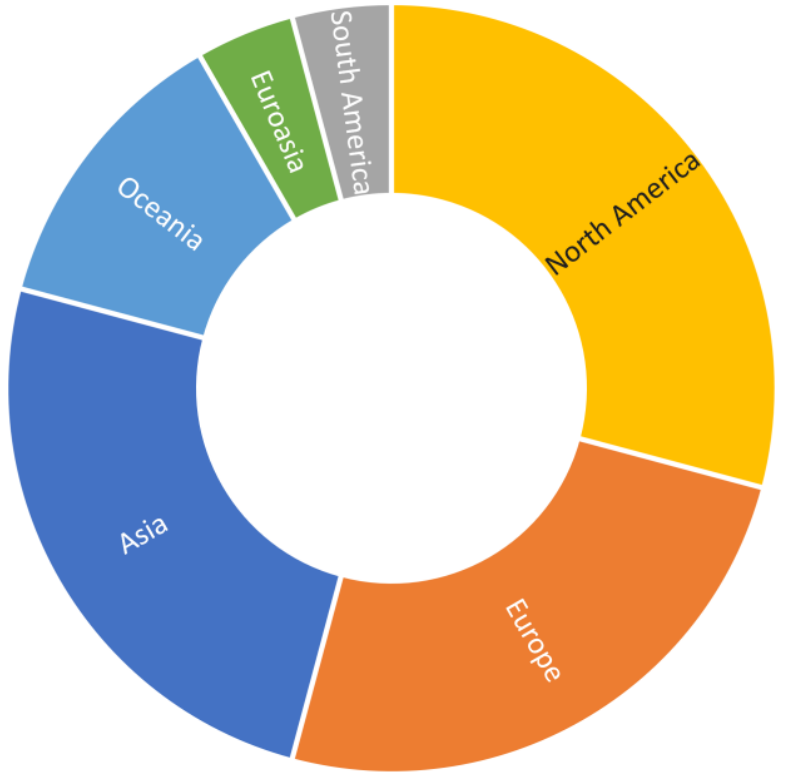

Figure 7 - World occurrence map in SO related papers

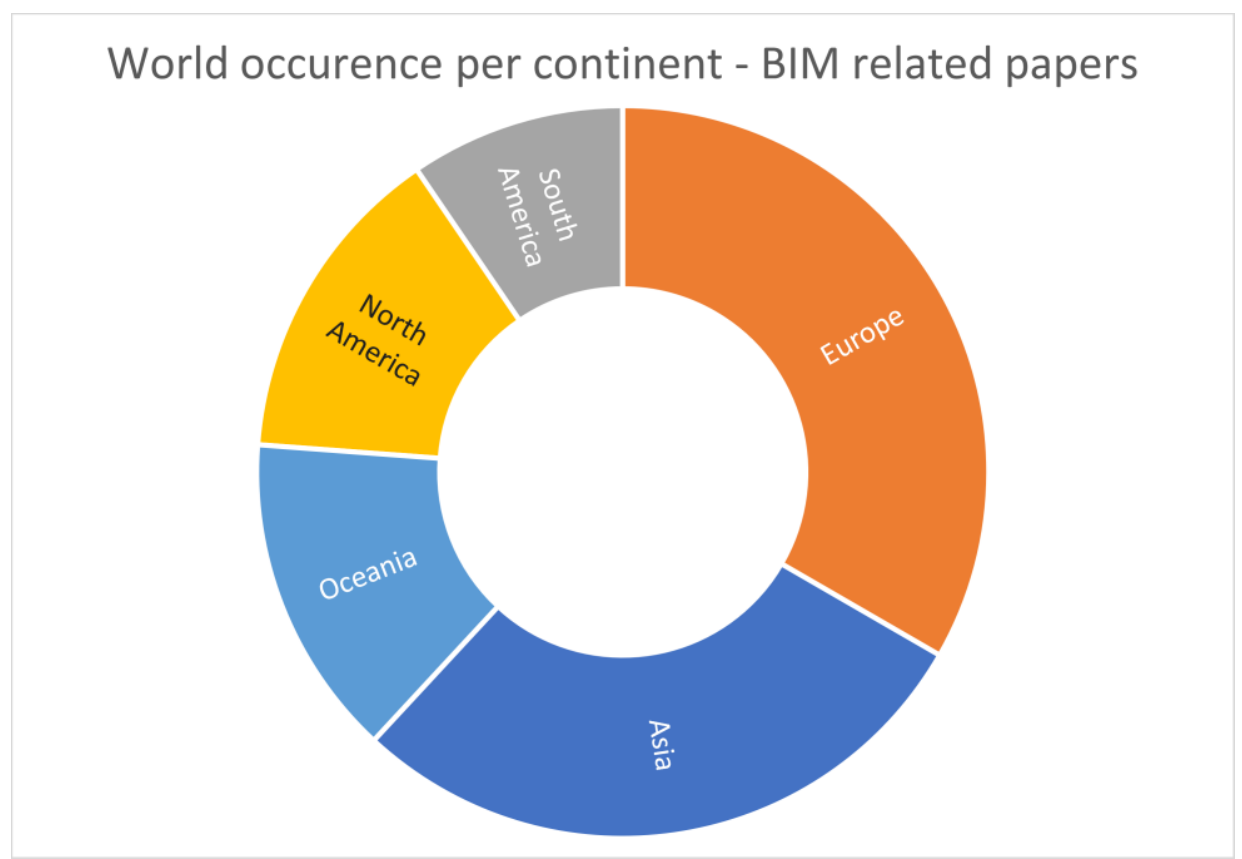

Figure 8 - World occurrence map in BIM related papers 
Related to the number of publications per year (Figure 9), it is possible to conclude that there exists a slight growth tendency in the number of publications in both areas. This can be associated with the recent advances in technology.

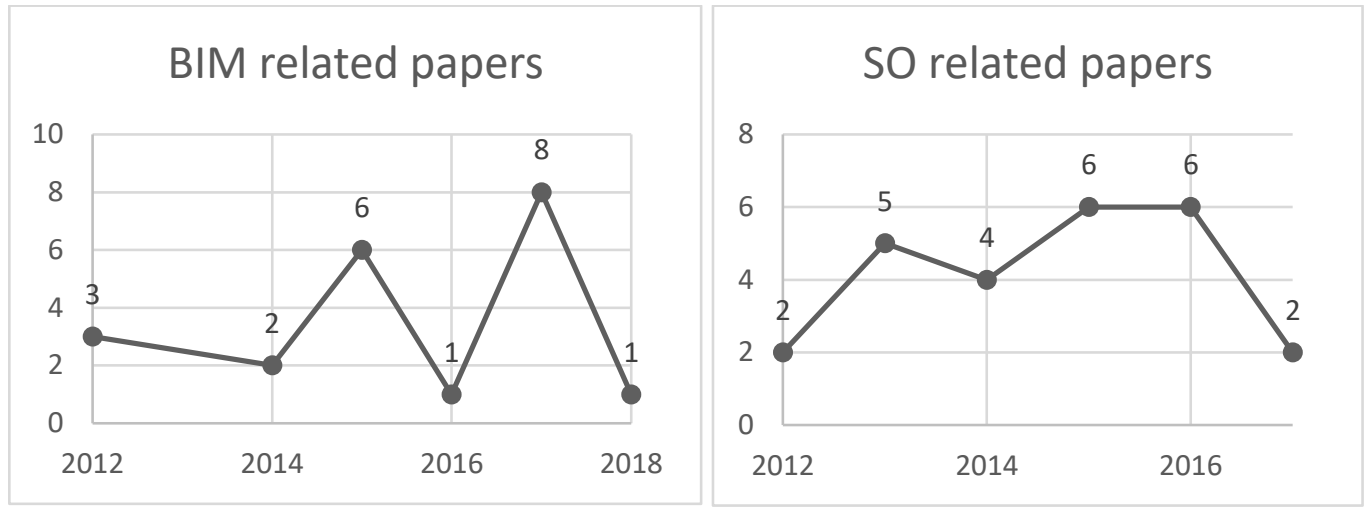

Figure 9 - Number of publications per year in each scientific area

\section{3.}

\section{Bibliometric analysis}

The software VOS viewer was used to better understand the connection between these publications. Using this tool, it is possible to analyze the occurrence of terms in the titles or abstracts of all papers, as well as their co-occurrence. Some parameters should be defined and the choice of parameters can vary depending on the number of articles; Table 8 presents the adopted inputs.

It was set, for the sample of 45 papers, that the term must occur at least three times, in binary type (presence or absence) and, thus, the term appears at least in three articles. Besides that, relevant terms were analyzed, eliminating common terms such as "introduction", "contributions", etc. After this configuration, a qualitative analysis was performed by reading all terms listed and words such as "findings" were discarded.

Table 8 - VOS viewer configuration to term search

\begin{tabular}{lc}
\hline \multicolumn{2}{c}{ Parameters Configuration } \\
\hline Minimum number of occurrences & 3 \\
\hline Type of occurrence & Binary (78 terms) \\
\hline$\%$ Relevant terms & $62 \%(48$ terms $)$ \\
\hline
\end{tabular}

The result of this analysis is illustrated in Figure 10, where blue and red represent zero occurrences and higher presence, respectively. The proximity between the terms represents the connections between them (co-occurrence); this 
reaffirms the initial conclusion, that there are two universes (BIM and structural optimization) with no clear connection.

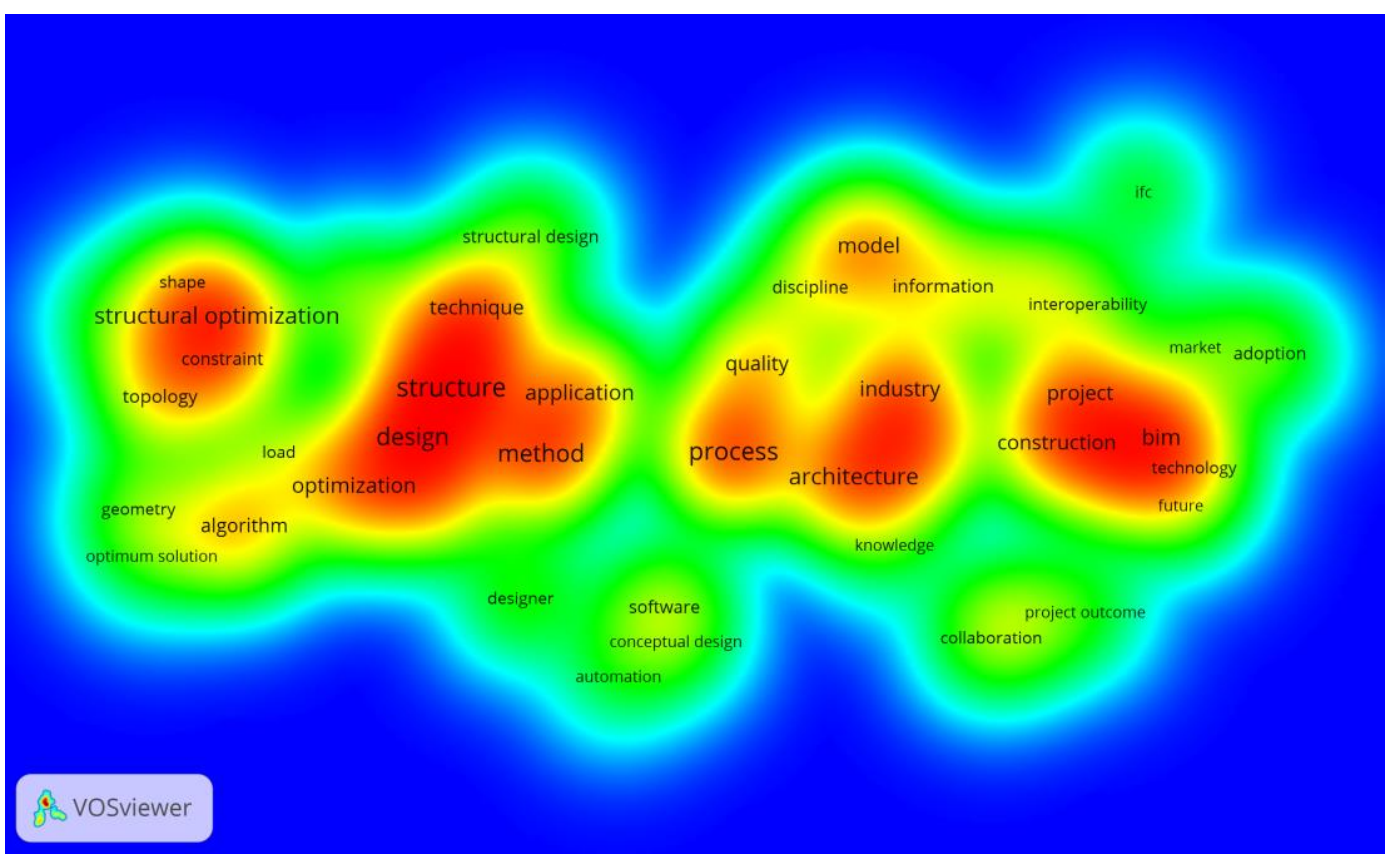

Figure 10 - Co-occurrence terms map from all articles

However, some common words appear in the BIM and SO related articles, establishing this initial scientific connection between these areas. In Figure 11, where blue boxes refer to terms that have more occurrence in SO related articles and green boxes in papers related to BIM, it shows one example in which the expression "conceptual design" establishes a link between BIM and SO. In doing this, it was possible to conduct a study with these initial terms and observe the bridge between BIM and SO. It also made it possible to better understand the barriers, challenges, and benefits.

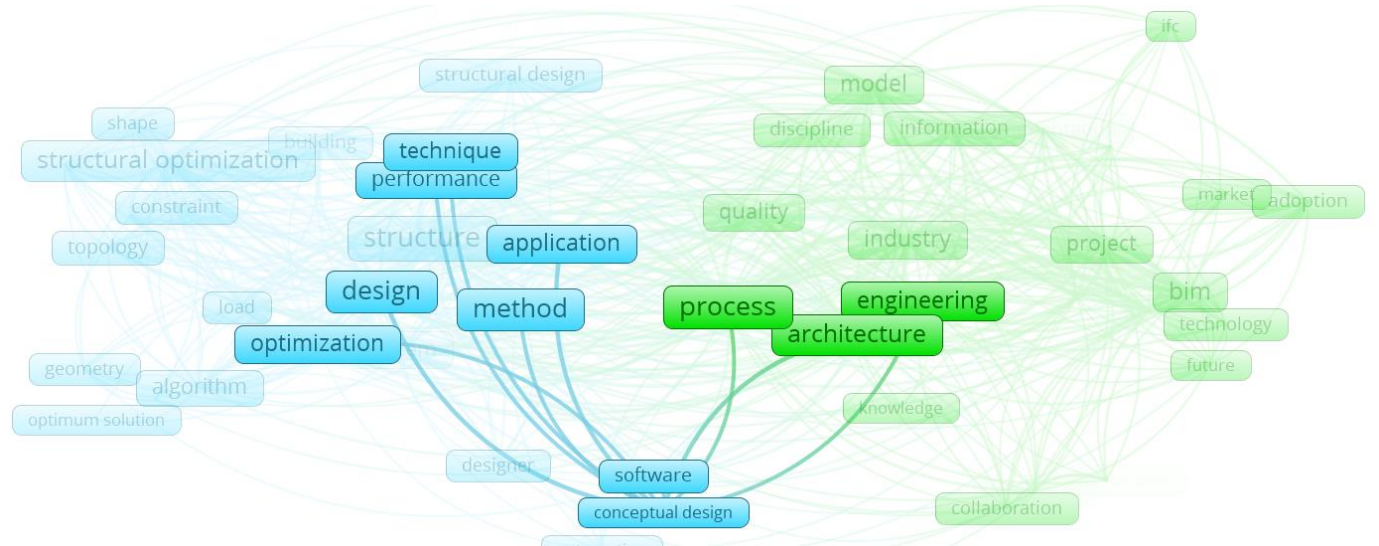

Figure 11 - Example of one word ("conceptual design") that connect BIM and SO worlds 


\section{4 . Selected articles review}

In this section, all papers listed in tables 6 and 7 are summarized and brief comments regarding their contributions are presented. To better understand the connection between them and their importance for this study, they were divided in three topics: BIM-related papers with no mention of SO, SO-related articles with no mention of BIM, and BIM and SO papers, i.e., works that have partial mentions of the two together.

\subsection{1.}

\section{BIM-related articles}

It is important to validate the BIM implementation when compared to traditional processes of the project and, thus, it is necessary to measure its implementation both qualitatively and quantitatively. Succar et al. (2012) developed five metrics to qualitatively measure BIM performance: capability, maturity, competency, organization, and granularity. They concluded that these metrics can analyze stages of BIM implementation and facilitate formal audits, standardize the process, and create a better environment for BIM education and training.

In another study, Lu et al. (2014) and Lu et al. (2015) measured BIM implementation quantitatively. By creating an analytical model of measurement, they presented a case study, which observes that in a BIM project there was an increase of $45.93 \%$ in cost in the design stage, compared to a non-BIM project. However, this was compensated in the construction stage, since the non-BIM project was more expensive. When they analyzed the entire process, they found that there was an overall savings of $6,92 \%$ in cost when BIM was adopted. Thus, they concluded that in the design stage the BIM project was more expensive (more effort) when compared to non-BIM project, but in the construction stage, there was a significant cost savings that compensated this initial extra cost. Thus, this further validates the MacLeamy's theory, which shows that in a BIM project more effort is expended in the design stage when compared to traditional workflow, but it results in lower cost of design change, therefore lowering the costs at the construction stage.

Even with these economic benefits, BIM adoption by the AEC professionals has not been easy and fast. To better understand the reasons for this, Ding et al. (2015) investigated BIM adoption by architects in China. A survey was elaborated 
and based on the answers a structural equation model, that is a logical combination of factor analysis and regression, to evaluate the critical factors in BIM adoption intention. The results show that there are three main factors in architects' intention to adopt BIM: motivation from economic benefits and better project quality that BIM promises, detection of technical defects in the project, and BIM capabilities or requirements such as prior experience and track record. In conclusion, they found that knowledge and management support were the lesser important when it comes to the architect's intention. This is in contrast with previous studies (Cheng and Teizer, 2013; Xu et al., 2014) that showed that management support was of crucial importance for BIM adoption.

The BIM implementation, however, should not be understood as a paradigm shift, but an evolutionary process, according to Davies et al. (2017). These authors interviewed BIM specialists who highlighted the current scenario of BIM implementation, describing benefits and barriers to organization culture, relationships, and project. This study was important to understand that the current practice in offices is oriented to a hybrid process, not a full BIM.

It is worth pointing out that BIM processes are not only technical, but they involve people. According to Gilkinson et al. (2015), BIM can no longer be solely based on technological issues and that human factors should be introduced to understand the benefits and barriers. This statement was concluded after a consistent state-of-the-art review of BIM, drafting the benefits, current and future challenges for engineering.

When people are involved, collaboration becomes a crucial factor to be understood. From a non-technical perspective, Poirier et al. (2017) studied social and psychologist aspects to assess the BIM influence in collaboration within the AEC industry. It studied the more abstract benefits (humans relations, feelings, etc.) and concluded that considerable effort is required to understand the BIM consequences on collaboration, and that further cognitive studies are required for collaboration success.

Also focused in collaboration, Oraee et al. (2017) studied its insertion in a BIM-based Construction Network $(\mathrm{BbCN})$ by analyzing the pentagon of factors that composes it: context, team, process, task, and actor. These elements compose the collaboration schema. It was concluded from this theory that three areas need more studies: task, team, and actor. Task is the area that needs more attention, according to the authors.

In parallel to human collaboration, "software collaboration" is also an important issue for successful BIM implementation. According to Ghaffarianhoseini 
et al. (2017), the non-adoption of BIM can be explained by the current lack of software interoperability, extra initial cost, lack of demand, lack of user-friendly interfaces, and lack of user skills and experience. This conclusion was achieved after a state-of-the-art review analyzing BIM benefits, implementation, risks and challenges.

Therefore, software interoperability appears as a critical factor in BIM implementation. For this reason, there is more effort in scientific studies to fill this gap. For example, Abanda et al. (2015) analyzed the existing BIM tools using a mixed research method in which they consulted the literature, vendors, websites, etc. After that, they created a table containing all of the commercial BIM tools from all areas, comparing them by their cost, interoperability, domain, and use. It was possible to understand the current scenario of available BIM technology/tools.

One way to "solve" the software interoperability problem is the standardization IFC. This expected solution was analyzed by Laakso and Kiviniemi (2012), who conducted an in-depth study on IFC, more focused on socio-technical issues than on the final output. This study highlighted the longitudinal progress associated to the object (standard), creator (organizations) and client (BIM-related $A E C$ industry), describing the origin and biggest shifts in the standardization process. It was concluded that the standardization process has an anticipatory characteristic, developed by a hybrid process, and is oriented to allow horizontal compatibility between tools.

In another study, also with the aim of help solving the interoperability problem, Ramaji et al. (2017) developed an IDM framework, oriented to modular building projects. After applying it to some case studies, it was concluded that the IDM proposed is capable to solve communication and information exchange problems in modular building projects.

Similarly, Liu et al. (2016) developed an interoperability plugin to exchange information between the physical model and structural analysis model, using IFC. This study examines the data transformation between modeling and analysis tools, comparing differences in this data flow. It was verified the difficulty to create a direct method in this process and highlighted that this article was only a preliminary effort for interoperation between the physical model and structural analysis model.

Related to BIM tools specific to structural engineering, Muller et al. (2017) studied structural interoperability using IFC standard over five years, by exporting files from Revit and importing the same file to TQS. It was concluded that there was an improvement of $38 \%$ in interoperability between Revit and TQS for cast-inplace concrete structures in these five years. 
In another study, also focused in structural engineering, Shin (2017) analyzed the interoperability issue inserted in a structural engineering environment, aiming to make the best use of BIM collaborations in order to improve work efficiency and efficacy. It was concluded that the pre-detailing design is currently the best stage to achieve satisfactory data interoperability from the structural engineering perspective.

Another important technical issue in a BIM environment is the parametrization that negatively affects interoperability between computational tools. However, parametrization allows better designs, mainly because it facilitates the generation of alternatives. Farr et al. (2014) showed that BIM can facilitate mass customization in the AEC industry, through a case study that illustrates the creation and parametrization in a customized wall facade family.

Also in the parametrization area, Abrishami et al. (2015) conducted a study on the conceptual design, suggesting a BIM tool that creates alternative solutions to the designer based on parametrization concepts. Through the development of a plugin framework it was concluded that parametrization can improve designers' abilities to project better solutions.

\subsection{2. \\ So related articles}

The SO process is older relatively than BIM. Thus, some studies focus on reviewing the historical evolution of $\mathrm{SO}$, in order to compare different approaches and to identify barriers in this area. Ghabraie (2015) provides deep review of concepts in ESO and concludes that ESO is not an outdated approach and can be used satisfactorily in problems within physical limitations and when a unidirectional approach is recommended, such as excavation works.

Xia et al. (2016) described ESO-type methods and presented current applications of the BESO method for the design of advanced structures and materials. They concluded that BESO is a satisfactory method that is widely used in engineering problems and academic research works.

In another study, Sigmund and Maute (2013) distinguished different topology optimization approaches, analyzing its weakness, acceptance, and applicability among other features. After an in-depth study on TO approaches, it was concluded that optimization methods have more similarities than differences, and the research community needs to concentrate on electing the "optimal optimization 
approach", instead of creating methods that are old applications with some modifications.

In the same way, Munk et al. (2015) studied the TO and ShO methods and its applications through a consistent literature review. They concluded that evolutionary algorithms have some shortcomings, such as non convergence and local optimum solution. However, these defects can be solved using a combination of other approaches with the classical methods (e.g. ESO/BESO, SIMP, LSM).

Deaton and Grandhi (2014) studied the history of SO focusing on investigating the advancements in TO from 2000 to 2012 for continuum structures. They observed that this area has evolved rapidly, in the last decade, with a greater insertion in commercial software and applicability in complex problems, such as nonlinearity, dynamics analysis, among others.

A number of publications encountered comparisons between optimization approaches. For example, Hofmeyer et al. (2013) compared TO and one-step ESO (1ESO) optimization methods, both applied to a virtual toolbox, which is a cyclic framework to create and optimize a building structure. As conclusion, they verified that TO is better than 1ESO, for this specific application (virtual toolbox), but has a higher computational cost.

In another work, focused on comparing structural and economics optimization results, Yi and Sui (2015) explored two distinct approaches of TO: one focused in structural performance, and the other was based on structural economic indexes. It was concluded that it is better to minimize the economic issues in TO, satisfying structural safety, than to maximize mechanical performance, for practical engineering problems (e.g. building projects).

In parallel, some authors strive to create new optimization methods. Wang et al. (2015), for example, created an improved BESO tool for 2D and 3D structures with a user-friendly interface. In this study, they aimed to facilitate the use of optimization tools by an engineer, even when the user is not familiar with either Finite Elements Analysis (FEA) or optimization processes. This practical improved BESO tool presents some problems with computational time, but according to the authors it can be solved using advanced techniques such as parallel computing.

Zhang et al. (2015) proposed a new optimization algorithm. Inspired in a tiebeam benchmark that failed with ESO (Zhou and Rozvany, 2001; Rozvany, 2009), this study presented an algorithm to solve this problem using the ESO approach. After applying it to the tie-beam benchmark problem, they concluded that resulting structure is the same optimal structure as the intuitive solution suggested by Zhou and Rozvany (2001), and that the additional time expended in this process is not 
significant. Thus, it also was concluded that ESO implementation is relatively easy, but needs improvements/modifications.

In another study, Zuo and Xie (2014) created a flowchart to understand the process involving TO of continuum structures. They based their TO objective on displacements control. This approach is followed by an algorithm that can be easily implemented in commercial FEA tools, according to the author. After practical applications of this code, it was concluded that this process is recommended for application to structures with crucial deformed exterior shapes, such as aircrafts wings, submarine body, etc.

Related to AEC structures, Kociecki and Adeli (2015) studied how TO can be applied to a roof structure with complex form, aiming to achieve better structural performance. It is worth pointing out that this roof structure was already optimized previously to reduce weight in another study (Kociecki and Adeli, 2013). So, applying a modified genetic algorithm to this complex roof structure, it was observed a satisfactory computational cost, which makes it feasible to be used in the project process.

Other studies were also developed applying SO in AEC industry. For example, Almeida et al. (2013) applied evolutionary optimization approaches in Reinforced Concrete (RC) structures. They used smooth ESO to obtain the strutand-tie models in RC elements. They verified that smooth ESO had good accuracy, low computational time and did not present classical optimization problems, such as checkerboards pattern.

In another study, involving experimental tests, Özkal and Uysal (2016) utilized TO in order to detail the reinforcement of RC elements based on the strutand-tie concept. They compared this detailing process (using TO) with the traditional method. It was verified that TO can be applied to the detailing process in reinforced concrete structures, resulting in a time-saving and better structural performance (better strength and stiffness values).

Similarly, Zhang and Mueller (2017) concentrated their efforts to optimizing a shear wall layout, satisfying both structural and architectural requirements. This study proposed a methodology that offers alternative optimized layouts for user choice, based on lower weight. In order to expend less computational time, Evolutionary Algorithms (EA) and Ground Structure (GS) - both optimization solvers - were applied in this proposed methodology. It was concluded that few modifications in global approaches can improve processing time. They also concluded after applying this methodology in case studies that they offer alternative solutions to the designer with satisfactory computational time. 
Related to modern civil construction, Sher et al. (2014) studied the kinetics of structures that have adaptive architecture according to a defined criteria. In this study, they used Genetic Algorithms (GA) and an artificial neural network to create a self-learning mechanism in a reduced model that simulates a kinetics of the structure oriented to maintaining its stability. The proposed structure is adaptable and can change its shape depending on the direction of the applied forces through its lifespan. This study represents a dynamic structural optimization applied in AEC industry.

In a study not focused on structural requirements, Zawidzki and Nishinari (2012) studied an optimization method applied to the modular construction of a self-supporting pedestrian brigde oriented towards improving its geometric. The adopted algorithm was elaborated to connect two points, deviating from obstacles but keeping the shortest distance possible so that the pedestrian network has the shortest length possible.

Still concerning modular construction, Alegria Mira et al. (2016) idealized the Universal Scissor Component (USC) to be adopted in the construction of pedestrian bridges, roof structures, among others applications. In this study, they used topology, shape and sizing optimization aiming to obtain a more efficient component based on weight, principally. It was verified that optimization with multiple objective functions creates isolated optimal solutions, for example, lighter weight component but without the lower displacement possible. As conclusion, they state that human intervention is fundamental to elect the optimization function priority classification.

Whiting et al. (2012) proposed a technique of structural optimization applied to generic masonry buildings. In this method, masonry blocks positionings are modified and optimized guaranteeing the system structural stability. It is worth pointing out that these blocks can have different thickness and also can have their volumes optimized. They concluded that this approach improved the design process in the early stages, satisfying both architectural and structural requisites.

As seen above, there are numerous authors developing new methods and solvers for SO. However, there are commercial optimization tools available that incorporate approaches and algorithms in its core. Choi et al. (2016) compared three structural optimization tools and highlighted their characteristics: OptiStruct achieves better solutions, Genesis achieves a satisfactory CPU time, and MSC Nastran has the highest time-consumption. As conclusion, it was impossible to choose the best one, because depends on the situation, and this study was 
important to verify that powerful optimization tool existing in the market to be used in AEC common projects.

To analyze the impact SO insertion has in a project in the AEC industry, Tseranidis et al. (2016) focused their studies on two problems of SO that impacts in AEC project: time-consumption and problem formulation. They applied a surrogate model based on training, validation, and testing to optimize civil structures. After performing some case studies using this method, they concluded that designers can reach more qualitative (more efficient structures) and quantitative (less time expended) solutions by adopting the proposed model.

Related to optimization with various objective functions, Richardson et al. (2013) developed a multiobjective TO method using GA to optimize a bracing facade system of a museum building. This structural system is subjected mainly to wind forces and the optimization approach consists in relocating the bracing systems until thus reach the optimal solution according to structural requirements. In this case study, the SO process was applied in the early stages of the project and resulted in significant cost savings.

The adoption of SO processes usually resulted in complex structures that are inviable to construct using traditional methods. Thus, in the literature, some authors connect SO with new technologies in civil construction. For example, Donofrio (2016) did an extensive review about the applicability of TO focusing on its benefits to production and design using advanced materials and techniques. In this study, the author concluded that TO associated with advanced manufacturing techniques (e.g. 3D printing) can result in benefits to AEC industry, especially in the development of sustainable buildings.

\subsection{3.}

\section{$\mathrm{BIM}$ and SO related articles}

Research on structural optimization within the BIM process is scarce in the literature. In terms of design optimization, Díaz et al. (2017) introduced a Process Integration and Design Optimization (PIDO) platform oriented to Multidisciplinary Design Optimization (MDO) in BIM tools, such as Autodesk Revit and Robot. They showed that any software can be integrated into a PIDO platform to develop a MDO workflow. However, they concluded that in order to promote better interoperability, process automation and parametrization, and challenging timeconsuming these tools need improvement. 
In another study, Chi et al. (2015) analyzed the growth of structural design domain associated with BIM. It was concluded that some revolution in structural design is required when BIM is adopted, and structural optimization can help solve this issue, even though it can be more time consuming. The authors recommend that more research is necessary along with technological improvements to fully solve this problem.

Also related to SO and BIM, Park et al. (2012) examined the integration problem between architects and structural engineers in the initial phases of the project. Understanding the role of structural issues in the conceptual architectural design, they suggest that structural layout optimization can help construct this connection between architects and engineers. However, current tools are not yet ready to make this connection and the optimization tool should be understood as an auxiliary tool and not be treated as an isolated task.

Gomes et al. (2018) developed a methodology to connect architects and structural engineers through the optimization of thin concrete shells in early stages of the project. In their work, they integrate a multi-criteria optimization with an Integrated Project Delivery (IPD) framework. Their optimization was based on limiting maximum displacement and minimizing cost and was oriented to support the process of decision making. They concluded that their method results in more efficient and higher quality solutions for the pre-design stage of shell structures, satisfying both structural and architectural requirements.

Two papers found in the present SLR methodology related to SO have something in common with BIM related articles: they deal with collaboration between AEC players. The first one, by Beghini et al. (2014), created a modified TO framework for the entire design process that connects the architecture and engineering universes. After applying this framework to experiments, it was concluded that a shared parametric model establishes a natural interaction between architects and engineers by means of a common language: topology optimization.

The second one, by Kingman et al. (2014), applied TO to large-scale projects and components. With some examples, it was shown that the optimization process turns the workflow slower, but it represents "a tool that can lead to greater collaboration between engineers and architects during the conceptual design process". However, some challenges were highlighted, such as complex geometry in optimization solutions and shortcomings in optimization when the problem is nontrivial (nonlinear, buckling, etc.). 
As a conclusion, almost all reviewed articles presented in the sections focused on structural performance or space arrangement, and do not consider a mix of architectural and structural requirements. This is incompatible with the philosophy of the BIM methodology. Thus, to be applicable within BIM framework, it is important to conduct an optimization that satisfies all involved actors: architects, engineers, contractors, clients, etc. Optimization of an individual specialty does not make sense within the BIM workflow.

Moreover, it can be concluded that without interfering in the architectural creative process and with the collaboration spirit intrinsic to the BIM methodology, optimization issues can be inserted earlier in the process. In particular, structural optimization can provide efficient alternatives that can be entertained by the architect early on in the design process. 


\section{4}

\section{METHODOLOGY}

This chapter presents the proposed framework to insert SO in a BIM building project in the early stages. It describes the technical basis that was used in the experiments (discussed in Chapter 5 ), such as tools and file standards. It is worth pointing out that this study is focused on improving a BIM project rather than a SO tool and, thus, BIM issues are the focus of this discussion.

\section{1.}

\section{Information Delivery Manual (IDM)}

To obtain better interoperability in an openBIM scenario, a common language is necessary. The IFC standard is intended to provide such interoperability. However, IFC is a data model and it must be combined with an Information Delivery Manual (IDM) and an International Framework for Dictionaries (IFD) to form the Model View Definition (MVD) (BUILDINGSMART, 2013).

As defined by buildingSMART, IDM refers to processes, IFD to dictionary/languages to be used in the MVD, and the MVD refers to the model that runs and includes these three items - IFC, IDM, and IFD. First, the IDM should be developed to initiate IFC standardization. According to the International Organization for Standardization ISO 29481-1:2016, IDM is the documentation that contains the processes and specific information exchanged and required by players in a particular stage of a project. Thus, it is possible to conclude that IDM is more local than IFC, treating with more detailed information (see Figure 12).

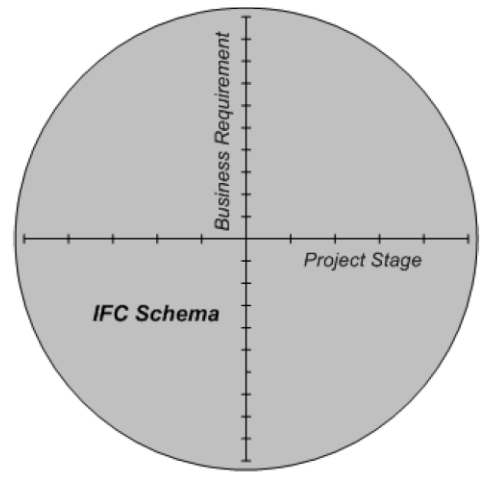

IFC supporting all business requirements at all project stages

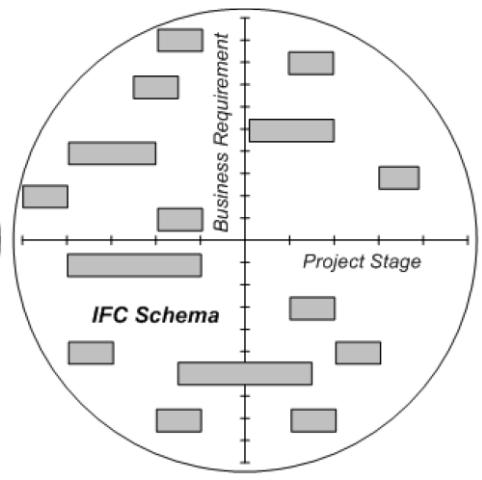

IDM supporting a business requirement at a project stage

Figure 12 - Difference of scope between IFC and IDM according to buildingSMART (2017) 


\section{2.}

\section{Proposed IDM}

The proposed IDM is oriented to understand how structural optimization processes can be inserted in BIM building projects in early stages. Thus, the focus of this study is the initial integration and collaboration between architects and structural engineers, after the first meeting between the client and the architect. In the proposed methodology, the architect is also the project coordinator and establishes the main communication between design teams and the client. Therefore, other tasks are shown in the IDM but they are not studied in-depth.

The developed approach that supports the proposed IDM is based on reverse engineering. It is assumed that tools capable to handle with the information exchanged between tasks and players already exist, but is necessary to upgrade them to read and understand the specification required in the information exchanged.

The following sub-section explain the IDM action plan and resources needed for the proposed methodology.

\subsection{1. \\ Process map}

In the way to create the IDM, the process map is outlined, and the information flow is described. So that, weak points in the workflow can be identified and IFC data can be placed correctly. One way to conduct a process map is by using the Business Process Modeling Notation (BPMN), which represents the symbols and notations that describe the workflow.

In this work, a process map was developed to insert structural optimization in the BIM conceptual design for building projects. Figure 13 shows the developed map. 


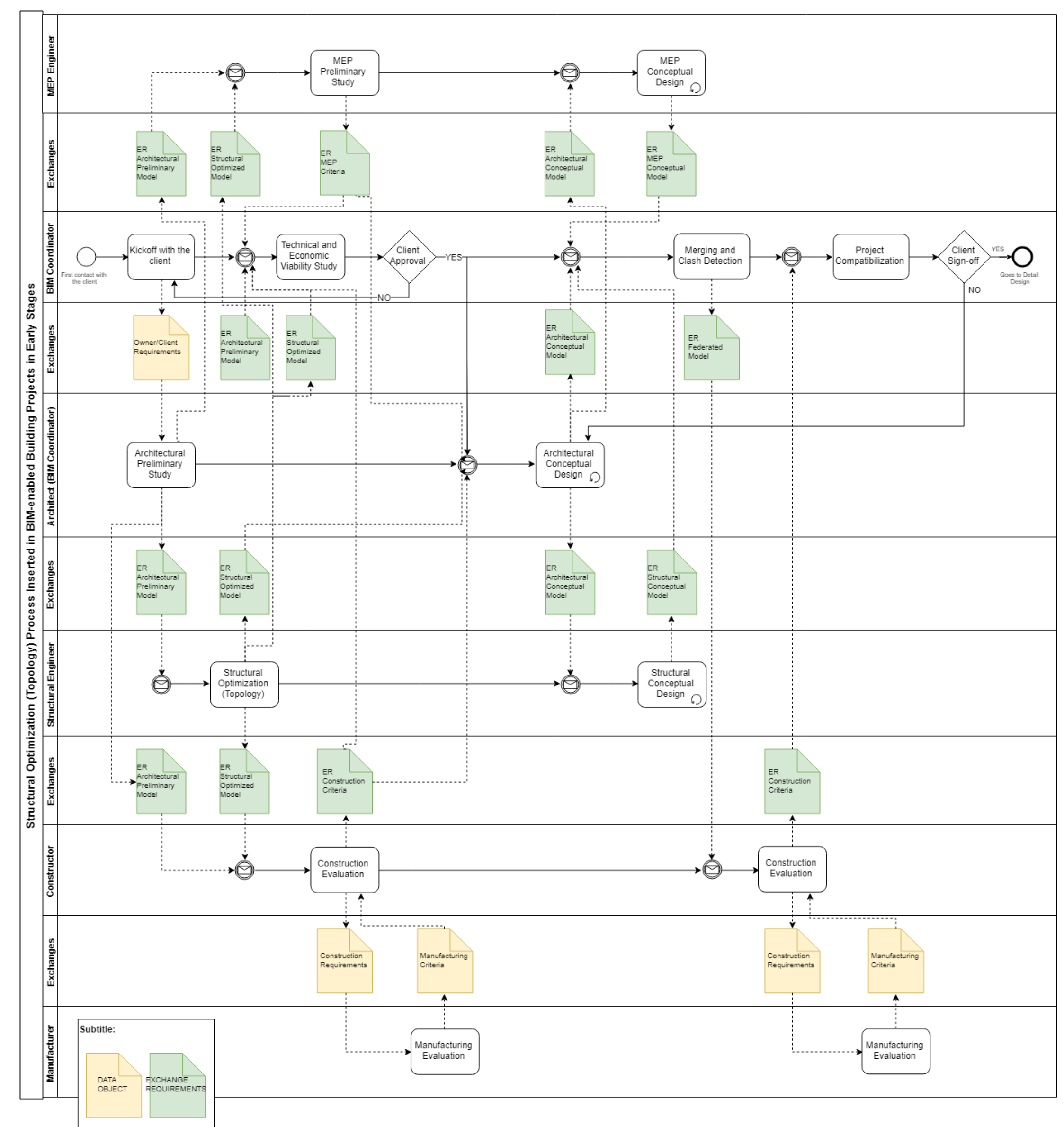

Figure 13 - Structural Optimization process inserted in the BIM methodology in the early stages for building projects 
As shown in Figure 13, SO works as a connection between engineers and architects in the early stages, aiming to anticipate this integration to improve design solutions and alternatives. This way architectural issues and other concerns regarding structural performance are considered from the beginning of the project. This promotes more collaboration and integration between BIM players in the initial phases of the project, which is a key concern within the BIM methodology.

It is worth pointing out that only structural optimization was included in this workflow, but other optimizations (e.g. energy optimization, space optimization, etc.) can also be included. However, it is important to notice that the consideration of different types of optimization may produce conflicting solutions.

The developed workflow includes all main actors involved in an AEC building project: architect, MEP (Mechanical, Electrical, and Plumbing) engineer, structural engineer, constructor, manufacturer, and client. Also, the BIM coordinator was inserted in the process map in order to manage the information and to be the main communication bridge with the client. However, other entities can be inserted in sub-processes or in specific projects.

As verified by Eastman et. al (2011), one of the differences between a traditional project and a BIM project is that in a BIM workflow, a greater information flow is exchanged between players. With the inclusion of SO in a BIM workflow, much more information is exchanged, mainly between architects and structural engineers. Moreover, the integration is anticipated and actors begin almost together; and all entities contribute to all stages, rather than being spectators.

\subsection{2. Tools}

Some BIM tools are necessary for each task to understand the manner in which the IDM works. The ones adopted in this research are listed in Table 9. Specific software tools were adopted according to the availability of their educational and trial versions, so highly restricted tools in these versions were discarded. Since the focus of this work is the connection between architects and engineers through the Structural Optimization, only the interoperability between SO process and architectural modeling is entertained on a complete openBIM schema. 
Table 9 - List of software used

\begin{tabular}{ll}
\hline \multicolumn{1}{c}{ Task } & \multicolumn{1}{c}{ Program } \\
\hline Architectural preliminary design & Revit - Architecture (Autodesk) \\
\hline Structural optimization (topology) & Fusion360 (Autodesk), ANSYS, and \\
& Abaqus/TOSCA \\
\hline Architectural conceptual design & Revit - Architecture (Autodesk) \\
\hline Structural conceptual design & Revit - Structural \& Robot (Autodesk) \\
\hline MEP preliminary study & Revit - MEP (Autodesk) \\
\hline MEP conceptual design & Revit - MEP (Autodesk) \\
\hline Merging and Clash Detection & Navisworks (Autodesk) or Solibri Model \\
\hline Project compatibilization & Checker \\
\hline Client approval & Navisworks (Autodesk) or Solibri Model \\
\hline Constructor evaluation & Checker \\
\hline Manufacturing evaluation & A360 (Autodesk) \\
\hline
\end{tabular}

\subsection{3. \\ Interoperability}

Figure 13 also shows how the tools communicate with each other. It was verified that none of the optimization tools can read the .IFC extension and the best interoperability can be achieved with the .SAT extension, a file that contains only geometrical information. When one file is exported to .SAT extension, any information regarding material or non-geometrical issues is lost. On the other hand, interoperability between non optimization tools from the same developer (Autodesk) is achieved in a non openBIM manner with native formats. However, even when native formats are used some information is still lost.

Figure 14 shows the software developers adopted in this work as well as the tools and how they are interoperable at the present time (2018), i.e. through the .SAT extension. However, ideally the IFC extension should be used to achieve a true openBIM environment. 


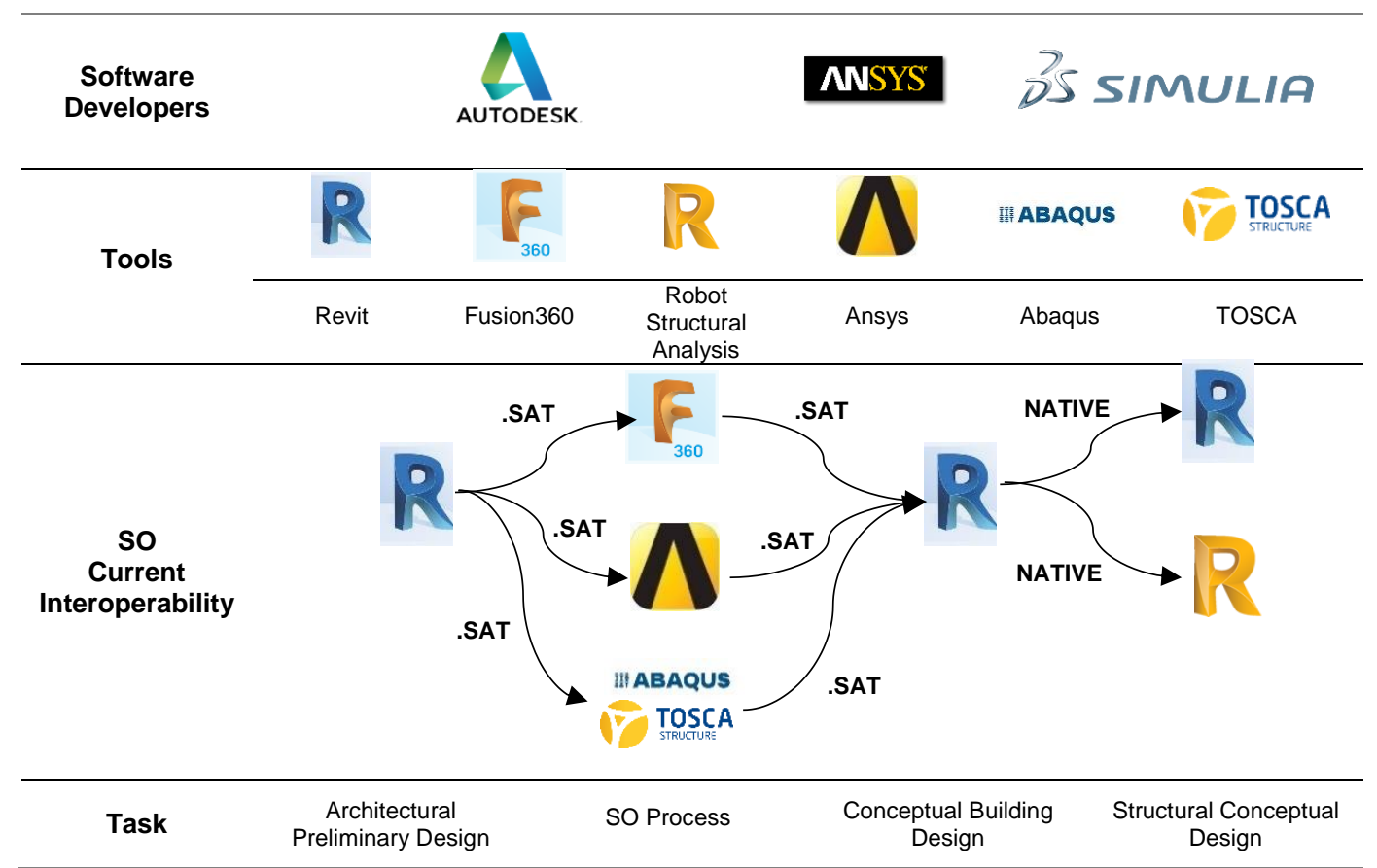

Figure 14 - BIM and SO tools interoperability between architect and structural engineer in early stages

\subsection{4. \\ Exchange requirements}

In this section, the document denominated by Exchange Requirements $(E R)$ is outlined in order to identify the information that is required in the SO exchanges presented in the process map. Thus, the ER aims to evaluate the information needed in the .IFC data exchanged, so that irrelevant data for a specific task is avoided.

According to buildingSMART, in the ER, the information needed to exchange between tasks should be described in non-technical terms in order to support the IFC schema. It is one of the last documentation before the technical development provided by software providers. Thus, after the proposed process map, it was created an ER to integrate the IDM proposed to the MVD development for structural optimization in BIM project in early stages.

As verified in the workflow, the main difficulty is concentrated between SO and modeling tools, the focus of this work. In the other exchanges, was considered a non openBIM scenario with the interoperability running within native formats. Thus, this study is oriented to initiate the improvement of interoperability in two information exchanges, both described in tables 10 and 11:

- ER_Architectural_Preliminary_Model;

- ER_Structural_Optimized_Model. 
Table 10 - Proposed Exchange Requirement for the architectural preliminary model

ER - Architectural Prelimiminary Model

\begin{tabular}{|c|c|c|c|c|c|c|}
\hline Type of Information & Information Needed & Description & Required & Optional & Data Type & Units \\
\hline \multicolumn{7}{|l|}{ Project } \\
\hline & ID & Unique identifier for the project. & $\mathrm{x}$ & & string & $\mathrm{n} / \mathrm{a}$ \\
\hline & Name & Name of the project, assigned by the client and architect. & $\mathrm{x}$ & & string & $\mathrm{n} / \mathrm{a}$ \\
\hline & Owner/Client & Name and contact information (email adress, phone, etc.) of the client. & & $\mathrm{x}$ & string & $\mathrm{n} / \mathrm{a}$ \\
\hline & Model author & Architect name, contacts and his or her style (modern, classic, etc.). & & $\mathrm{X}$ & string & $\mathrm{n} / \mathrm{a}$ \\
\hline & Description & Brief project description: client needs and architect idealization. & $\mathrm{x}$ & & string & $\mathrm{n} / \mathrm{a}$ \\
\hline & Geograph location & In relation to the center of the project. & $\mathrm{x}$ & & latitude, longitude & degree, minutes, seconds \\
\hline & Units sytem & metric or imperial. & $\mathrm{x}$ & & string & $\mathrm{n} / \mathrm{a}$ \\
\hline & Site datum & Reference for building location, can be the street or a light pole for example. & $\mathrm{x}$ & & coordinates & meters \\
\hline & Site perimeter & The limits of the site. & $\mathrm{x}$ & & real number & meters \\
\hline & Site preserved areas & Untouchable areas on the site (e.g. green areas, parkings). & $\mathrm{x}$ & & real number & square meters \\
\hline \multicolumn{7}{|l|}{ Building Elements } \\
\hline & External volume (3D Geometry) & Mass building volume proposed by the architect. & $\mathrm{x}$ & & real number & cubic meters \\
\hline & Stories definition & Definition how many floors exist in the building and its elevation. & & $\mathrm{x}$ & real number & meters \\
\hline & Elevation & Building height related to ground floor. & $\mathrm{x}$ & & real number & meters \\
\hline & Type of ocupation & Specification about the building usage (e.g. a library, a museum, etc). & $\mathrm{x}$ & & string & $\mathrm{n} / \mathrm{a}$ \\
\hline & True north orientation & Building orientation related to the true north. & $\mathrm{X}$ & & real number & degrees \\
\hline & Openings & Openings in the buidling envelope(doors, windows, etc.) & $\mathrm{x}$ & & real number & square meters \\
\hline & Constrution type & What kind of construction will be adopted, for example modular construction, in loco construction, etc. & & $\mathrm{X}$ & string & $\mathrm{n} / \mathrm{a}$ \\
\hline \multicolumn{7}{|l|}{ Stairs/Elevator } \\
\hline & Location & Positioning of stairs and elevators. & & $\mathrm{x}$ & coordinates & meters \\
\hline & Area & Stairs and elevators projected areas. & & $\mathrm{x}$ & real number & square meters \\
\hline \multicolumn{7}{|l|}{ Roof } \\
\hline & Type & Type of roof (flat, curved, etc.). & & $\mathrm{X}$ & string & $\mathrm{n} / \mathrm{a}$ \\
\hline & Thickness & Roof Thickness & & $\mathrm{x}$ & real number & meters \\
\hline \multicolumn{7}{|l|}{ Material } \\
\hline & Structural system & Material chosen to be used in the structural system (RC, steel, etc.) & $\mathrm{X}$ & & string & $\mathrm{n} / \mathrm{a}$ \\
\hline & Roof & Material that will compose the roof. & & $\mathrm{X}$ & string & $\mathrm{n} / \mathrm{a}$ \\
\hline & Façades finish & Material used as finish for the facades. & & $x$ & string & $\mathrm{n} / \mathrm{a}$ \\
\hline \multicolumn{7}{|l|}{ Structural Particularities } \\
\hline & Special loads & Special loads, such as green roof. & $\mathrm{x}$ & & string & $\mathrm{n} / \mathrm{a}$ \\
\hline
\end{tabular}


Table 11 - Proposed Exchange Requirement for the structural optimized model

\begin{tabular}{|c|c|c|c|c|c|}
\hline Type of Information & Information Needed & Description & Required Optional & Data Type & Units \\
\hline \multicolumn{6}{|l|}{ Project } \\
\hline & $\mathrm{ID}$ & Unique identifier for the project. & $\mathrm{X}$ & string & $\mathrm{n} / \mathrm{a}$ \\
\hline & Name & Name of the project, assigned by the client and architect. & $\mathrm{X}$ & string & $\mathrm{n} / \mathrm{a}$ \\
\hline & Owner/Client & Name and contact information (email adress, phone, etc.) of the client. & $\mathrm{X}$ & string & $\mathrm{n} / \mathrm{a}$ \\
\hline & Model author & Structural Engineer name and contact. & $\mathrm{X}$ & string & $\mathrm{n} / \mathrm{a}$ \\
\hline & Units sytem & metric or imperial.. & $\mathrm{X}$ & string & $\mathrm{n} / \mathrm{a}$ \\
\hline \multicolumn{6}{|c|}{ Optimized Structural Solutions } \\
\hline & Description & Brief description about the structural optimization results alternatives. & $\bar{x}$ & string & $\mathrm{n} / \mathrm{a}$ \\
\hline & External volume (3D Geometry) & Mass building volume proposed in each optimization alternative. & $\mathrm{x}$ & real number & cubic meters \\
\hline & Openings & Sugestion fo possible building envelope openings and its areas (doors, windows, etc.). & $\mathrm{X}$ & real number & square meters \\
\hline & Constrution type & Suggestion the recommmended construction technique in each alternative. & $\mathrm{X}$ & string & $\mathrm{n} / \mathrm{a}$ \\
\hline & URL for the optimized alternatives. & It contains a report showing all solutions generated by the optimization process. & $\mathrm{X}$ & URL & $\mathrm{n} / \mathrm{a}$ \\
\hline & URL for the optimization report. & It contains a report that indicates the "better" alternative according to material volume reduction. & $\mathrm{X}$ & URL & $\mathrm{n} / \mathrm{a}$ \\
\hline \multicolumn{6}{|c|}{ 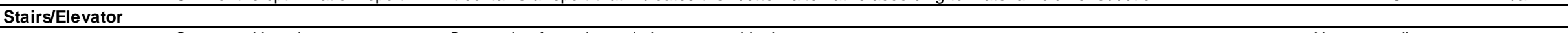 } \\
\hline & Suggested location & Suggestion for stairs and elevators po & $\mathrm{X}$ & coordinates & meters \\
\hline & Suggestion area & Suggestion for stairs and elevators projected areas. & $\mathrm{x}$ & real number & square meters \\
\hline \multicolumn{6}{|c|}{. } \\
\hline & Suggested type & Suggestion of the type of the roof according to opimization alternative (flat, curver, etc.). & $\bar{x}$ & string & $\mathrm{n} / \mathrm{a}$ \\
\hline & Suggested thickness & Suggestion of the roof thickness following optimzation solutions. & $\mathrm{x}$ & real number & meters \\
\hline \multicolumn{6}{|l|}{ eri } \\
\hline & Structural s & Suggestion of material choice for the structural system (RC, steel, etc.) & $\mathrm{X}$ & string & $\mathrm{n} / \mathrm{a}$ \\
\hline & Roof & Suggestion of the roof material. & & & \\
\hline
\end{tabular}


As observed, few information pieces are required in these two ERs because the insertion of SO is considered in early stages of the projects (conceptual phase). At this project maturity level, few details exist when compared to advanced stages, thus, facilitating the interoperability study. Since the interoperability can be solved in this phase, the study can advance to the next steps, in the pre-detail and detailed designs. 


\section{ANALYSIS}

This chapter presents the validation of the proposed methodology by applying the developed framework to three distinct experiments. The interoperability is evaluated by tracking information flow errors and proposing what can be done to help fixing them.

\section{1. \\ Description}

With the aim of testing the proposed IDM, three experiments were developed using Structural Optimization in the conceptual design. It is worth pointing out that these studies start after the kickoff phase with the client and the architect, and finish before the detailed design phase. Thus, all cases initiate with a mass model that has already taken into account owner necessities, solar and wind orientation, and other architectural issues; and finalizes with the structural conceptual design, with no pre-detailing studies, which is important in future stages.

The first study (case A - Egg House) is a low-cost house; the second study (case B - Tree Building) is a commercial building; and the final study (case $\mathrm{C}$ Bamboo Project) is a group of residential buildings. All enterprises are supposed to be located in Rio de Janeiro, Brazil. Table 12 presents the owner requirements defined by the architect after the kickoff with the client.

Table 12 - Cases studies initial description with owner requirements

\begin{tabular}{llll}
\hline & \multicolumn{1}{c}{ Egg House } & \multicolumn{1}{c}{ Tree Building } & \multicolumn{1}{c}{ Bamboo Project } \\
\hline Building type & Low-cost house & Commercial & Residential \\
\hline Structural material & ABS Plastic & Steel & Concrete \\
\hline Construction technique & 3D printing & Modular construction & Traditional construction \\
\hline Floor plan & $47 \mathrm{~m}^{2}$ & $475 \mathrm{~m}^{2} / \mathrm{floor}$ & $250 \mathrm{~m}^{2} / \mathrm{floor} /$ building \\
\hline
\end{tabular}

It is worth pointing out that these kinds of information can vary according to different architectural offices. In this study, this range of information was obtained after some interviews with Brazilian architects, who adopted this level of information at this design stage in their offices. However, in other countries or office 
cultures there could exist another level of information with more or less data. For example, the structural material choice is, in general, the responsibility of the architect, according to the interviews, but it should not be understood as a rule.

As can be observed, these experiments tried to sweep various situations for a building project to understand if $\mathrm{SO}$ is efficient and useful in all of them. For example, the structural material and construction technique ranges from traditional to futuristic situations, because maybe SO can be applied more effectively when advanced construction techniques are adopted than traditional ones. It is important to notice that the scalability factor can also be analyzed with these three studies, from individual houses to set of residential buildings.

\section{2. \\ Task evolution}

In this section, all processes from the proposed IDM are listed and described to elucidate the structure of all experiments. The chronological process of these tasks is also shown in Figure 13.

\subsection{1.}

\section{Architectural preliminary study}

According to the Finland BIM standard COBIM-3 (2012), the initial modeling of a building, here called by architectural preliminary study, should be preceded by the owner's requirements statement, list of deliverables within a chronogram, and budget. This requirements information can be expressed in a database table and represents the input data from the kickoff meeting with the client.

After the initial discussion with the client, following the proposed IDM, the architect can develop a volumetric model with the defined material. In this stage, the neighborhood and its interaction with the new building are studied. In addition, energy issues, such as solar and wind orientation of the building, are defined. However, there are no specific details of the building, such as openings, internal walls, etc. These kinds of information are only defined in the conceptual design, according to the process map proposed (Figure 13).

In the proposed workflow methodology considering SO, the preliminary model is sent to the structural engineer to start the next task. Figures 15, 16, and 17 show the preliminary models for each experiment. According to COBIM-3 (2012), in the preliminary model, also called by initial and spatial model, the following data should be included: 2D drawings, 3D models and images, 
neighboring structures, measurement results from topography, preliminary space study, and energy efficiency goals.

In this study, the 3D model, containing the spatial design, is sent to the SO tool using .SAT extension (only geometrical information is exchanged), because the utilized optimization tools does not read .RVT or .IFC files. Thus, in this first exchange, the material definition and all other non geometrical information described in the ER (Table 10) are lost, because .IFC standard is not applied yet in available optimization tools.

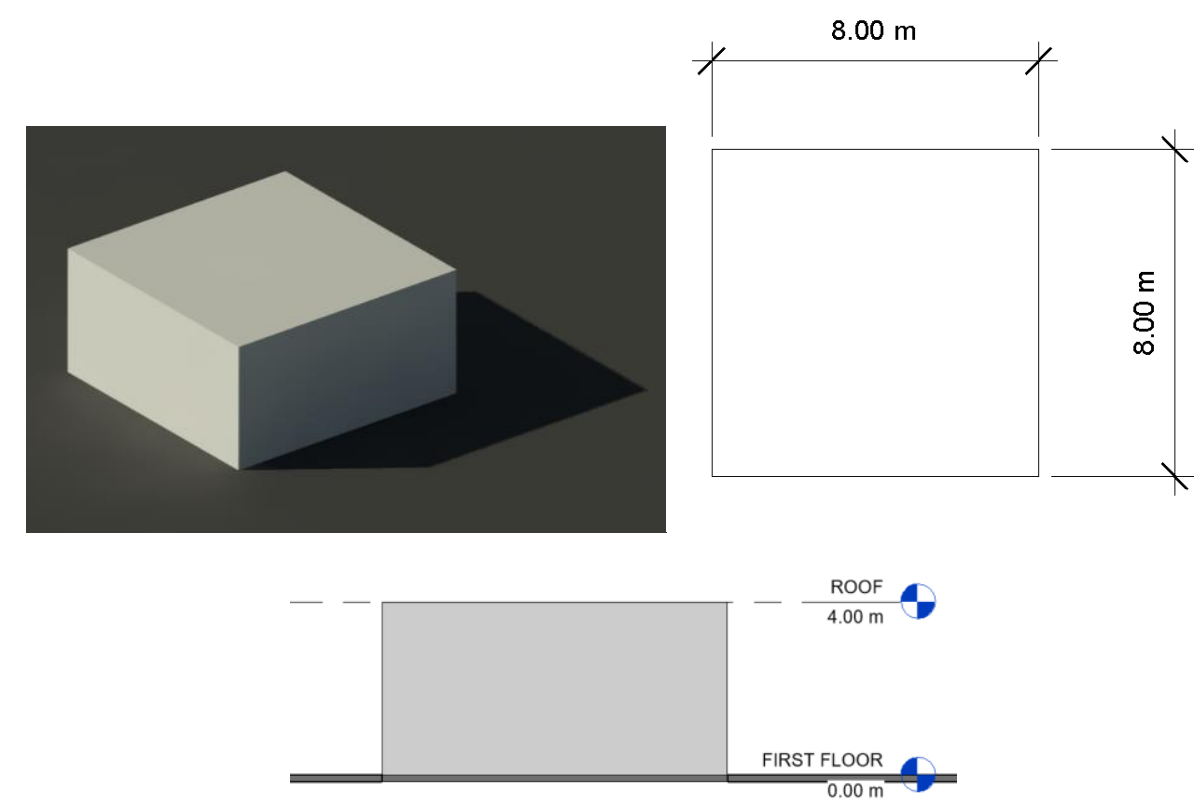

Figure 15 - Preliminary architectural model A
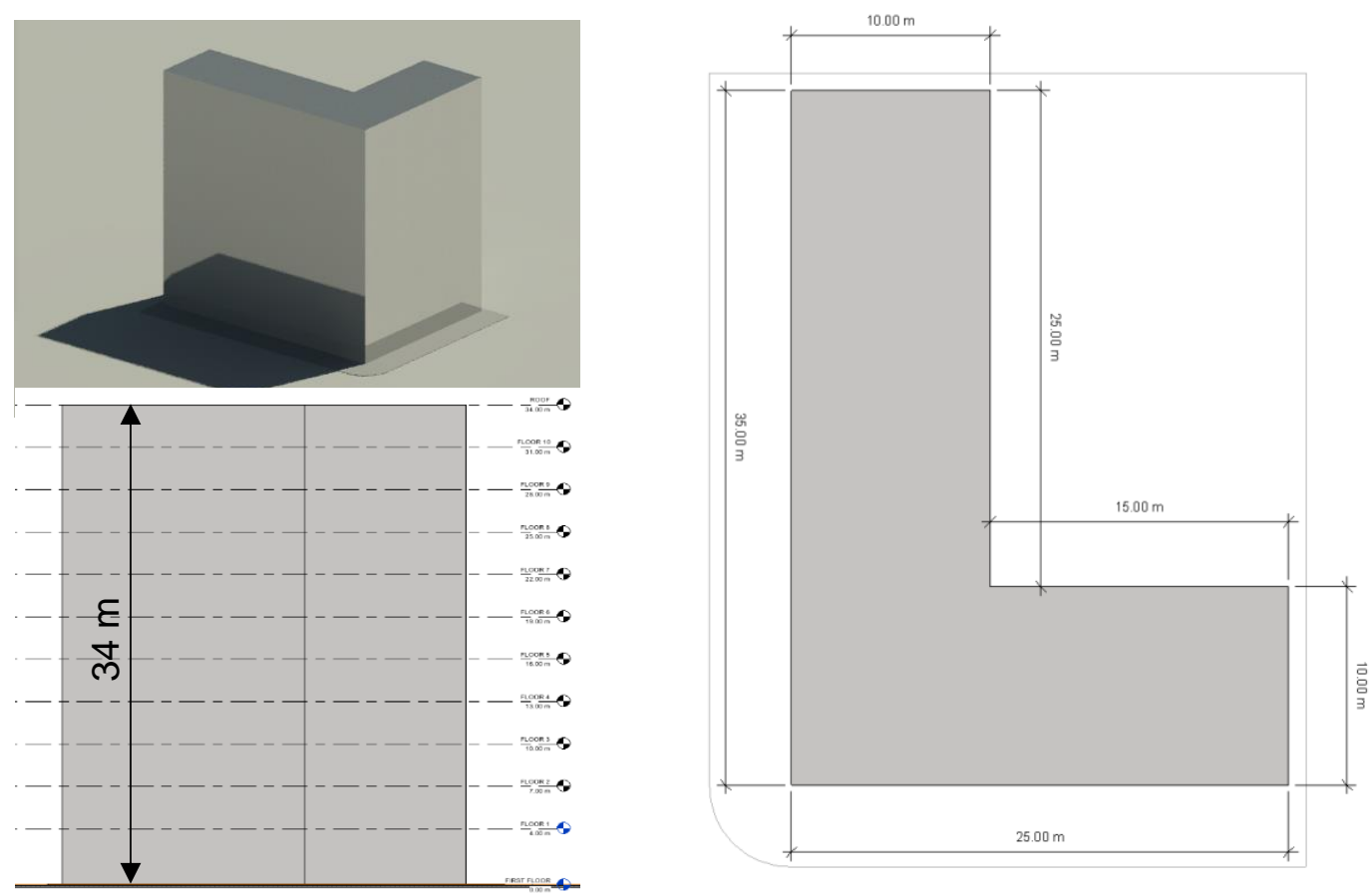

Figure 16 - Preliminary architectural model B 


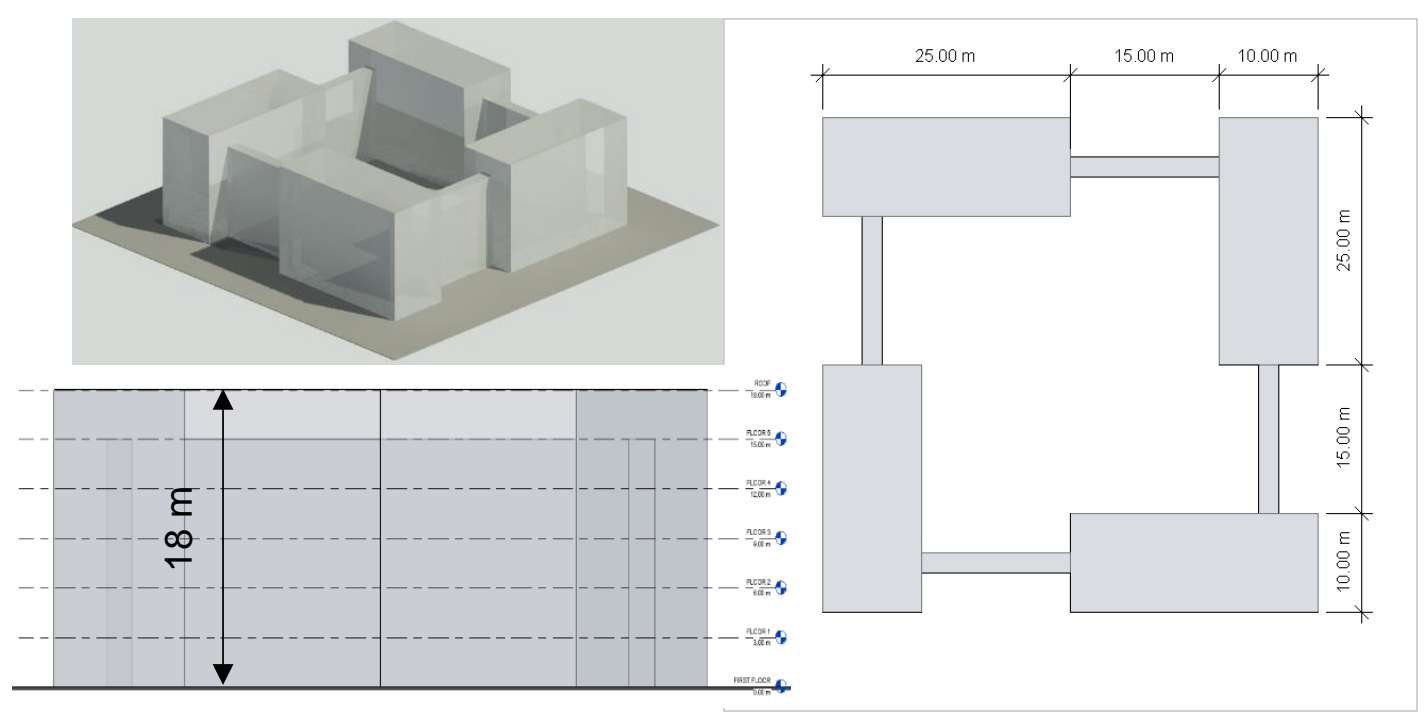

Figure 18 - Preliminary architectural model C

\subsection{2.}

\section{Structural optimization}

With the aim of connecting architects and structural engineers, the initial structural optimization is conducted to obtain the building shape with the best structural performance in terms of structural stiffness, according to the proposed workflow. Thus, using the volume and material defined previously, the structural engineer generates the "optimal" shapes for the building that can be considered or not by the architect. This initial SO should not be seen as a magical tool, returning a unique solution, but as a generative design tool that results in alternatives for design.

The structural optimized models for the three studies are defined by combining the separate optimizations and sending them to the architect as design alternatives (further details are provided in section 5.3.1). It is worth pointing out that in this task, the material data has to be re-entered because this information is lost in the initial exchange. This information is sent by .SAT file (only geometrical information is exchanged) to the next stage, because as mentioned before the adopted tools (Fusion 360, Abaqus/TOSCA, and Ansys) does not export .IFC files. So, once again in this second exchange, the material definition and other nongeometrical information described in Table 11 are lost. 


\subsection{3.}

\section{Technical and economic viability study}

Following the proposed methodology, with all of the SO design alternatives, the BIM coordination can adopt more structurally optimized buildings shapes based on technical and economic studies, but this is not obligatory. For example, in the Egg House (Figure 34) experiment, the BIM coordination can adopt option A entirely, with some modifications, or ignore the $S O$ results and proceed to the next task. The initial structural optimization works as auxiliary tool that can be discarded or improved, depending on the results from the technical and economic viability study.

In this task, other alternatives and suggestions from different disciplines can be taken into account to further guide the conceptual design. This step is the last opportunity to change the preliminary study before the development of the conceptual design and, thus, it is the time for all actors involved in the project to state their opinions. However, it is up to the BIM coordinator, manage and organize all suggestions and to decide whether or not to adopt them in the next task. It is worth pointing out that in small-scale projects the BIM coordinator can be the architect also.

\subsection{4.}

\section{Architectural conceptual design}

The project advances and the conceptual building design is achieved. In this phase, specific architectural elements, such as wall, windows, among others, are defined, following COBIM-3 (2012). In contrast to the detailed design, elements details are not modeled, such as connections in windows sill. In this stage, green studies (e.g. energy analysis, $\mathrm{CO} 2$ emissions, etc.) can also be conducted, to optimize sustainability issues.

It is worth pointing out that this task is intended to be cyclical and can be modified several times. The conceptual model, shown for the three studies in Figures 22, 23, and 24, is then sent to the engineering teams to start the next tasks, via .RVT, configuring a non openBIM scenario with native formats. 

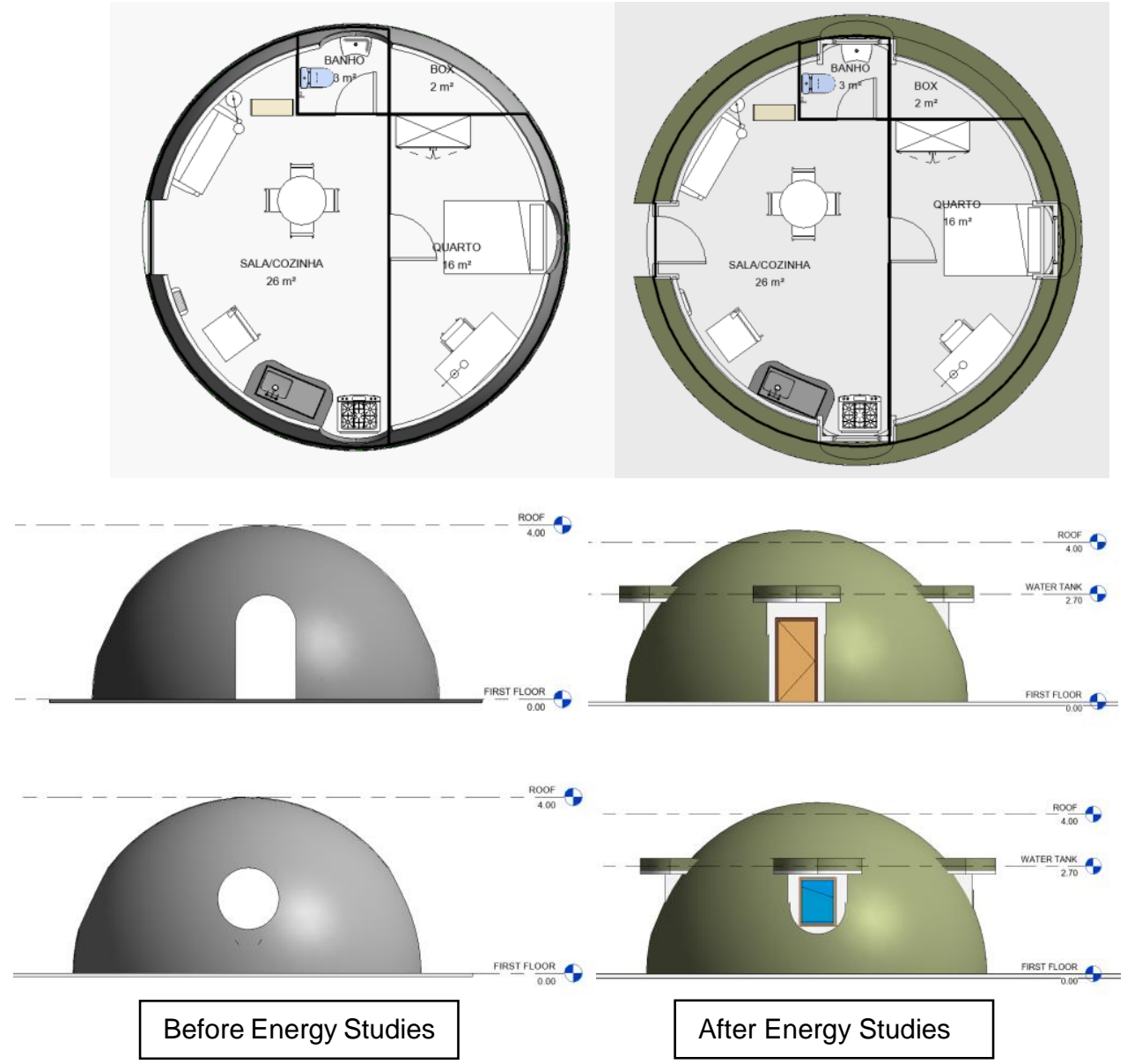

Figure 19 - Architectural conceptual model A

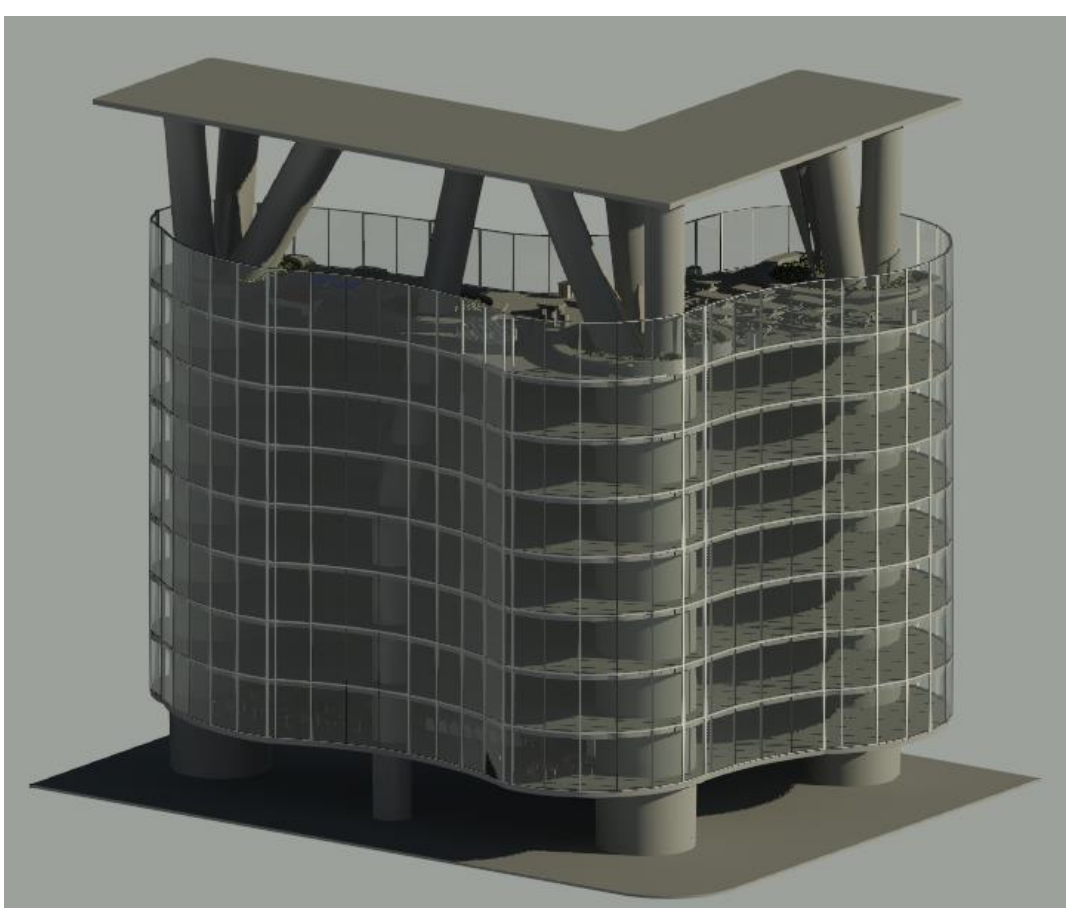

Figure 20 - Architectural conceptual model B 


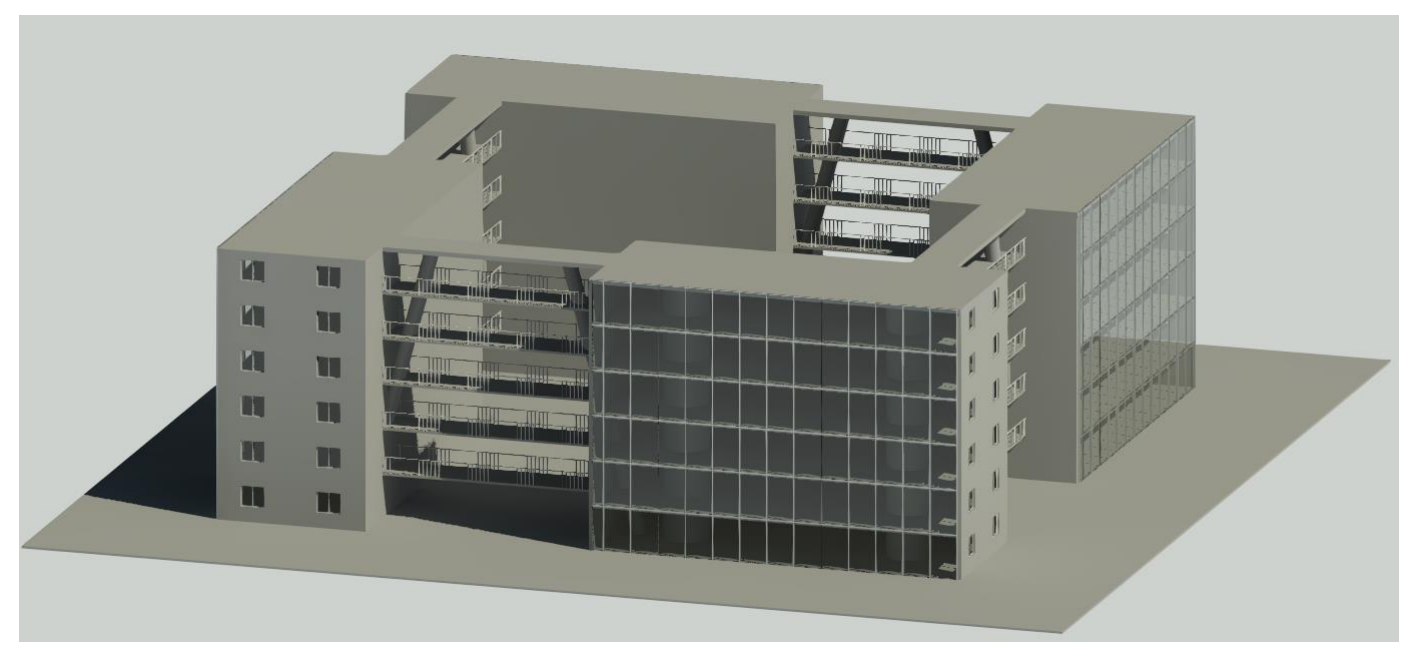

Figure 21 - Architectural conceptual model C

\subsection{5.}

\section{Conceptual structural project}

In the proposed workflow methodology, during the architectural conceptual design, the conceptual structural model can be initiated (Figures 25, 26, and 27). It is worth pointing out that the conceptual structural design is also intended to be a cyclical task and can be modified several times. The information flow between the chosen software packages, i.e., from the architectural program (Revit) to the structural analysis tool (Robot) occurs via native formats from Autodesk. Even in this non openBIM scenario, there is a loss of information, as highlighted by Papadopoulos et al. (2017).

It is worth pointing out that the MEP model is also sent to the structural engineer and important decisions can be made based on this, such as the structural system to support the water tank. This information flow is conducted via .RVT. For more details about the structural model and analysis, see section 5.3.2.

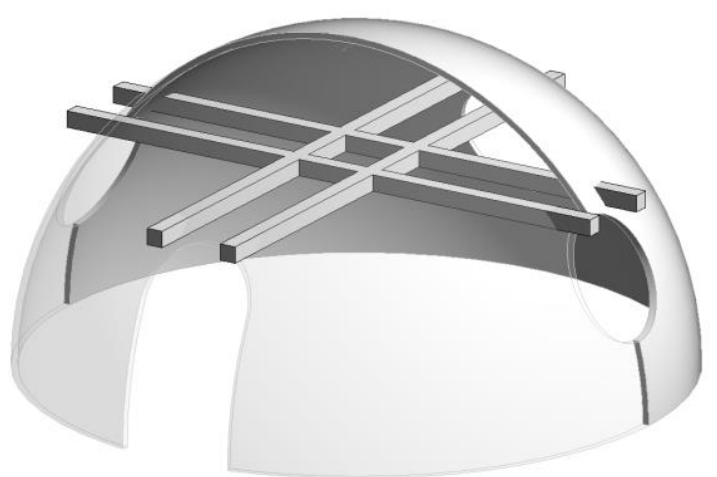

Figure 22 - Structural conceptual model A 


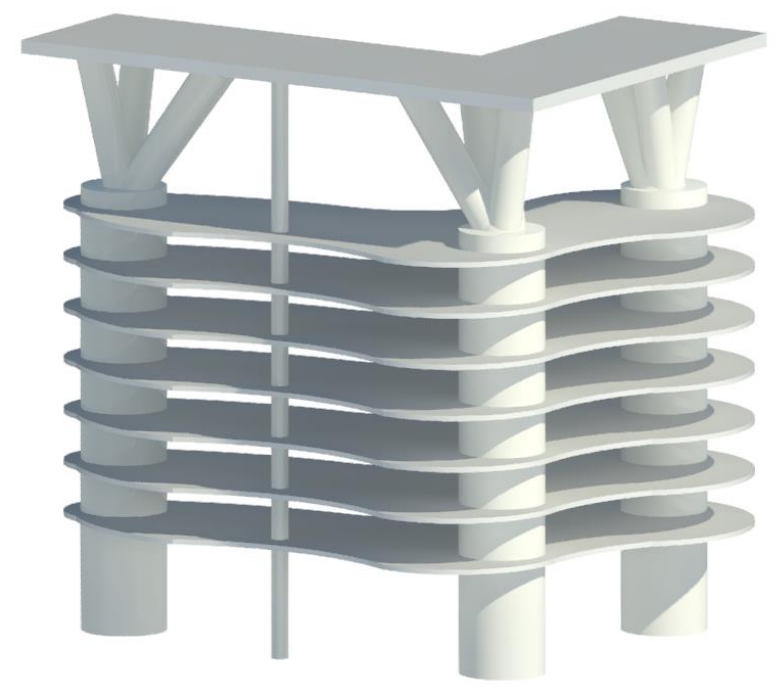

Figure 23 - Structural conceptual model B

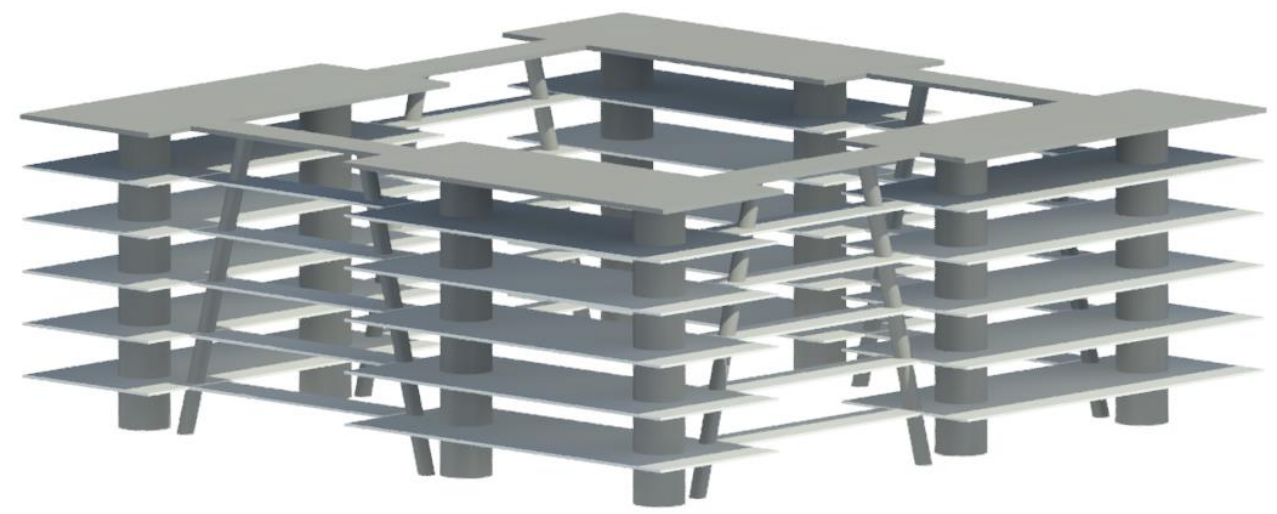

Figure 24 - Structural conceptual model C

\subsection{6.}

\section{Other tasks}

In the proposed workflow methodology, there are some tasks that are not related directly to $\mathrm{SO}$, but can affect its results. For example, the constructability evaluated by the constructor can invalidate a complex shape resulting from the optimization process. As the objective of this study is to analyze the connection between architect and structural engineer using $\mathrm{SO}$, other tasks will be described briefly only.

Related to the MEP preliminary study, for example the MEP team will assess possible positions for the water tank, probable necessary gap between the slab and the lining, among other preliminary studies that can help them in future stages. This task is oriented to help the architect with future choices for the conceptual 
design and can be in conflict with other teams suggestions, such as the result from the structural optimization model.

Related to the MEP conceptual design, the MEP engineer can develop it with the conceptual architectural project in hand. In this work, the software Revit was adopted for this task. The file exchanged between the MEP team and the architect is the .RVT format. It is worth pointing out that this task is also cyclical and can be modified several times but should be finalized before project compatibilization. Moreover, MEP optimization can be conducted in this task, like the shortest piping layout.

The task of merging the different specialties projects and clash detection, gross errors, such as conflicts between elements from different disciplines and duplicated elements, for example, are eliminated. Commonly, this task identifies modeling errors rather than design problems. At the end of this task, it is possible to generate a "clean" model to be assessed by the constructor.

Once the conceptual models are finalized and gross conflicts are fixed, they are aggregated and compatibilized by the BIM coordinator mainly to identify possible non-geometric conflicts such as code disagreements. This is considered a very important task because it avoids unforeseen costly problems during construction (Eastman et. al, 2011).

In this study, the software Autodesk Navisworks was used for this task, but there are other programs that can perform this task, for example Solibri Model Checker. Basically, the models, in .IFC or .RVT formats, were imported into Navisworks where clashes and inconsistences were identified and communicated to responsible teams via .HTML, .PDF, or .BCF formats reports.

Another task, that indirectly can affect SO results, is the constructor participation. There are two moments for this interaction: immediately after the structural optimization and after the conclusion of the conceptual model. The first interaction is required to anticipate the constructor and manufacturer participation in order to assess the viability of the architectural and structural optimized models.

In the proposed workflow methodology, once all conceptual designs have been compatibilized, the constructor is able to study the chronological phases of the construction, representing the second interaction. For that end, a planning tool, such as Autodesk Navisworks, Synchro, Vico Office, among others, can be used to merge all models. Following the information flow presented in the IDM (Figure 13), problems with constructability are communicated to the architect in reports (.HTML, .PDF, or .BCF extensions for example), who will coordinate the teams to fix them. 
Related to manufacturer participation, in the proposed BIM workflow using $\mathrm{SO}$, the manufacturer is responsible for analyzing the viability of manufacturing the elements and communicating problems to the constructor. For this task, a software oriented to mechanical engineering design can be used, such as Fusion 360 or Inventor. Once again, according to the proposed IDM, problems with the manufacturing process should be reported to the constructor in reports, who will communicate responsible teams and seek a solution.

Finally, the methodology proposed and adopted in this study establishes the process that concludes the conceptual design and is the client approval. In this gate-task, the client approves or does not approve the project via cloud visualization (Autodesk A360), for example. If not approved, the BIM coordinator should communicate with the teams to fix the problems. As observed, the BIM coordinator has the responsibility of a leader, establishing the communication bridge between the designers and the client.

\section{3. \\ Structural engineering processes}

In this section, the tasks of the structural engineer are detailed, following the proposed IDM. The intention behind by explaining these specific tasks is to show that SO can be applied in a BIM building project without using complicated optimization tools and that it can result in feasible and safe solutions as verified through structural analysis.

\subsection{1.}

\section{Structural optimization}

According to the proposed methodology, the structural work starts when the architect issues the preliminary model (.SAT extension). This input contains only geometrical information and, thus, the original material should be entered again by the structural engineer. The optimization tool, Fusion360, ANSYS, and Abaqus/TOSCA were used in this study. The structural engineer imports the .SAT file and re-enters the material properties.

Then, structural parameters should be assembled in the model, for example boundary conditions and structural loads. Following this step, optimization parameters can be defined, such as preserved regions (to not be modified by the optimization), \% mass target, objective function (e.g., maximize stiffness). For more details regarding the model configuration in Fusion360, see Table 13. 
With all configurations set, the optimization process is conducted and the results in Fusion360 are shown in Figures 28, 29, and 30. Red represents the essential elements in the load path, and blue represents elements that can be removed because they do not affect the load path. The arrows represent the applied loads with direction and the magnitude is also provided. These results are composed of mesh elements, specifically tetrahedron solid elements, which cannot be read by the modeling tools.

Thus, before exporting the model to Revit, it is necessary to transform the optimized results into a geometrical volume. In this phase, irregularities in the results can be fixed, such as surface roughness. Moreover, some alternatives are modeled with the aim of generating design alternatives for the architect; these .SAT models are illustrated in Figures 19, 20, and 21.

Table 13 - Optimization parameters in F360

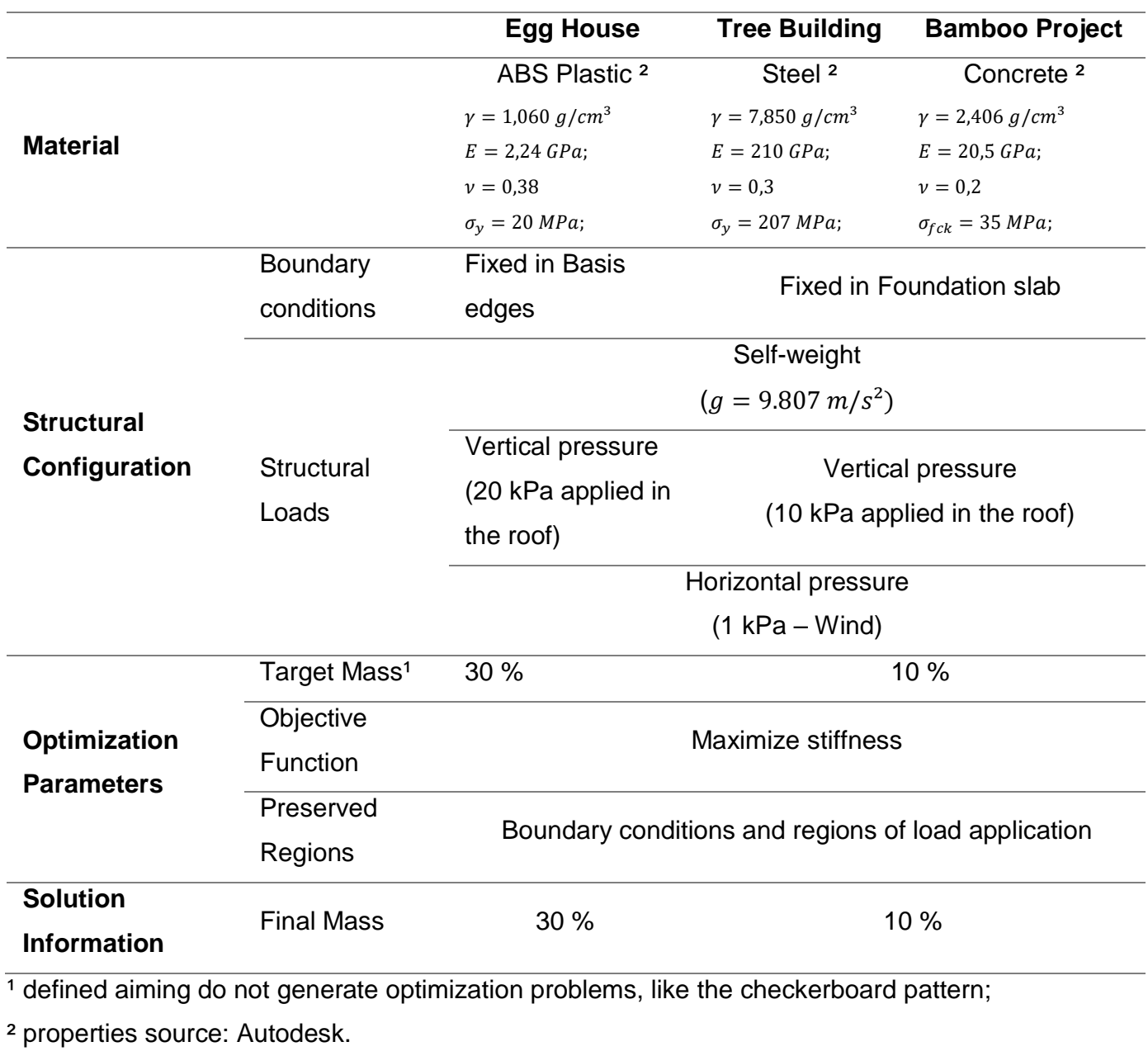



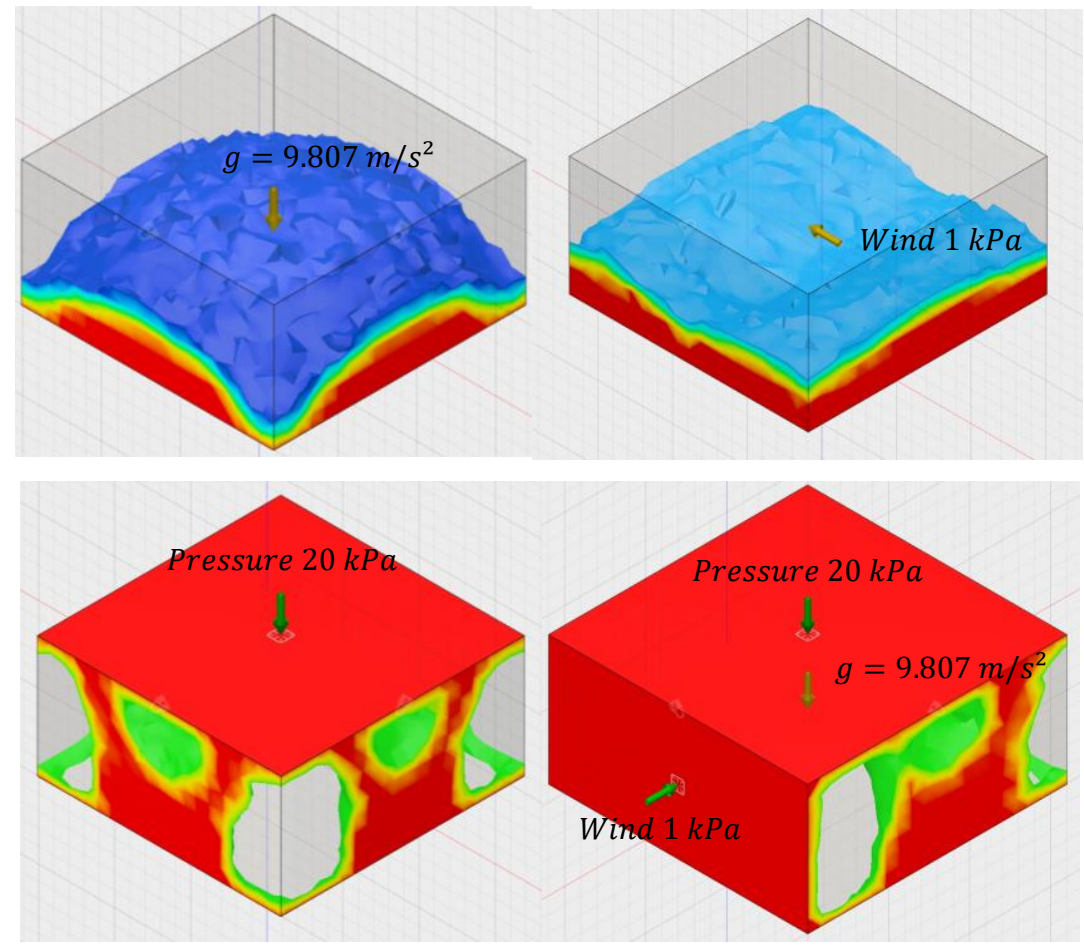

Figure 25 - Conceptual SO process in case A using Fusion360

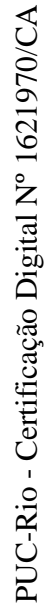
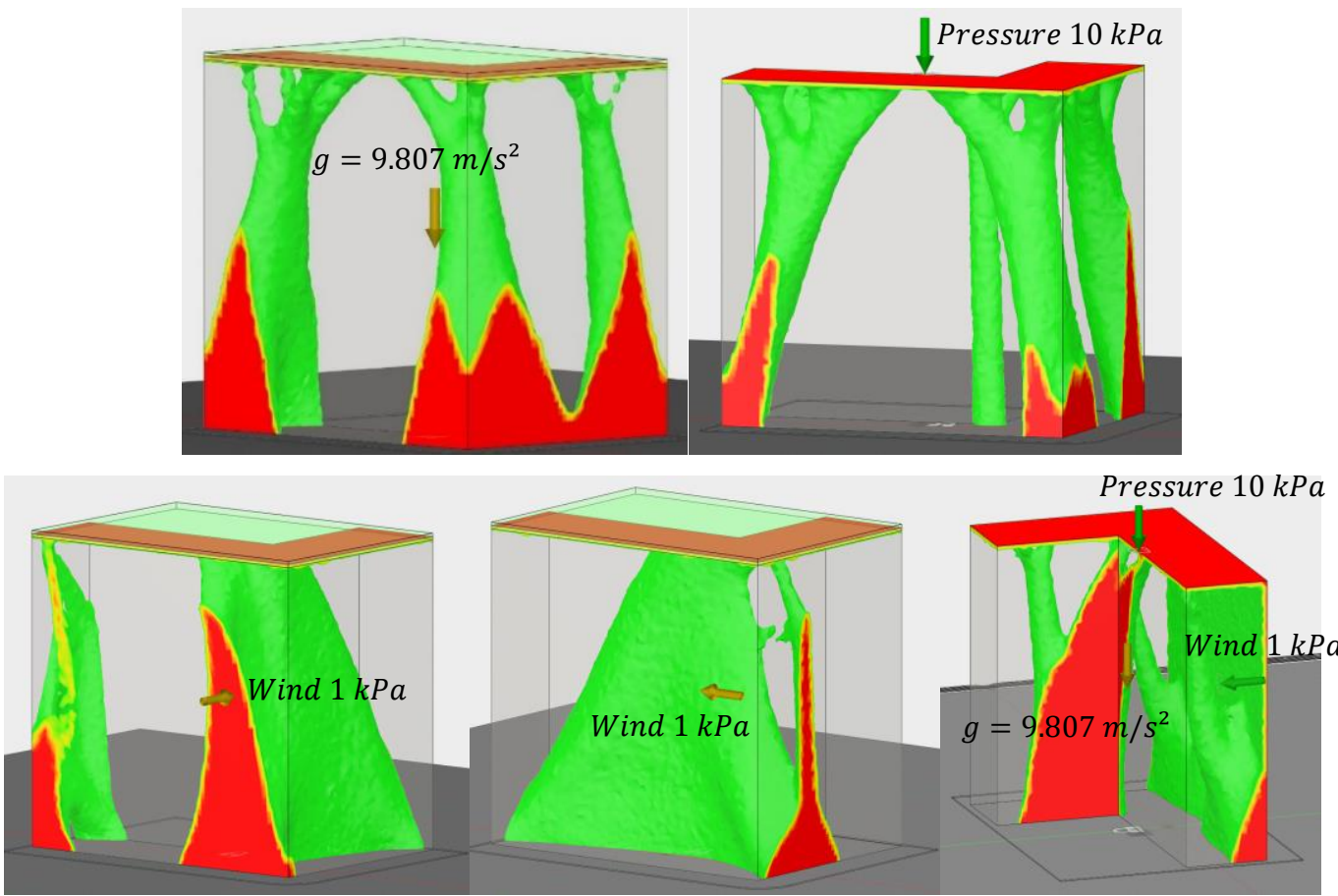

Figure 26 - Conceptual SO process in case B using Fusion360 


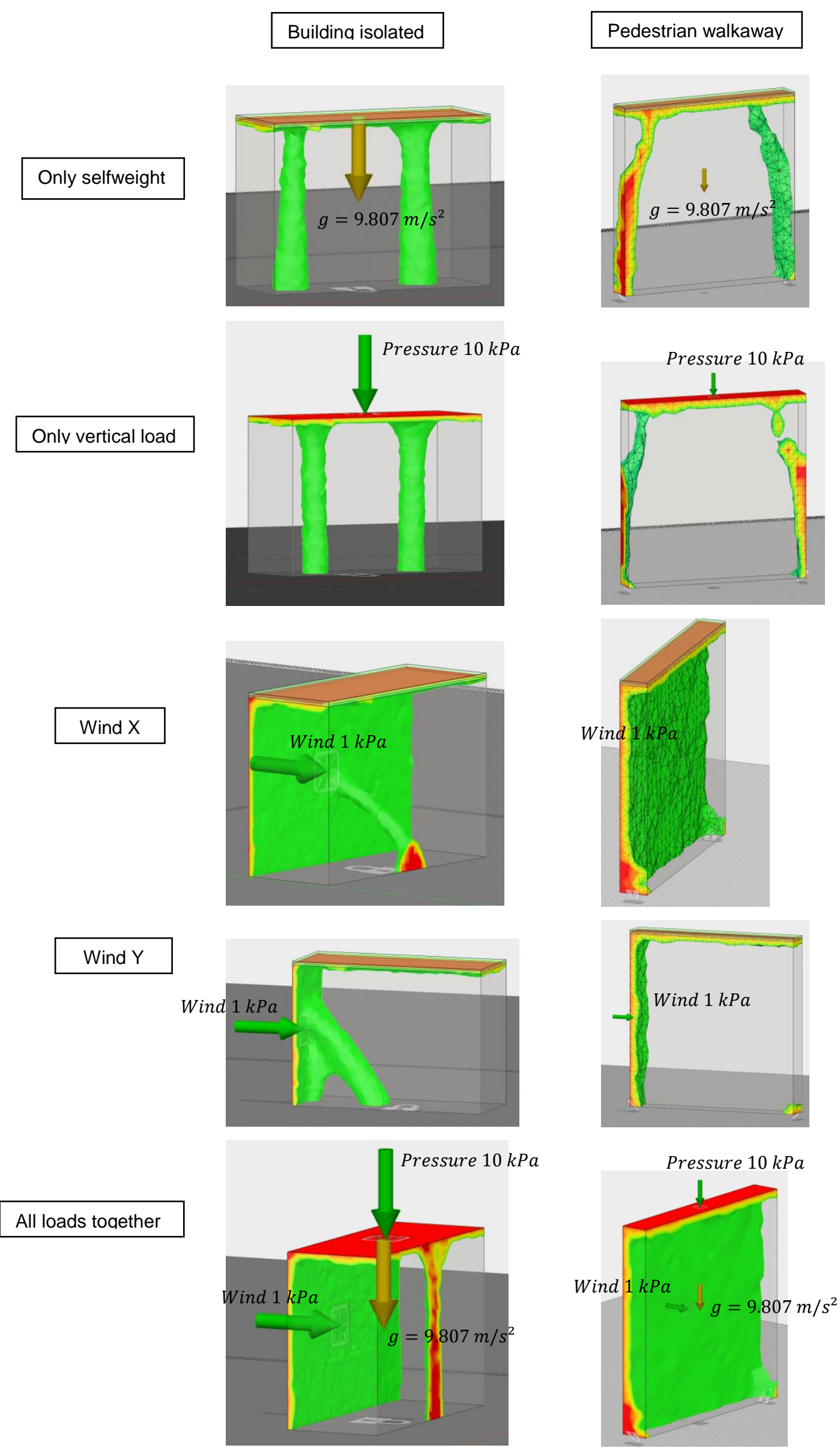

Figure 27 - Conceptual SO process in case B using Fusion360 
The Egg House case also used ANSYS to optimize the roof thickness. Initially, the roof thickness optimized in Fusion360 was equal to $20 \mathrm{~cm}$. Thus, after optimization using similar loads as in Fusion360, the thickness was reduced to 8 $\mathrm{cm}$. The relation between the span and the thickness in this house is $1 / 100$, which is the same as that of an eggshell, confirming that SO often returns natural structures.

The parameters set in ANSYS are listed in Table 14 and the results are illustrated in Figure 28, where the optimized model is on the left and the material elimination or reduction on the right.
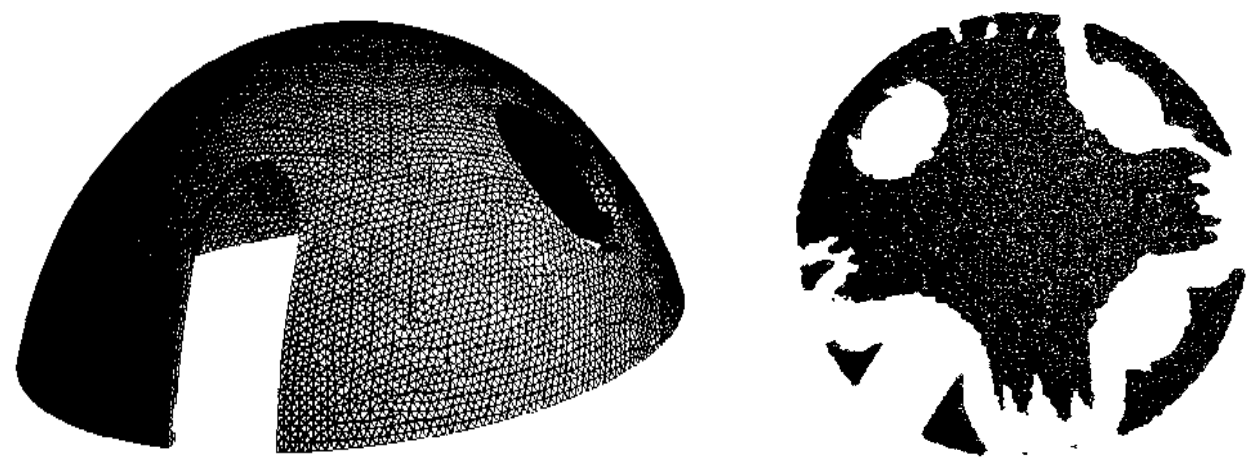

Figure 28 - SO process in case A using ANSYS

Table 14 - Optimization parameters in ANSYS

\begin{tabular}{|c|c|c|c|c|}
\hline & & Egg House & Tree Building & Bamboo Project \\
\hline Material & & $\begin{array}{c}\text { ABS Plastic } \\
\text { (properties same }\end{array}$ & $\begin{array}{l}\text { Steel } \\
\text { (properties same }\end{array}$ & $\begin{array}{c}\text { Concrete } \\
\text { (properties same }\end{array}$ \\
\hline \multirow{3}{*}{$\begin{array}{l}\text { Structural } \\
\text { Configuration }\end{array}$} & $\begin{array}{l}\text { Boundary } \\
\text { conditions }\end{array}$ & $\begin{array}{l}\text { Fixed in Basis } \\
\text { edges }\end{array}$ & \multicolumn{2}{|c|}{ Fixed in Foundation slab } \\
\hline & Structural & $\begin{array}{l}\text { Vertical pressure } \\
\text { ( } 20 \mathrm{kPa} \text { applied in } \\
\text { the roof) }\end{array}$ & \multicolumn{2}{|c|}{$\begin{array}{c}\text { Vertical pressure } \\
\text { (10 kPa applied in the roof) }\end{array}$} \\
\hline & & \multicolumn{3}{|c|}{$\begin{array}{c}\text { Horizontal pressure } \\
\qquad(1 \mathrm{kPa}-\text { Wind })\end{array}$} \\
\hline \multirow{3}{*}{$\begin{array}{l}\text { Optimization } \\
\text { Parameters }\end{array}$} & Target Mass $^{1}$ & $1 \%$ & & $\%$ \\
\hline & $\begin{array}{l}\text { Objective } \\
\text { Function }\end{array}$ & \multicolumn{3}{|c|}{ Minimize force and displacements (program controlled) } \\
\hline & $\begin{array}{l}\text { Preserved } \\
\text { Regions }\end{array}$ & \multicolumn{3}{|c|}{ Boundary conditions and regions of load application } \\
\hline \multirow{2}{*}{$\begin{array}{l}\text { Solution } \\
\text { Information }\end{array}$} & Final Mass & $40 \% 1$ & $14 \% 2$ & $20 \%{ }^{2}$ \\
\hline & $\begin{array}{l}\text { № Iterations to } \\
\text { Convergence }\end{array}$ & 9 & 45 & 40 \\
\hline
\end{tabular}

1 related to already optimized Egg House in F360, that resulted in roof thickness equals to $20 \mathrm{~cm}$;

2 related to the mass preliminary model, not optimized yet. 
For cases B (Tree Building) and C (Bamboo Project), were used the same proceedings: initial SO carried out in Fusion360 and a second parallel SO in ANSYS, both optimization feed by the .SAT preliminary architectural model and with all parameters set according to tables 13 and 14. The results of the optimization conducted by ANSYS are shown in Figures 32 and 33.

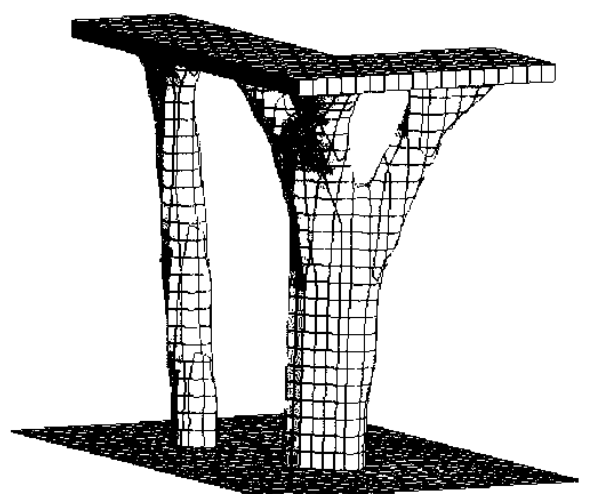

Figure 29 - Parallel conceptual SO process in case B, using ANSYS

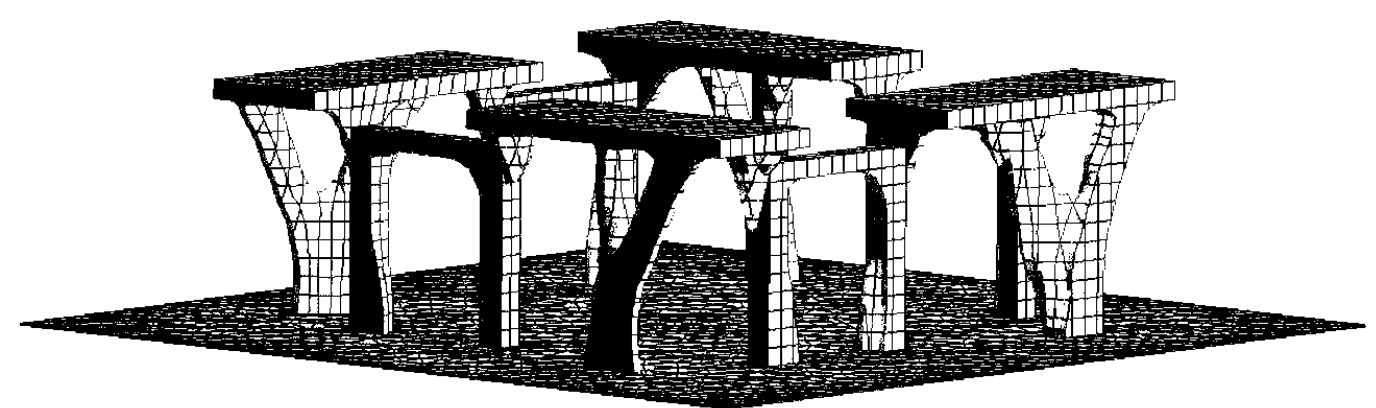

Figure 30 - Parallel conceptual SO process in case C, using ANSYS

Another optimization process was conducted using the software Abaqus/TOSCA, aiming to generate more alternatives for the designer and to validate the results given by the other tools. The parameters set in Abaqus/TOSCA are listed in Table 15 and the results are illustrated in Figures 34, 35, and 36. As observed, optimization results from different tools are very similar, indicating that the optimization was done properly.

In this work, optimization processes were carried out using an $17-6700 \mathrm{HQ}$ CPU @2.60 GHz and the Windows 10 Home operating system, with 16.0 GB of RAM. Comparing the structural optimization tools, used in this study, in terms of processing time, it is difficult to say which one is the faster, because it depends on the CPU configuration, mesh quality, internet speed. However, comparing the user interfaces, F360 seems to be more intuitive and user-friendly. 
Table 15 - Optimization parameters in Abaqus/TOSCA

\begin{tabular}{|c|c|c|c|c|}
\hline & & Egg House & Tree Building & Bamboo Project \\
\hline \multirow[t]{2}{*}{ Material } & & $\begin{array}{c}\text { ABS Plastic } \\
\text { (properties same }\end{array}$ & $\begin{array}{c}\text { Steel } \\
\text { (properties same }\end{array}$ & $\begin{array}{c}\text { Concrete } \\
\text { (properties same }\end{array}$ \\
\hline & & as used in F360) & as used in F360) & as used in F360) \\
\hline \multirow{3}{*}{$\begin{array}{l}\text { Structural } \\
\text { Configuration }\end{array}$} & $\begin{array}{l}\text { Boundary } \\
\text { conditions }\end{array}$ & $\begin{array}{l}\text { Fixed in Basis } \\
\text { edges }\end{array}$ & \multicolumn{2}{|c|}{ Fixed in Foundation slab } \\
\hline & Structural & $\begin{array}{l}\text { Vertical pressure } \\
\text { ( } 20 \mathrm{kPa} \text { applied in } \\
\text { the roof) }\end{array}$ & \multicolumn{2}{|c|}{$\begin{array}{c}\text { Vertical pressure } \\
\text { (10 kPa applied in the roof) }\end{array}$} \\
\hline & & \multicolumn{3}{|c|}{$\begin{array}{l}\text { Horizontal pressure } \\
\qquad(1 \mathrm{kPa}-\mathrm{Wind})\end{array}$} \\
\hline \multirow{3}{*}{$\begin{array}{l}\text { Optimization } \\
\text { Parameters }\end{array}$} & $\begin{array}{l}\text { Target } \\
\text { Volume }^{1}\end{array}$ & \multicolumn{3}{|c|}{$10 \%$} \\
\hline & $\begin{array}{l}\text { Objective } \\
\text { Function }\end{array}$ & \multicolumn{3}{|c|}{ Minimize strain energy of the whole model } \\
\hline & $\begin{array}{l}\text { Preserved } \\
\text { Regions }\end{array}$ & \multicolumn{3}{|c|}{ None (Load and BC regions were not frozen) } \\
\hline $\begin{array}{l}\text { Solution } \\
\text { Information }\end{array}$ & $\begin{array}{l}\text { № Iterations to } \\
\text { Convergence }\end{array}$ & 47 & 32 & 37 \\
\hline
\end{tabular}

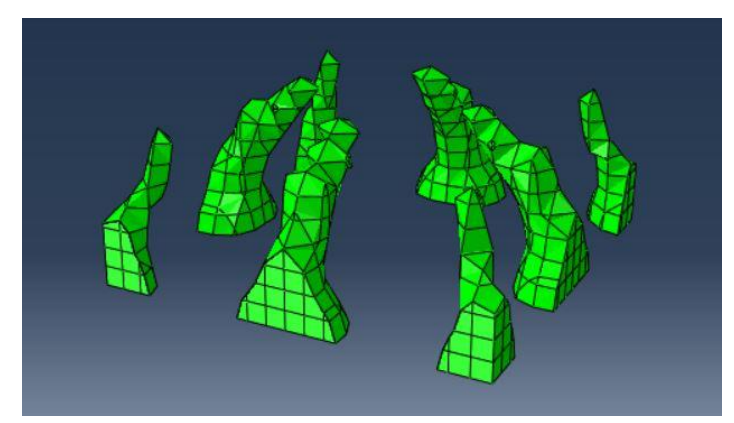

Figure 31 - SO process in case A using Abaqus/TOSCA

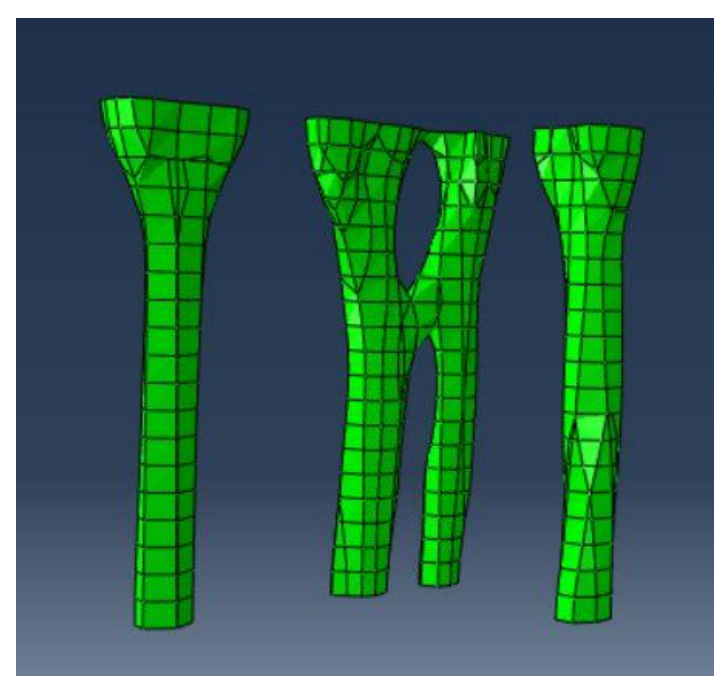

Figure 32 - SO process in case B using Abaqus/TOSCA 


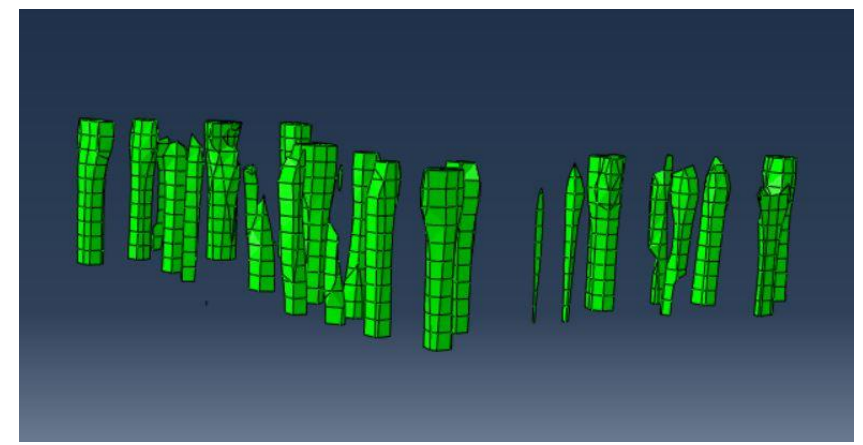

Figure 33 - SO process in case C using Abaqus/TOSCA (half building)

After the optimization processes in all SO tools are finished, the structural engineer generates alternatives for the architect, see Figures 19, 20, and 21. These options are not mandatory but auxiliary to the architect's inspiration and, thus, they can be discarded or the most optimized option be adopted.

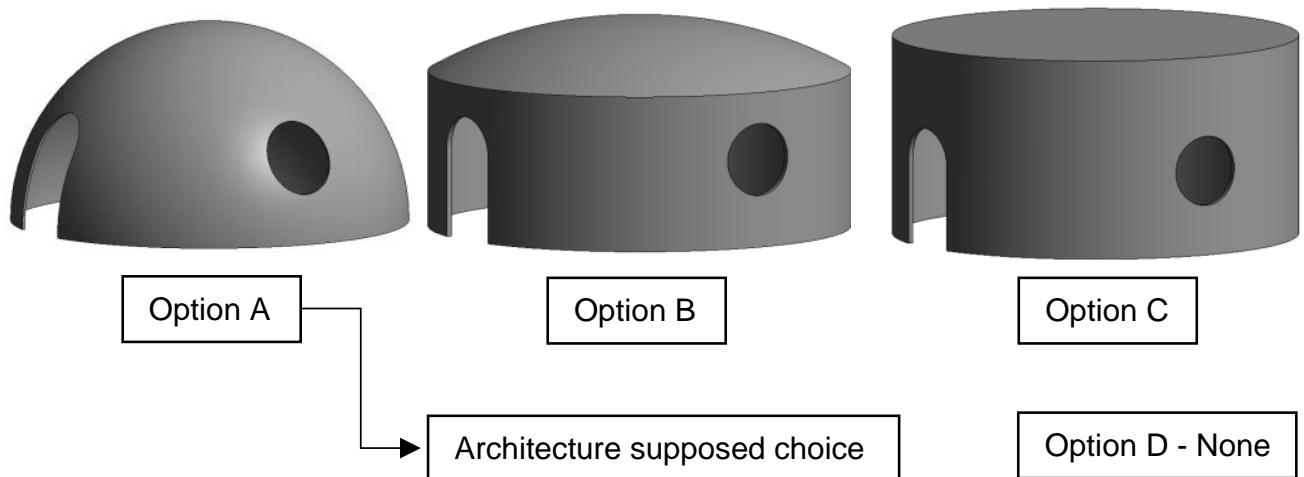

Figure 34 - Design alternatives based on structural optimized model A
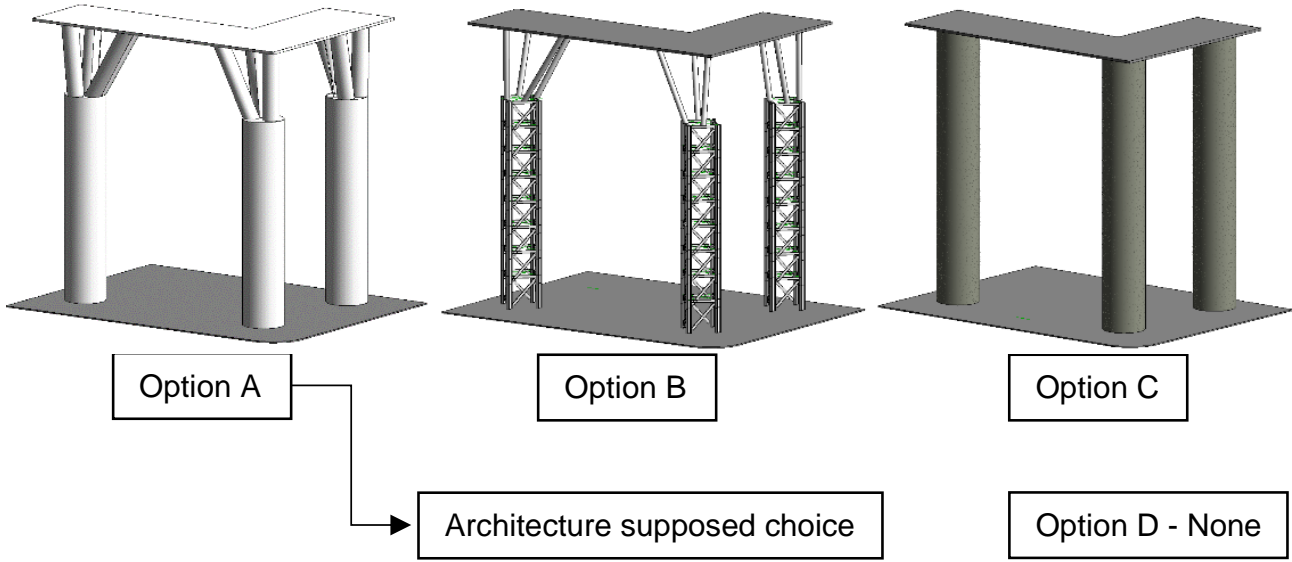

Figure 35 - Design alternatives based on structural optimized model B 


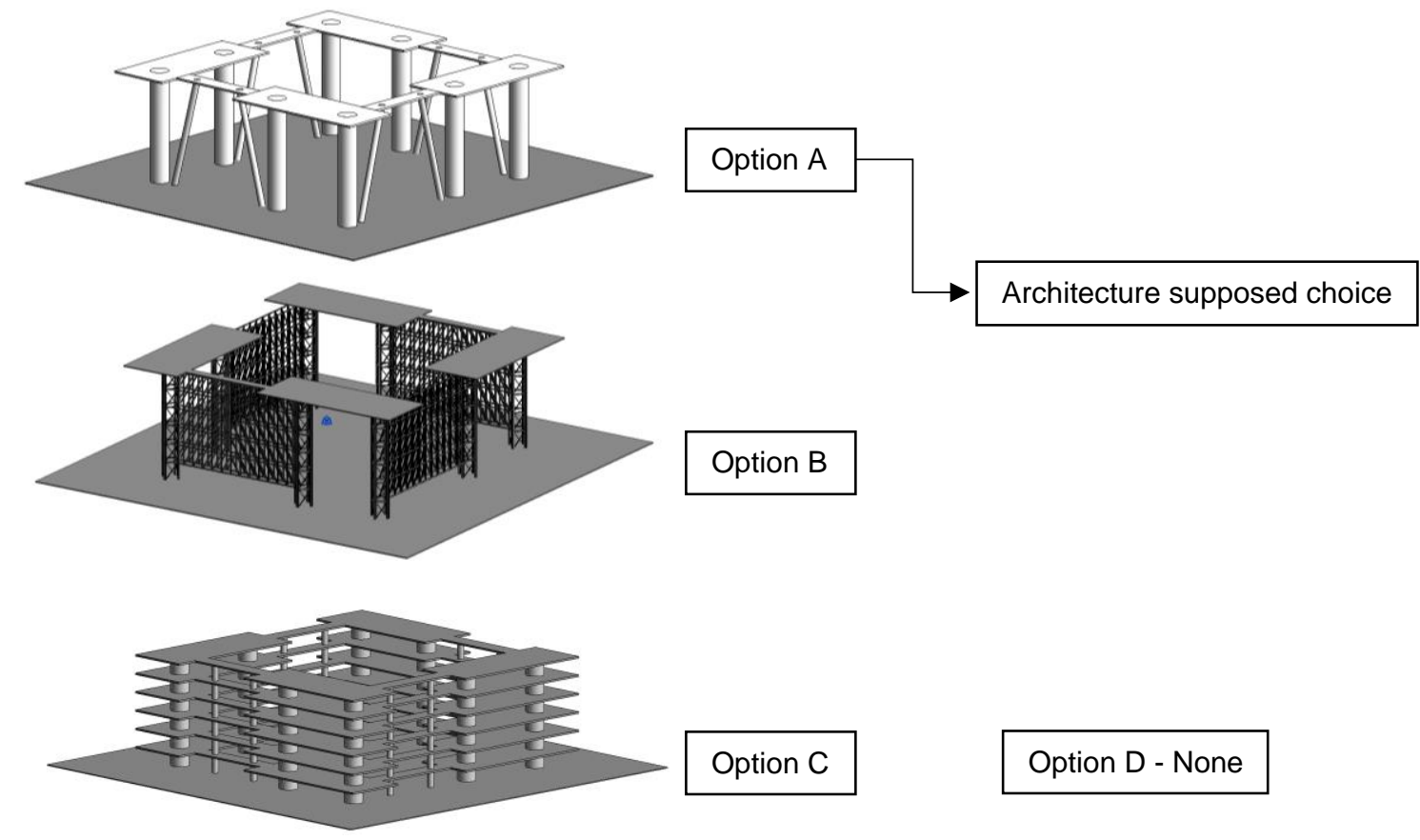

Figure 36 - Design alternatives based on structural optimized model C

\subsection{2. \\ Structural analysis}

In the proposed methodology, at this point, the architect is in charge of developing the conceptual model and the structural engineer should wait for completion of the architectural task. This is because it is not guaranteed that any optimized model will be adopted. In this way, when the architectural conceptual model is complete (or during this process), the engineer receives the model (.RVT) and can start the structural conceptual model using structural analysis tools. In this study, Robot (FE structural analysis) was adopted and should be noted that only a preliminary structural analysis was carried out to demonstrate that the optimized solution is viable and safe.

In case $A$, the structural model is composed of curved structural walls, obtained from SO, and beams with square section $(20 \times 20 \mathrm{~cm})$ to support the water tank. The solution adopted to support the water tank is a structural grid (Figure 22) supported on the curved walls. As for the SO shape, the grid material is selected as ABS plastic. The resulting structural model is presented in Figure 37.

In cases B and C, the structural system is composed of columns and slabs, without beams. In both cases, all slabs are made of reinforced concrete and modeled by quadratic and triangle shell elements, while the columns were modeled as beam elements. These models can be seen in Figures 38 and 39 . 
The loads considered in this study for all cases were: self-weight, vertical dead loads, vertical live loads such as occupation, and wind loads. For the vertical load (a combination of permanent and accidental loads) it was adopted $10 \mathrm{kPa}$ and the wind force was of $1 \mathrm{kPa}$ applied laterally. Both values were based on Brazilian standards (ABNT NBR 6120:1980 and ABNT NBR 6123:1988, respectively). Regarding loads combinations, no load factors were considered, taking into account that this task represents the conceptual project in the proposed methodology. For further detail regarding these parameter configurations, see Table 16.

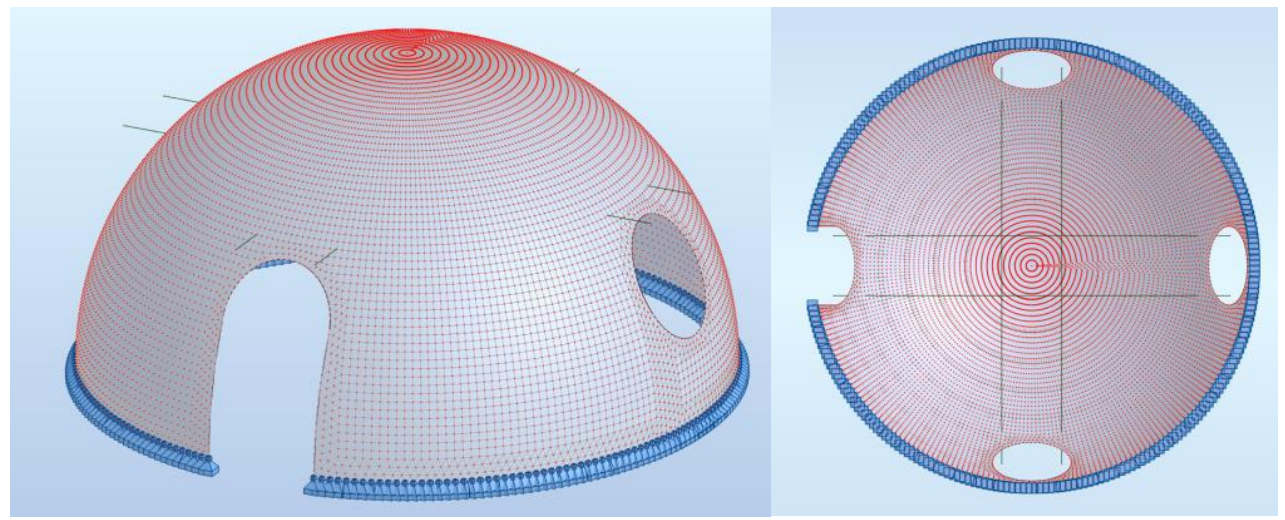

Figure 37 - FE model for case A

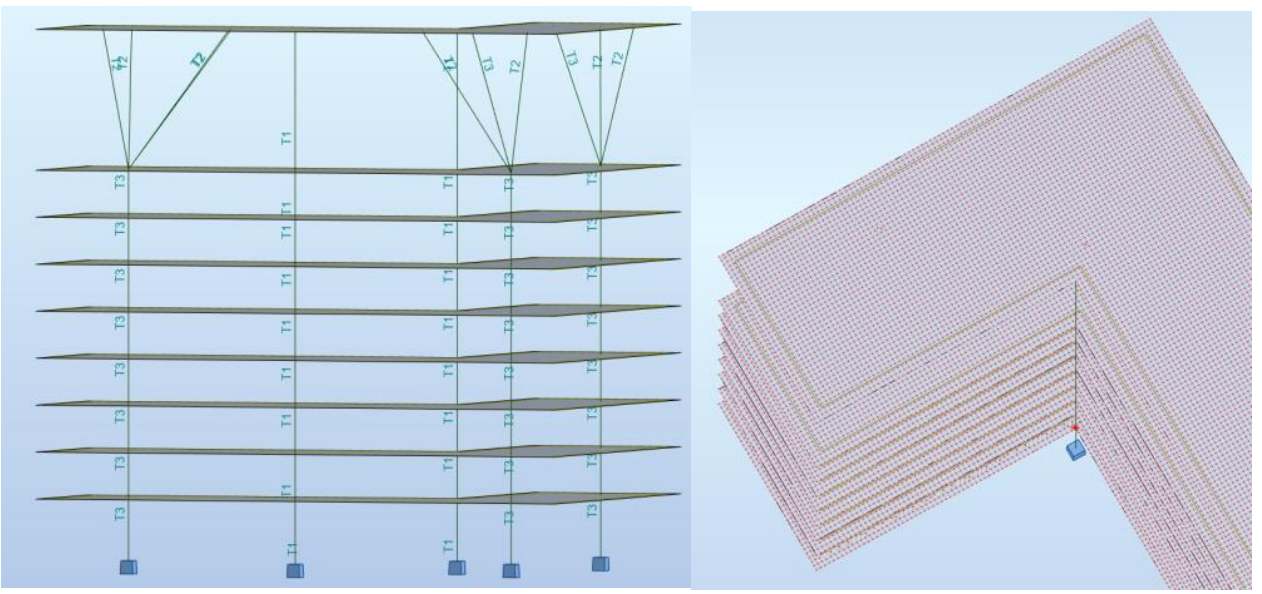

Figure 38 - FE model for case B

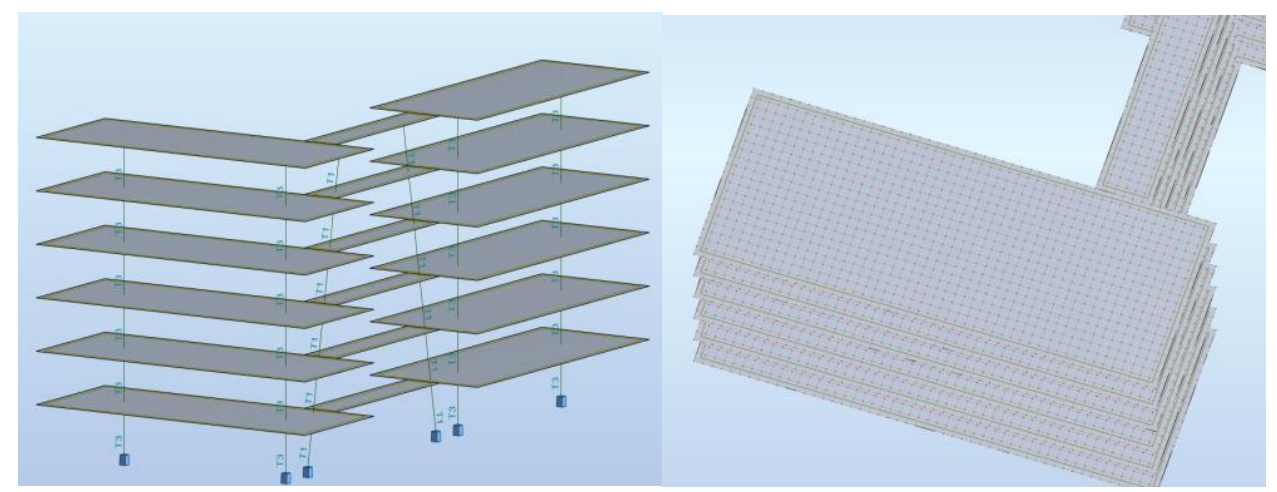

Figure 39 - FE model for case C 
Table 16 - FEA configuration for case A, B, and C

\begin{tabular}{|c|c|c|c|}
\hline & Egg House & Tree Building & Bamboo Project \\
\hline $\begin{array}{c}\text { FEM } \\
\text { elements }\end{array}$ & $\begin{array}{l}\text { - Quadratic and } \\
\text { triangle shell ( } 8 \mathrm{~cm} \\
\text { thickness) for the } \\
\text { roof; } \\
\text { - Beam elements ( } 20 \\
\times 20 \mathrm{~cm} \text { ) for the grid. }\end{array}$ & $\begin{array}{l}\text { - Quadratic and } \\
\text { triangle shell ( } 30 \mathrm{~cm} \\
\text { thickness) for all } \\
\text { slabs; } \\
\text { - Hollow columns } \\
\text { with 100, 200, and } \\
300 \mathrm{~cm} \text { as diameter } \\
\text { (T1, T2, and T3) } \\
\text { modeled by shell } \\
\text { elements ( } 2,5 \mathrm{~cm} \\
\text { thickness). }\end{array}$ & $\begin{array}{l}\text { - Quadratic and } \\
\text { triangle shell ( } 20 \mathrm{~cm} \\
\text { thickness) for all } \\
\text { slabs; } \\
\text { - Hollow columns } \\
\text { with } 100,200 \text {, and } \\
300 \mathrm{~cm} \text { as diameter } \\
\text { ( } \mathrm{T} 1, \mathrm{~T} 2 \text {, and T3) } \\
\text { modeled by shell } \\
\text { elements ( } 20 \mathrm{~cm} \\
\text { thickness). }\end{array}$ \\
\hline $\begin{array}{l}\text { Degrees of } \\
\text { Freedom }\end{array}$ & 88638 & 444588 & 56352 \\
\hline $\begin{array}{l}\text { Boundary } \\
\text { conditions }\end{array}$ & $\begin{array}{l}\text { Nodes fixed in all } \\
\text { directions in the } \\
\text { lowest level. }\end{array}$ & $\begin{array}{l}\text { Nodes cannot tran } \\
\text { directions in the lowe }\end{array}$ & $\begin{array}{l}\text { ate and rotate in all } \\
\text { level of the columns. }\end{array}$ \\
\hline \multirow{4}{*}{$\begin{array}{l}\text { Loads } \\
\text { applied }\end{array}$} & & Self-weight (DL1); & \\
\hline & $\begin{array}{l}20 \mathrm{kPa} \text { as the } \\
\text { vertical pressure in } \\
\text { all roof (DL2); }\end{array}$ & \multicolumn{2}{|c|}{$\begin{array}{l}5 \mathrm{kPa} \text { as the vertical pressure in all slabs } \\
\text { (DL2); }\end{array}$} \\
\hline & $\begin{array}{l}10 \mathrm{kN} \text { as the vertical } \\
\text { load from the water } \\
\text { tank (DL2); }\end{array}$ & \multicolumn{2}{|c|}{$\begin{array}{l}5 \mathrm{kN} / \mathrm{m} \text { as wind uniform load acting in } \\
\text { columns located in the direction considered } \\
\text { (WX and } \mathrm{WY}) .\end{array}$} \\
\hline & $\begin{array}{c}1 \mathrm{kPa} \text { as wind } \\
\text { pressure acting in } \\
90^{\circ}(\mathrm{WX}) \text { and } 180^{\circ} \\
(\mathrm{WY}) \text { directions. }\end{array}$ & \\
\hline
\end{tabular}

COMB1: DL1 + DL2

Combinations

COMB2: DL1 + DL2 + WX

COMB3: DL1 + DL2 + WY

It is worth pointing out that for all models, convergence tests were done to validate the mesh refinement. It consisted of modifying mesh refinement, increasing the number of nodes, and observing the displacement results. The test stops when results produce a convergence tendency, in this study $2 \%$ of tolerance and, thus, the mesh can be defined as satisfactory. As an example, Table 17 presents the details of this test for case A model (Egg House). 
It should be noted that for Case A, the structural grid was eliminated from the mesh as its presence causes the inclusion of additional elements at the connection between the grid and the main model. This was done only for the convergence test.

Table 17 - Convergence test for mesh refinement in model A

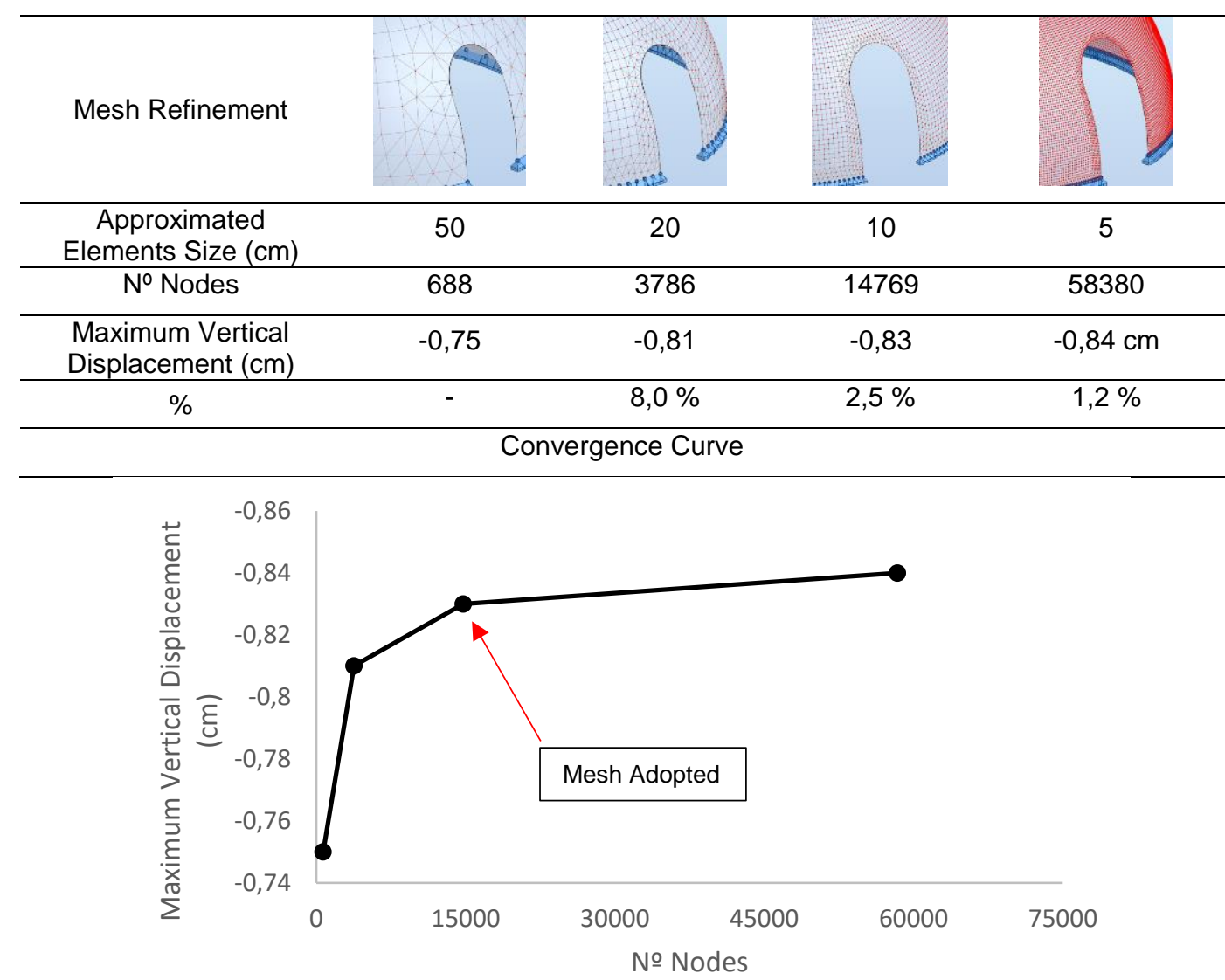

For the analyses of Case A, the structural grid was added to the model as beam elements and four concentrated loads were applied in it to simulate the water tank. Considering a family living in this house was adopted a water tank capacity of $1000 \mathrm{~L}$ what produces $2,5 \mathrm{kN}$ in each point of the central grid in the gravity direction, see Figure 40. 


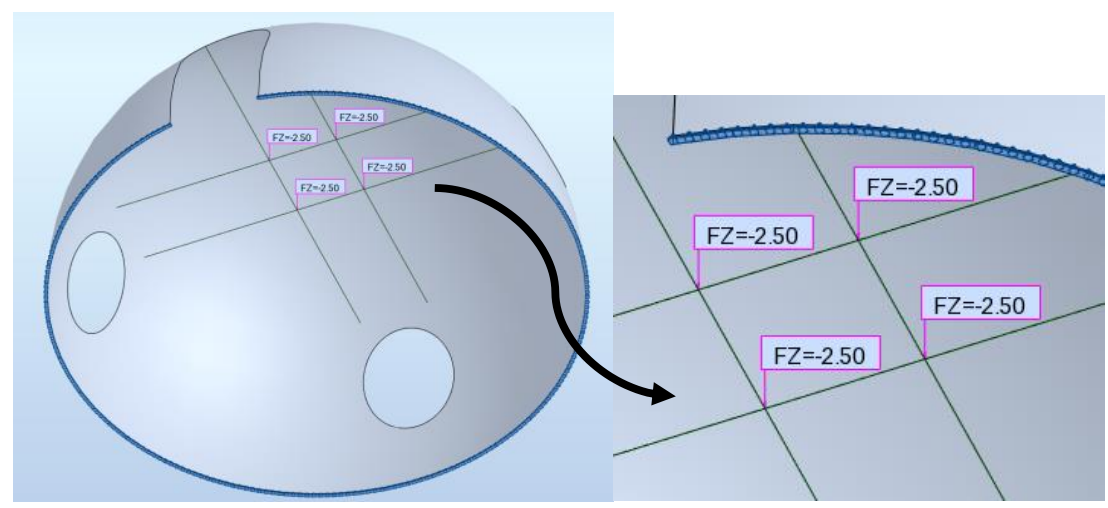

Figure $40-$ Water tank loads (kN) applied to the structural grip support

As results, the structural grid collaborated to decrease horizontal displacements in the curved shells and does not affect the vertical displacements. However, the maximum vertical displacement observed in the structural grid was bigger than the observed in the curved shells, equals to $-2,3 \mathrm{~cm}$. This value should be used to verify the user visual comfort according to Brazilian code and this checking was done in topic 6.1.

For case B it was necessary to develop a secondary structural model for the elastic buckling analysis of the columns. The critical columns are positioned on the first floor, where the axial force has the highest value. Thus, these columns have diameters equals to 1.0 or 3.0 meters and all of them were verified. In the structural model adopted, columns were composed of shell elements, which have thickness equals to $2,5 \mathrm{~cm}$ and steel as material.

In this analysis, to be in the conservative side, the column was considered simply supported on both ends with effective buckling length equals to the floor height, as illustrated by Figure 41 . The slab influence was represented by the boundary conditions: all degree of freedom fixed at the bottom and only the $z$ displacement was freed at the top of the column. The critical factor illustrated is the relation between the Euler's critical load and the working load. 


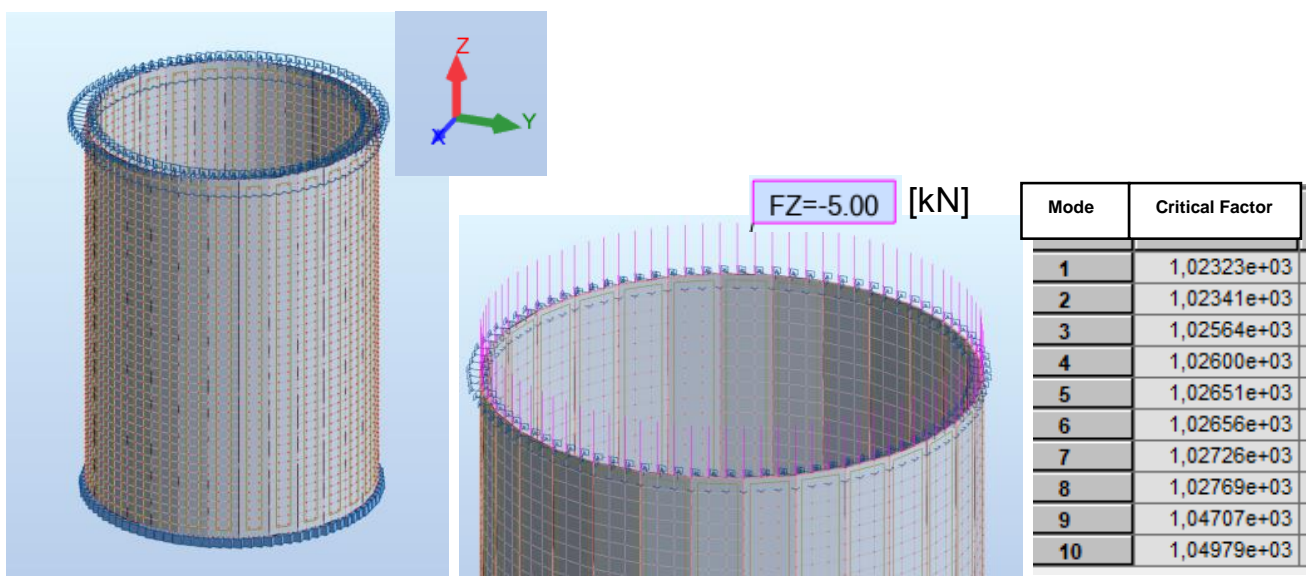

Figure 41 - Structural model for buckling analysis in case B, column T3

The acting loads at the top of the columns was extracted from the main model and applied as shown in Figure 41. For example, for the column represented in Figure 41 , the extracted vertical force was - $415 \mathrm{kN}$ at the top of the column and this value distributed proportionally to the number of nodes in this region on the secondary model. This produced a force of $5 \mathrm{kN}$ (compression) for each node.

An elastic buckling analysis was performed in the secondary model, where the first 10 buckling modes were captured. As results, the first buckling mode, represented in Figure 42, is the critical mode with lower critical factor $\left(10^{3}\right)$ and no more modes were captured because the factor tendency indicated that the critical mode was the mode 1 . Thus, there were no problems with elastic buckling in this structure.
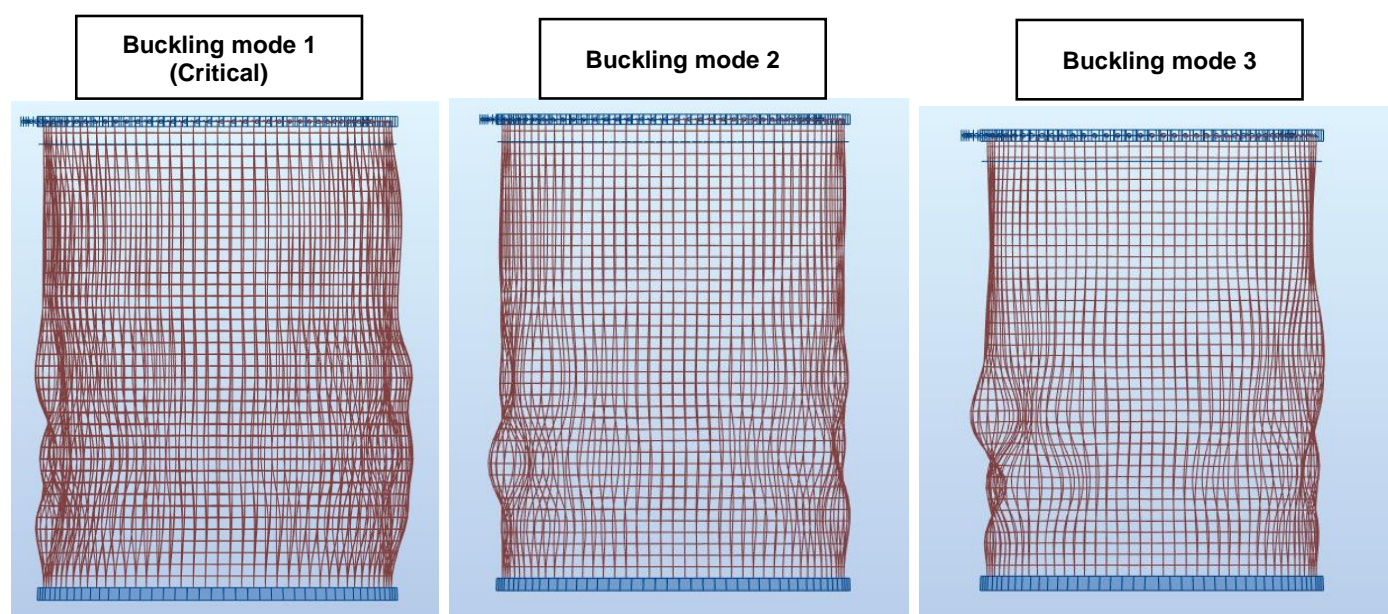

Figure 42 - First (critical), second and third buckling modes for the more solicited column T3 in the first floor of Tree Building

The other columns also were checked using the same methodology, and also no problem with buckling was identified. It is worth pointing out that this 
methodology for buckling analysis was conservative and, thus, it can be concluded that the columns are safe in terms of stability.

In the third case (Case $\mathrm{C}$ ) no stability verifications were performed because the column height selected for the $\mathrm{RC}$ columns followed the Brazilian design manual NBR 6118:2014. 


\section{6 \\ RESULTS AND DISCUSSION}

This chapter presents the results and analyzes the application of the proposed IDM methodology proposed and the optimization solutions for the three experiments. The objective is to validate or not the structural optimization results as a feasible structural conceptual model to be adopted in the early stages of a project. Doing that, it is expected that the initial questions that oriented this work can be answered and, thus, it can help to conclude if SO can be inserted, how can it be inserted and what impacts it can generate in the project.

\section{1. From structural analysis}

In this section, the optimization results are validated as possible structural solutions for real projects. Both the stresses and displacements results are analyzed so that the stresses do not overcome the material's strength and the displacements do not exceed values that can affect user comfort and building functionality, following Brazilian structural codes.

The results for Case $A$ showed that the maximum stresses obtained were 7.42 $\mathrm{MPa}$ (compression), 5.39 MPa (tension), and 2.62 MPa (shear), and the maximum vertical displacement was $1.0 \mathrm{~cm}$ in the roof and $2.3 \mathrm{~cm}$ in the structural grid that supports the water tank. In case $B$, the maximum normal stresses identified in the columns were $166 \mathrm{MPa}$ (compression), $20.5 \mathrm{MPa}$ (tension), and 7.87 MPa (shear), and the maximum vertical displacement was $13.0 \mathrm{~cm}$. The last model, the Bamboo Project, presented the maximum normal stress identified in columns as 7,01 MPa (compression), 1.02 MPa (tension), 0.29 MPa (shear) and the maximum vertical displacement was $12.8 \mathrm{~cm}$.

With these results, it was possible to validate the structural conceptual models by comparing the results with the maximum displacement allowed in Brazilian standards (ABNT NBR 6118:2014) and the ultimate stress allowed for the material. According to NBR 6118:2014, for visible displacements in structural elements, the maximum vertical displacement should not exceed L/250. Therefore, all models were considered acceptable. 
With regards to material, according to Autodesk material library and properties, $A B S$ plastic, steel, and concrete have the following ultimate strength values: $20 \mathrm{MPa}$ - compression/tension, $255 \mathrm{MPa}$ - compression/tension, and 25 $\mathrm{MPa}$ - compression/2,5 MPa - tension, respectively. Thus, comparing material limits to stress values observed in cases $A, B$, and $C$, it is verified that optimization solutions were considered acceptable. It is worth pointing out that, for Case $B$ and $\mathrm{C}$, these stresses are located in load concentration regions because columns are represented as beam elements (bar) so in fact, it is expected that their actual values would be lower.

From the results above, it is possible to conclude that SO resulted in structurally acceptable models, as expected. However, more variables are necessary, besides of material takeoff and stiffness, such as construction technique, structural foundation project, man-hour consumed, construction quality, to define if SO is impactful in conceptual design, especially when it comes to cost analysis.

\section{2. \\ From BIM implementation}

In terms of interoperability between the utilized BIM tools, in all examples, the information flow consisted only of exchanging geometrical data. The adopted modeling tool can only export the following formats: .DWG, .DXF, .DGN, .SAT, .FBX, and .IFC, while the optimization tools can only read the following formats: .DWG, .DXF, and .SAT, and can interpret only geometrical information. From the SO tool to the structural analysis tool, it was impossible to carry mesh elements, material definition, and numerical optimization results. However, since in this work the structural analysis tool and the modeling tool were from the same vendor (non openBIM), the interoperability worked better than it generally would with non native formats.

This lack of interoperability may difficult SO insertion in a BIM project, but it would not preclude it. With this in mind, it can be concluded that SO processes can be inserted in the conceptual design phase and can result in better projects. To be effectively inserted in the BIM methodology, however, interoperability issues must be resolved to facilitate the exchange of files. This could be achieved using, for example, the .IFC format.

The IDM proposed in this work is the first step towards achieving this improvement in SO interoperability. In this work, a process map was developed 
that worked properly in all three experiments and an Exchange Requirements to orient next studies to improve interoperability in this area, tracking all information needed in each flow. This issue can only be resolved when software providers apply it in a Model View Definition (MVD) to run in the related tools. 


\section{7 \\ CONCLUSION}

Through a Systematic Literature Review combined with a bibliometric analysis, it was verified that there is a scientific research gap between Structural Optimization and BIM universes. Few journal papers and conference articles addressed SO and BIM methodologies together. However, in each separated area, there is a steady tendency in paper publications, more markedly in developed countries.

Moreover, three initial questions that guide this work apparently were not completely answered yet by the scientific community:

1. Can the structural optimization process be inserted in the BIM methodology?

2. How can the structural optimization process be inserted in the BIM methodology?

3. What impact does the structural optimization process generate in the BIM process?

Taking this into account, this work was oriented to answer these questions and for that, an information management study was conducted. First, a process map was proposed to understand if it can and how SO can be inserted in a BIM project by analyzing the information flow and its particularities, such as exchanges requirements that were organized in the proposed Exchange Requirements (ER). To achieve this, an IDM structure was developed as an initial effort to create a .IFC standardization in this area to improve interoperability issues in a BIM environment. It is worth pointing out that the focus was on the conceptual stage of a building project.

After that, to test the proposed IDM three examples were developed: the Egg House (low-cost project for a single family residence), the Tree Building (commercial building of 34 meters) and the Bamboo Project (four residential buildings of 18 meters and connected with pedestrian walkways). In all cases, SO was used as an initial idea for an architectural conceptual model, generating design options for the architect's consideration as indicated by the IDM structure, but not as an imposition. 
This collaboration between structural engineer and architect is intended to improve and to be improved by the BIM environment. In other words, by anticipating the team's integration and collaboration, BIM implementation could be facilitated. On the other hand, by implementing the BIM methodology this collaboration is also improved. The main idea is that the architect develops the conceptual project considering structural issues and the structural engineer thinks more about architectural questions when developing the structural design.

For all the studied cases, the software tools Fusion360, ANSYS, and Abaqus/TOSCA were used for the SO task. It was found that these commercial software packages can provide good and reliable results for structural optimization with a high level of detailing and low processing time. However, interoperability between these tools and BIM packages is still difficult, the flow of information was only possible using .SAT format which contains only geometrical information.

This lack of interoperability can explain why SO has not yet been adopted within BIM. Therefore, this study was limited to the initial stages of a project, when files containing only geometrical and material information are necessary. After this first step, the next step will be to resolve the interoperability issue so that it will be possible to advance to the next stages, such as pre-detailing and detailed design.

In doing so, the first and second questions were answered: SO can be inserted in a BIM project as an auxiliary tool that supports architect decisions as long as the shortcomings in interoperability issues are solved. The last question about the impacts of this insertion is probably the most difficult question to answer without a real project, but some speculative conclusions were drawn.

In terms of the structural viability of the optimized models, it was found that SO resulted in acceptable structural solutions with possibly lower weight and higher stiffness compared to non-optimized solutions. This conclusion is based on displacements, stresses and buckling modes compared to allowed values in Brazilian standards. This positive impact may be explained intuitively by the fact of SO returns shapes closer to nature which have, in general, the best force distribution possible.

Concerning the BIM methodology, it was found that the insertion of $\mathrm{SO}$ in a building project in early stages can improve architect and engineer collaboration by anticipating this connection. On the other hand, SO requires a higher level of software interoperability maturity, since current level of information flow is based only on geometrical data (.SAT format).

Finally, related to real projects, it is worth pointing out that the structural conceptual project resulted from SO processes may not be acceptable, depending 
on the construction technique adopted. For example, the project may be feasible using modern techniques (modular construction, 3D printing, e.g.), since they can handle complicated forms. However traditional techniques generally cannot easily handle complex shapes, and this will require more time and higher cost, which can make the project unfeasible. For this reason, more studies should be directed towards analyzing cost comparison between different construction techniques and $\mathrm{SO}$, taking into account project quality, Man Hour (MH) consumption, material usage, construction time, project time, etc.

In this sense, it is possible to conclude that both areas, SO and BIM, have similar goals for the AEC industry, what can help to connect them and to achieve positive aftereffects in the project workflow. As technology advances, mainly related to IFC development, the lack of software interoperability will be solved and, thus, the structural optimization process will be more easily adopted in actual building projects. However, with the current technology, architects and structural engineers can already experiment the use of $\mathrm{SO}$ at early stages of design and together with the BIM methodology it can improve and anticipate collaboration between these two players. 


\section{8}

\section{BIBLIOGRAPHY}

ABANDA, F. H.; VIDALAKIS, C.; OTI, A. H.; TAH, J. H. M. A critical analysis of Building Information Modelling systems used in construction projects. Advances in Engineering Software, v. 90, n. 1, p. 183-201, Dec. 2015.

ABRISHAMI, S.; GOULDING, J.; POUR RAHIMIAN, F.; GANAH, A. Virtual generative BIM workspace for maximising AEC conceptual design innovation. Construction Innovation, v. 15, n. 1, p. 24-41, 5 Jan. 2015.

ALEGRIA MIRA, L.; THRALL, A. P.; DE TEMMERMAN, N. The universal scissor component: Optimization of a reconfigurable component for deployable scissor structures. Engineering Optimization, v. 48, n. 2, p. 317-333, 18 Feb. 2016.

ALMEIDA, V. S.; SIMONETTI, H. L.; NETO, L. O. Comparative analysis of strut-and-tie models using Smooth Evolutionary Structural Optimization. Engineering Structures, v. 56, p. 1665-1675, Nov. 2013.

ASHCRAFT, H. W. Building information modeling: A framework for collaboration. Construction Lawyer, v. 28, n. 3, p. 1-14, 2008.

ASSOCIAÇÃO BRASILEIRA DE NORMAS TÉCNICAS. NBR 6120 Cargas para o cálculo de estruturas de edificações. p. 7, 1980.

ASSOCIAÇÃO BRASILEIRA DE NORMAS TÉCNICAS. NBR 6123 Forças devidas ao vento em edificações. p. 66, 1988.

ASSOCIAÇÃO BRASILEIRA DE NORMAS TÉCNICAS. NBR 6118 Projeto de estruturas de concreto - Procedimento. p. 256, 2014.

AZHAR, S.; KHALFAN, M.; MAQSOOD, T. Building information modelling (BIM): now and beyond. Australian Journal of Construction Economics and Building, v. 12, n. 4, p. 15, 4 Dec. 2012.

BEGHINI, L. L.; BEGHINI, A.; KATZ, N.; BAKER, W. F.; PAULINO, G. $\mathrm{H}$. Connecting architecture and engineering through structural topology optimization. Engineering Structures, v. 59, p. 716-726, Feb. 2014. 
BELEGUNDU, A. D. A general optimality criteria algorithm for a class of engineering optimization problems. Engineering Optimization, v. 47, n. 5, p. 674-688, 2015.

BENDS $\varnothing \mathrm{E}, \mathrm{M}$. P. Optimal shape design as a material distribution problem. Structural Optimization, v. 1, n. 4, p. 193-202, Dec. 1989.

BUILDINGSMART. IFC Introduction. 2013.

BUILDINGSMART FINDLAND. COBIM-Common Bim Requirements Series 3- Architecuture Design. p. 1-27, 2012.

CHENG, T.; TEIZER, J. Real-time resource location data collection and visualization technology for construction safety and activity monitoring applications. Automation in Construction, v. 34, p. 3-15, 2013.

CHI, H.-L.; WANG, X.; JIAO, Y. BIM-Enabled Structural Design: Impacts and Future Developments in Structural Modelling, Analysis and Optimisation Processes. Archives of Computational Methods in Engineering, v. 22, n. 1, p. 135-151, 7 Jan. 2015.

CHOI, W.; KIM, J.; PARK, G. Comparison study of some commercial structural optimization software systems. Structural and Multidisciplinary Optimization, v. 54, n. 3, p. 685-699, 1 Sep. 2016.

DAVIES, K.; MCMEEL, D. J.; WILKINSON, S. Making friends with Frankenstein: hybrid practice in BIM. Engineering, Construction and Architectural Management, v. 24, n. 1, p. 78-93, 16 Jan. 2017.

DEATON, J. D.; GRANDHI, R. V. A survey of structural and multidisciplinary continuum topology optimization: Post 2000. Structural and Multidisciplinary Optimization, v. 49, n. 1, p. 1-38, 2014.

DENYER, D.; TRANFIELD, D. Producing a Systematic ReviewThe SAGE Handbook of Organizational Research Methods, 2009.

DÍAZ, H.; ALARCÓN, L. F.; MOURGUES, C.; GARCÍA, S. Multidisciplinary Design Optimization through process integration in the AEC industry: Strategies and challenges. Automation in Construction, v. 73, p. 102-119, Jan. 2017.

DING, Z.; ZUO, J.; WU, J.; WANG, J. Y. Key factors for the BIM adoption by architects: a China study. Engineering, Construction and Architectural Management, v. 22, n. 6, p. 732-748, 16 Nov. 2015.

DONOFRIO, M. Topology Optimization and Advanced Manufacturing 
as a Means for the Design of Sustainable Building Components. Procedia Engineering, v. 145, p. 638-645, 2016.

EASTMAN, C., TEICHOLZ, P.; SACKS, R.; LISTON, K. BIM Handbook: A Guide to Building Information Modeling for Owners, Managers, Designers, Engineers and Contractors. 2nd. ed. New Jersey: John Wiley \& Sons, Inc., Hoboken, 2011.

FARR, E. R. P.; PIROOZFAR, P. A. E.; ROBINSON, D. BIM as a generic configurator for facilitation of customisation in the AEC industry. Automation in Construction, v. 45, p. 119-125, Sep. 2014.

GALLAHER, M. P.; O'CONOR, A. C.; DETTBARN, J. L.; GILDAY, L. T. Cost Analysis of Inadequate Interoperability in the U.S. Capital Facilities Industry. NIST, p. 1-210, 2004.

GEBISA, A. W.; LEMU, H. G. A case study on topology optimized design for additive manufacturing. IOP Conference Series: Materials Science and Engineering, v. 276, n. 1, p. 012026 , Dec. 2017.

GHABRAIE, K. The ESO method revisited. Structural and Multidisciplinary Optimization, v. 51, n. 6, p. 1211-1222, 20 Jun. 2015.

GHAFFARIANHOSEINI, A.; TOOKEY, J.; GHAFFARIANHOSEINI, A.; NAISMITH, N.; AZHAR, S.; EFIMOVA, O.; RAAHEMIFAR, K. Building Information Modelling (BIM) uptake: Clear benefits, understanding its implementation, risks and challenges. Renewable and Sustainable Energy Reviews, v. 75, n. November, p. 1046-1053, 2017.

GILKINSON, N.; RAJU, P.; KIVINIEMI, A.; CHAPMAN, C. Building information modelling: the tide is turning. Proceedings of the Institution of Civil Engineers - Structures and Buildings, v. 168, n. 2, p. 81-93, Feb. 2015.

GOMES, C.; PARENTE, M.; AZENHA, M.; LINO, J. C. An integrated framework for multi-criteria optimization of thin concrete shells at early design stages. Advanced Engineering Informatics, v. 38, n. June, p. 330342, Oct. 2018.

HART, C. Doing a literature review: Releasing the social science research imagination. SAGE: London, v. 1, n. 1, p. 1-25, 1998.

HOFMEYER, H.; DAVILA DELGADO, J. M. Automated design studies: Topology versus One-Step Evolutionary Structural Optimisation. 
Advanced Engineering Informatics, v. 27, n. 4, p. 427-443, Oct. 2013.

INTERNATIONAL ORGANIZATION FOR STANDARDIZATION. ISO 29481-1:2016 Building information models -- Information delivery manual -Part 1: Methodology and format. v. 2016, 2016.

JONES, S. A; YOUNG JR., N. W.; BERNSTEIN, H. M. Building Information Modeling (BIM): Transforming Design and Construction to Achieve Greater Industry Productivity. McGraw Hill Construction SmartMarket Report, p. 45, 2008.

KHAN, K. S.; KUNZ, R.; KLEIJNEN, J.; ANTES, G. Five steps to conducting a systematic review. Journal of the Royal Society of Medicine, v. 96, n. 3, p. 118-121, 2003.

KINGMAN, J. J. J.; TSAVDARIDIS, K. D.; TOROPOV, V. V. Applications of topology optimisation in structural engineering: high-rise buildings \& steel components. Jordan Journal of Civil Engineering, v. 9, n. 3, p. 335-357, 2014.

KITCHENHAM, B.; CHARTERS, S. Guidelines for performing Systematic Literature reviews in Software Engineering Version 2.3. Engineering, v. 45, n. 4ve, p. 1051, 2007.

KOCIECKI, M.; ADELI, H. Two-phase genetic algorithm for size optimization of free-form steel space-frame roof structures. Journal of Constructional Steel Research, v. 90, p. 283-296, 2013.

KOCIECKI, M.; ADELI, H. Shape optimization of free-form steel space-frame roof structures with complex geometries using evolutionary computing. Engineering Applications of Artificial Intelligence, v. 38, p. 168-182, Feb. 2015.

LAAKSO, M.; KIVINIEMI, A. The IFC standard-a review of history, development, and standardization. Journal of Information Technology in ..., v. 17, n. May, p. 134-161, 2012.

LIU, Z.; ZHANG, F.; ZHANG, J. The Building Information Modeling and its Use for Data Transformation in the Structural Design Stage. Journal of Applied Science and Engineering, v. 19, n. 3, p. 273-284, 2016.

LU, W.; FUNG, A.; PENG, Y.; LIANG, C.; ROWLINSON, S. Costbenefit analysis of Building Information Modeling implementation in building projects through demystification of time-effort distribution curves. Building 
and Environment, v. 82, p. 317-327, Dec. 2014.

LU, W.; FUNG, A.; PENG, Y.; LIANG, C.; ROWLINSON, S. Demystifying Construction Project Time-Effort Distribution Curves: BIM and Non-BIM Comparison. Journal of Management in Engineering, v. 31, n. 6, p. 04015010, Nov. 2015.

MATTHECK, C. Engineering Components grow like trees. Materialwissenschaft und Werkstofftechnik, v. 21, n. 4, p. 143-168, Apr. 1990.

MULLER, M. F.; GARBERS, A.; ESMANIOTO, F.; HUBER, N.; LOURES, E. R.; CANCIGLIERI, O. Data interoperability assessment though IFC for BIM in structural design - a five-year gap analysis. Journal of Civil Engineering and Management, v. 23, n. 7, p. 943-954, 3 Oct. 2017.

MUNK, D. J.; VIO, G. A.; STEVEN, G. P. Topology and shape optimization methods using evolutionary algorithms: a review. Structural and Multidisciplinary Optimization, v. 52, n. 3, p. 613-631, 20 Sep. 2015.

NBIMS. National BIM Standard-United States ${ }^{\circledR}$ Version 3 । National BIM Standard - United States. [s.l: s.n.].

OLAWUMI, T. O.; CHAN, D. W. M.; WONG, J. K. W.; CHAN, A. P. C. Barriers to the integration of BIM and sustainability practices in construction projects: A Delphi survey of international experts. Journal of Building Engineering, v. 20, p. 60-71, 2018.

ORAEE, M.; HOSSEINI, M. R.; PAPADONIKOLAKI, E.; PALLIYAGURU, R.; ARASHPOUR, M. Collaboration in BIM-based construction networks: A bibliometric-qualitative literature review. International Journal of Project Management, v. 35, n. 7, p. 1288-1301, Oct. 2017.

ÖZKAL, F. M.; UYSAL, H. A computational and experimental study for the optimum reinforcement layout design of an $R C$ frame. Engineering Computations, v. 33, n. 2, p. 507-527, 18 Apr. 2016.

PAPADOPOULOS, N. A.; SOTELINO, E. D.; MARTHA, L. F.; NASCIMENTO, D.; FARIA, P. S. Evaluation of integration between a bim platform and a tool for structural analysis. v. 12, p. 108-116, 2017.

PAPALAMBROS, P. Y.; WILDE, D. J. Principles of Optimal Design. Cambridge: Cambridge University Press, 2000. v. 59 
PARK, P.; GILBERT, M.; TYAS, A.; POPOVIC-LARSEN, O. Potential Use of Structural Layout Optimization at the Conceptual Design Stage. International Journal of Architectural Computing, v. 10, n. 1, p. 13-32, Mar. 2012.

POIRIER, E. A.; FORGUES, D.; STAUB-FRENCH, S. Understanding the impact of BIM on collaboration: a Canadian case study. Building Research \& Information, v. 45, n. 6, p. 681-695, 18 Aug. 2017.

PRAGER, W.; ROZVANY, G. I. N. Optimal Layout of Grillages†. Journal of Structural Mechanics, v. 5, n. 1, p. 1-18, 16 Jan. 1977.

RAMAJI, I. J.; MEMARI, A. M.; MESSNER, J. I. Product-Oriented Information Delivery Framework for Multistory Modular Building Projects. Journal of Computing in Civil Engineering, v. 31, n. 4, p. 04017001, Jul. 2017.

RICHARDSON, J. N.; NORDENSON, G.; LABERENNE, R.; FILOMENO COELHO, R.; ADRIAENSSENS, S. Flexible optimum design of a bracing system for façade design using multiobjective Genetic Algorithms. Automation in Construction, v. 32, p. 80-87, Jul. 2013.

ROGERS, J.; CHONG, H.-Y.; PREECE, C. Adoption of Building Information Modelling Technology (BIM): Perspetives from Malaysian Engineering COnsulting Services Firms. Engineering, Construction and Architectural Management, v. 22, n. 4, p. 424-445, 2015.

ROJAS-LABANDA, S.; STOLPE, M. Benchmarking optimization solvers for structural topology optimization. Structural and Multidisciplinary Optimization, v. 52, n. 3, p. 527-547, 17 Sep. 2015.

ROZVANY, G. I. N. Optimal load transmission by flexure. Computer Methods in Applied Mechanics and Engineering, v. 1, n. 3, p. 253-263, 1972a.

ROZVANY, G. I. N. Grillages of maximum strength and maximum stiffness. International Journal of Mechanical Sciences, v. 14, n. 10, p. 651-666, Oct. 1972b.

ROZVANY, G. I. N. A critical review of established methods of structural topology optimization. Structural and Multidisciplinary Optimization, v. 37, n. 3, p. 217-237, 2009.

SHER, E.; CHRONIS, A.; GLYNN, R. Adaptive behavior of structural 
systems in unpredictable changing environments by using self-learning algorithms: A case study. Simulation, v. 90, n. 8, p. 991-1006, 2014.

SHIN, T.-S. Building information modeling (BIM) collaboration from the structural engineering perspective. International Journal of Steel Structures, v. 17, n. 1, p. 205-214, 31 Mar. 2017.

SIDDAWAY, A. What is a systematic literature review and how do I do one? University of Stirling, n. li, p. 1-13, 2014.

SIGMUND, O.; MAUTE, K. Topology optimization approaches. Structural and Multidisciplinary Optimization, v. 48, n. 6, p. 1031-1055, 21 Dec. 2013.

SUCCAR, B.; SHER, W.; WILLIAMS, A. Measuring BIM performance : Five metrics. Architectural Engineering and Design Management, v. 8, n. 2, p. 120-142, 2012.

SUWAL, S.; SINGH, V. Assessing students' sentiments towards the use of a Building Information Modelling (BIM) learning platform in a construction project management course. European Journal of Engineering Education, v. 43, n. 4, p. 492-506, 4 Jul. 2018.

SVANBERG, K. The method of moving asymptotes-a new method for structural optimization. International Journal for Numerical Methods in Engineering, v. 24, n. 2, p. 359-373, 1987.

TSERANIDIS, S.; BROWN, N. C.; MUELLER, C. T. Data-driven approximation algorithms for rapid performance evaluation and optimization of civil structures. Automation in Construction, v. 72, p. 279-293, Dec. 2016.

VENUGOPAL, M.; EASTMAN, C. M.; SACKS, R.; TEIZER, J. Semantics of model views for information exchanges using the industry foundation class schema. Advanced Engineering Informatics, v. 26, n. 2, p. 411-428, 2012.

WANG, X.; ZHANG, X.; CHENG, K. Computer program for directed structure topology optimization. Acta Mechanica Solida Sinica, v. 28, n. 4, p. 431-440, Aug. 2015.

WHITING, E.; SHIN, H.; WANG, R.; OCHSENDORF, J.; DURAND, F. Structural optimization of 3D masonry buildings. ACM Transactions on Graphics, v. 31, n. 6, p. 1, 1 Nov. 2012. 
XIA, L.; XIA, Q.; HUANG, X.; XIE, Y. M. Bi-directional Evolutionary Structural Optimization on Advanced Structures and Materials: A Comprehensive Review. Archives of Computational Methods in Engineering, v. 25, n. 2, p. 437-478, 19 Apr. 2016.

XU, H.; FENG, J.; LI, S. Users-orientated evaluation of building information model in the Chinese construction industry. Automation in Construction, v. 39, p. 32-46, 2014.

YI, G. L.; SUI, Y. K. Different effects of economic and structural performance indexes on model construction of structural topology optimization. Acta Mechanica Sinica, v. 31, n. 5, p. 777-788, 21 Oct. 2015.

ZAWIDZKI, M.; NISHINARI, K. Modular Truss-Z system for selfsupporting skeletal free-form pedestrian networks. Advances in Engineering Software, v. 47, n. 1, p. 147-159, May 2012.

ZHANG, D. K.; LIANG, S.; YANG, Y.; ZHOU, H. A constraint and algorithm for stress-based evolutionary structural optimization of the tiebeam problem. Engineering Computations, v. 32, n. 6, p. 1753-1778, 3 Aug. 2015.

ZHANG, Y.; MUELLER, C. Shear wall layout optimization for conceptual design of tall buildings. Engineering Structures, v. 140, p. 225 240, Jun. 2017.

ZHOU, M.; ROZVANY, G. I. N. On the validity of ESO type methods in topology optimization. Structural and Multidisciplinary Optimization, v. 21, n. 1, p. 80-83, 2001.

ZILLOBER, C. A globally convergent version of the method of moving asymptotes. Structural Optimization, v. 6, n. 3, p. 166-174, 1993.

ZUO, Z. H.; XIE, Y. M. Evolutionary topology optimization of continuum structures with a global displacement control. Computer-Aided Design, v. 56, p. 58-67, Nov. 2014. 


\section{APPENDIX A - SLR initial quantitative and qualitative analysis, before the full reading}

\begin{tabular}{|c|c|c|c|c|c|c|}
\hline \multirow{2}{*}{$\begin{array}{l}\text { TERMS: } \\
\text { DATABASE }\end{array}$} & \multicolumn{6}{|c|}{ BIM \& ARCH } \\
\hline & $\begin{array}{c}\text { Without Exc/lnc } \\
\text { Criteria }\end{array}$ & $\begin{array}{l}\text { Within Exc/lnc } \\
\text { Criteria }\end{array}$ & $\begin{array}{c}\text { Subtopics } \\
\text { included }\end{array}$ & Title Analysis & Mixed Data & $\begin{array}{c}\text { Abstract Analysis } 8 \\
\text { Chosen Articles }\end{array}$ \\
\hline SCOPUS & 1169 & 275 & 148 & 76 & \multirow{4}{*}{138} & \multirow{4}{*}{28} \\
\hline ENGIN. VILLAGE & 848 & 193 & 98 & 95 & & \\
\hline SCIENCE DIRECT & 190 & 165 & 31 & 17 & & \\
\hline WEB OF SCIENCE & 639 & 191 & 78 & 60 & & \\
\hline TERMS: & \multicolumn{6}{|c|}{ BIM \& STROPT } \\
\hline DATABASE & $\begin{array}{c}\text { Without Exc/Inc } \\
\text { Criteria }\end{array}$ & $\begin{array}{c}\text { Within Exc/lnc } \\
\text { Criteria }\end{array}$ & $\begin{array}{c}\text { Subtopics } \\
\text { included }\end{array}$ & Title Analysis & Mixed Data & $\begin{array}{c}\text { Abstract Analysis } \\
\text { Chosen Articles }\end{array}$ \\
\hline SCOPUS & 23 & 11 & 2 & 2 & \multirow{4}{*}{4} & \multirow{4}{*}{4} \\
\hline ENGIN. VILLAGE & 21 & 11 & 2 & 2 & & \\
\hline SCIENCE DIRECT & 4 & 4 & 0 & 0 & & \\
\hline WEB OF SCIENCE & 3 & 2 & 0 & 0 & & \\
\hline TERMS: & \multicolumn{6}{|c|}{ BIM \& TOPOPT } \\
\hline DATABASE & $\begin{array}{c}\text { Without Exc/lnc } \\
\text { Criteria }\end{array}$ & $\begin{array}{c}\text { Within Exc/lnc } \\
\text { Criteria }\end{array}$ & $\begin{array}{c}\text { Subtopics } \\
\text { included }\end{array}$ & Title Analysis & Mixed Data & $\begin{array}{c}\text { Abstract Analysis } 8 \\
\text { Chosen Articles }\end{array}$ \\
\hline SCOPUS & 3 & 0 & 0 & 0 & \multirow{4}{*}{4} & \multirow{4}{*}{2} \\
\hline ENGIN. VILLAGE & 3 & 0 & 0 & 0 & & \\
\hline SCIENCE DIRECT & 0 & 0 & 0 & 0 & & \\
\hline WEB OF SCIENCE & 3 & 2 & 0 & 0 & & \\
\hline TERMS: & \multicolumn{6}{|c|}{ STROPT \& TOPOPT } \\
\hline DATABASE & $\begin{array}{c}\text { Without Exc/lnc } \\
\text { Criteria }\end{array}$ & $\begin{array}{l}\text { Within Exc/lnc } \\
\text { Criteria }\end{array}$ & $\begin{array}{c}\text { Subtopics } \\
\text { included }\end{array}$ & Title Analysis & Mixed Data & $\begin{array}{c}\text { Abstract Analysis } 8 \\
\text { Chosen Articles }\end{array}$ \\
\hline SCOPUS & 2660 & 228 & 197 & 185 & \multirow{4}{*}{308} & \multirow{4}{*}{24} \\
\hline ENGIN. VILLAGE & 2278 & 698 & 446 & 159 & & \\
\hline SCIENCE DIRECT & 215 & 125 & 30 & 20 & & \\
\hline WEB OF SCIENCE & 1377 & 207 & 142 & 107 & & \\
\hline TERMS: & \multicolumn{6}{|c|}{ STROPT \& ARCH } \\
\hline DATABASE & $\begin{array}{c}\text { Without Exc/Inc } \\
\text { Criteria }\end{array}$ & $\begin{array}{c}\text { Within Exc/lnc } \\
\text { Criteria }\end{array}$ & $\begin{array}{c}\text { Subtopics } \\
\text { included }\end{array}$ & Title Analysis & Mixed Data & $\begin{array}{c}\text { Abstract Analysis } \\
\text { Chosen Articles }\end{array}$ \\
\hline SCOPUS & 758 & 74 & 7 & 33 & \multirow{4}{*}{53} & \multirow{4}{*}{10} \\
\hline ENGIN. VILLAGE & 661 & 142 & 4 & 18 & & \\
\hline SCIENCE DIRECT & 56 & 25 & 0 & 1 & & \\
\hline WEB OF SCIENCE & 109 & 13 & 1 & 6 & & \\
\hline TERMS: & \multicolumn{6}{|c|}{ TOPOPT \& ARCH } \\
\hline DATABASE & $\begin{array}{c}\text { Without Exc/Inc } \\
\text { Criteria }\end{array}$ & $\begin{array}{l}\text { Within Exc/lnc } \\
\text { Criteria }\end{array}$ & $\begin{array}{c}\text { Subtopics } \\
\text { included }\end{array}$ & Title Analysis & Mixed Data & $\begin{array}{c}\text { Abstract Analysis } \\
\text { Chosen Articles }\end{array}$ \\
\hline SCOPUS & 244 & 26 & 3 & 21 & \multirow{4}{*}{37} & \multirow{4}{*}{8} \\
\hline ENGIN. VILLAGE & 163 & 25 & 3 & 14 & & \\
\hline SCIENCE DIRECT & 56 & 37 & 1 & 4 & & \\
\hline WEB OF SCIENCE & 117 & 10 & 1 & 7 & & \\
\hline & & & & TOTAL & 544 & 76 \\
\hline
\end{tabular}

